\title{
TCT Hybrid \\ Preconceptual Blanket Design Studies
}

January 1978

Prepared for the U.S. Department of Energy under Contract EY-76-C-06-1830 


\title{
NOTICE
}

This report was prepared as an account of work sponsored by the United States Government. Neither the United States nor the Department of Enetgy, nor any of their employees, nor any of their contractors. subcontractors, or their employees, makes any warranty, express or implied, or assumes any legal liability or responsibility for the accuracy, completeness or usefiulness of any information, apparatus, product or process disclosed, or represents that its use would not intringe privately owned rights.

The views, opinions and conclusions contained in this report are those of the contractor and do not necessarily represent those of the United States Government or the United States Department of Energy:

\author{
PACIFIC NORTHWEST LABORATORY \\ operated by \\ BATTELLE \\ for the \\ UNITED STATES DEPARTMENT OF ENERCY \\ Under Contract EY-76-C-06-7830
}

\author{
Printed in the Unted States of America \\ Avaliable from \\ Natianal Technical Informatian Service \\ United States Department of Commerce \\ 5285 Port Royai Road \\ Springfield, Virginia 22751
}

Price: Printed Cons 5 - Mticrofiche $\$ 3.00$

NTIS

- Pages

Selling Price

$001-025$

026-050

$057-075$

$076-100$

101.125

$126-150$

$151 \cdot 175$

$176-200$

201.225

226. 250

$251-275$

$276 \cdot 300$

$\$ 5.30$

56.00

56.50

5700

57.73

58,50

58.75

59.00

570.00

s10.25 
TCT HYBRID PRECONCEPTUAL BLANKET DESIGN STUDIES

by

D. T. Aase

M. C. C. Bampton

T. J. Doherty

B. R. Leonard

R. A. McCann

D. F. Newman

R. T. Perry

C. W. Stewart

January 1978

BATTELLE

Pacific Northwest Laboratories

Richland, Washington 99352 
$-$

-

- 
CONTENTS

ABSTRACT . . . . . . . . . . . . . . . . . . . . . .

INTRODUCTION

SUMMARY, CONCLUSIONS AND RECOMMENDATIONS . . . . . . . . . . . . 3

FIRST WALL . . . . . . . . . . . . . . . . . . . 4

CONVERTER REGION . . . . . . . . . . . . . . . . . 10

BURNER AND MODERATOR REGION . . . . . . . . . . . . . . 15

ENGINEERING EVALUATION OF BLANKET COMPONENTS . . . . . . . . . . . . 21

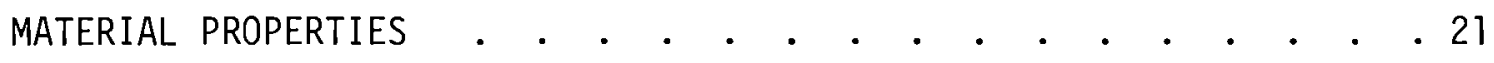

Volumetric Swelling. . . . . . . . . . . . 22

Tensile Strength . . . . . . . . . . . . 24

Creep Rupture . . . . . . . . . . . . . . . . . 25

Crack Propagation . . . . . . . . . . . . . 26

Fatigue . . . . . . . . . . . . . . 27

FIRST WALL . . . . . . . . . . . . . . . . . . . 29

First Wall Structure Analysis . . . . . . . . . . 31

First Wall Failure Modes . . . . . . . . . . . . 43

Fabrication Considerations . . . . . . . . . . 46

CONVERTER REGION . . . . . . . . . . . . . . . . 52

Converter Region Layout . . . . . . . . . . . . . 53

Converter Thermal-Hydraulic Analysis . . . . . . . . 56

BURNER AND MODERATOR REGION . . . . . . . . . . . . . . 75

NEUTRONICS . • . . . . . . . . . . . . . . . . . . . . 79

RESULTS PART I . • . . . . . . . . . . . . . 81

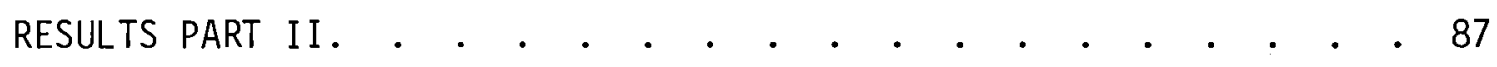

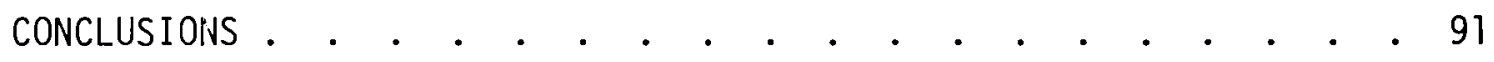


BIBLIOGRAPHY • • . . . . . . . . . . . . . . . . . .

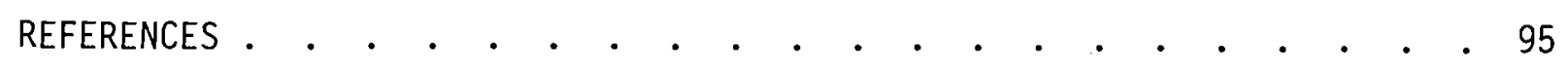

APPENDIX A . . . . . . . . . . . . . . . . . . . . . . . . . .

APPENDIX B . . . . . . . . . . . . . . . . . . . . . . . . . . . . . .

APPENDIX C . . . . . . . . . . . . . . . . . . . ..$C^{-1}$ 


\section{FIGURES}

1 Hybrid Salt Blanket and Shield . . . . . . . . . . . 3

2 First Wal1 Concepts . . . . . . . . . . . . . . . . 4

3 Characterizations of First Wall Coolant Flow Path . . . . . . 5 Normalized Wall Load Around Minor Circumference . . . . . . . 6

4 TCT Hybrid First Wall Operating Temperature . . . . . . . . 6

5 Maximum Stress Component Operating Conditions . . . . . . . . 8

6 TCT Hybrid First Wall Fabrication . . . . . . . . . . . . 9

7 Converter Geometry . . . . . . . . . . . . . . . 11

8 Temperature Transients During Operating Cycle . . . . . . . 12

9 Converter $60^{\circ}$ Segment . . . . . . . . . . . . . . . . 14

10 Radial Support Plate Concept . . . . . . . . . . . . 15

11 Schematic of Burner and Moderator . . . . . . . . . . 16

12 Thermal Profile in Burner and Moderator at Mid/Plane . . . . 18

13 Irradiation Induced Swelling Function . . . . . . . . . . 23

14 Swelling Behavior of $\mathrm{Ni}, 316 \mathrm{SS}$ and $\mathrm{PE}-16$ at $25^{\circ} \mathrm{C}$ with Bombardment by $20 \mathrm{MeV}$ atoms. . . . . . . . . . . . 24

15 The Effect of Irradiation Upon 316 Stainless Steel Tensile Strength . . . . . . . . . . . . . . . . 25

Correlation of Rupture Life Tests and Calculated Rupture
Life for Annealed 316 Stainless Steel Specimens . . . . . 27

17 Comparison of Crack Propagation Behavior at $1000^{\circ} \mathrm{F}$ $\left(538^{\circ} \mathrm{C}\right)$ of $20 \%$ Cold-Worked Type 316 SS in the Irradiated and Unirradiated Conditions . . . . . . . . . 28

18 Influence of Irradiation on Crack Growth Rate in Type 316 Base and Weld Metals at $1700^{\circ} \mathrm{F}\left(593^{\circ} \mathrm{C}\right)$. 
20 Meridional Section of Single-Wall Toroid, BOSOR4 Analysis

21 Toroid Buckling Study BOSOR4 Analysis

22 Double Wall Concept . . . . . . . . . . . . . . 36

23 A Sector of the Toroidal First Wall ANSYS Geometry Mode 1

24 Shell Section (Infinite Major Radius) BOSOR4 Local Stability Analysis

25 Variation of Buckling Eigenvalues $\lambda$ With Circumferential Wave Number $N$. . . . . . . . . . 40

26 Local Buckling of Coolant Channel BOSOR4 Analysis . . . . . . 41

27 Two Wall Section AXISOL Analysis . . . . . . . . . . . . 42

28 Maximum Stress Components Temperature Stresses . . . . . . . 43

29 Two Wall Section AXISOL Analysis . . . . . . . . . . . . 44

30 Large Thin Sheets Forming $30^{\circ}$ Segments . . . . . . . . . . 48

31 Welds . . . . . . . . . . . . . . . . . . . . . 49

32 Penetration . . . . . . . . . . . . . . . . 49

33 Stretch Form to Minor R Over Blocks . . . . . . . . . . 51

34 Cooling Flowpath Layout . . . . . . . . . . . . . . 54

35 Flow Area Variation With Inner Diameter . . . . . . . . . 58

36 Temperature and Pumping Power Variation with Inner Diameter . . . . . . . . . . . . . . . . . 60

37 U-Mo Radial Temperature Distributions with Blocked Channels -- $D_{1}=0.9236$. . . . . . . . . . . . . 61

38 U-Mo Radial Temperatures with Blocked Channels $D=1.254$ 
39 Pumping Power, Head and Velocity versus Tube Length for Constant Exit Temperature

40 Pressure Head Base Case

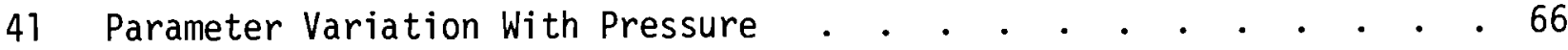

42 Standard Fuel Element Geometry . • . • . . . . . . . . 67

43 Analysis Model Section . . . . . . . . . . . . . . . . . 68

44 Uranium Mol.ybdenum Properties .

45 Approximate Bilinear Stress Strain Relationship

for AXISOL Analysis 316 SST . . . . . . . . . . . . . . 73

46 Wall Loading Versus Allowable Converter Power Density . • • • • • 80

47 Case 1 of TCT Hybrid Blanket Survey Calculations . . . . . . . . 83

48 Case 2 of TCT Hybrid Blanket Survey Calculations. . . . . • • 85

49 Case 3 of TCT Hybrid Blanket Survey Calculations . . . . • . . 86

50 Hybrid Blanket Model . . . . . . . . . . . . . . . . . 87

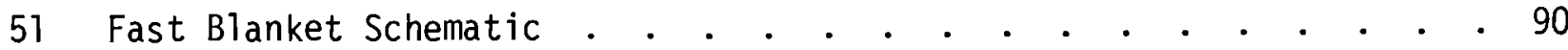

\begin{tabular}{l} 
A-1 Angular Dependence of the $14 \mathrm{MeV}$ Cross \\
Section for $238 \mathrm{U}$. \\
\hline
\end{tabular}

A-2 Experiment Configuration . . . . . . . . . . . . . . . A-4

A-3 Distribution of $n, 2 n$ Reaction Rate in ${ }^{63} \mathrm{Cu}$. . . . . . . . . . . A-5

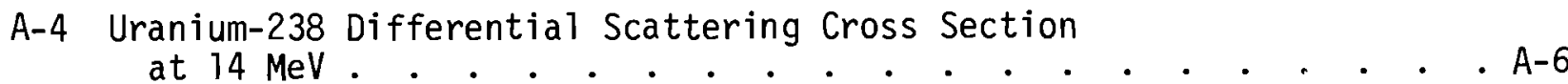

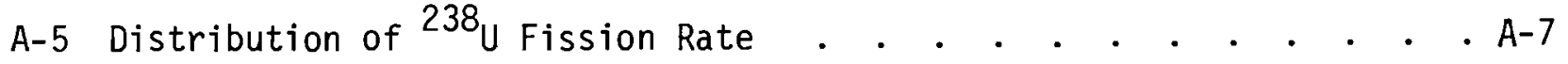

C-1 The Finite Element Idealization . . . . . . . . . . . . . C-6 


\section{$\underline{\text { TABLES }}$}

1 First Wal1 Temperatures and Coolants Pressures . . . . . . . . 31

2 Range of Operating Conditions Considered in

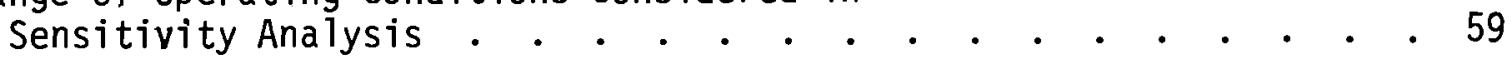

3 Neutron Production Rates Per Source for Case 1 Blanket Configurations . . . . . . . . . . . . . . 84

4 Neutron Production Rates Per Source for Case 2 Blanket Configuration . . . . . . . . . . . . . . 84

5 Neutron Production Rates Per Source for Case 3 Blanket Configuration . . . . . . . . . . . . . . . 86

6 Production Rates for Blanket with Helium-Cooled Carbon and Pin Lattice. . . . . . . . . . . . . . . . . 88

7 Production Rates for Blanket with Converter and

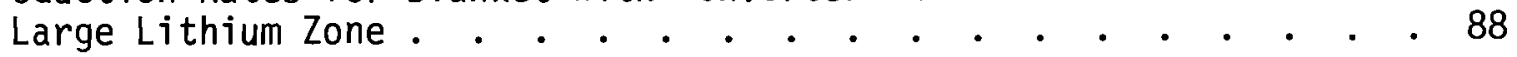

8 Production Rates, for Enriched Lattice and Depleted Converter . . . . . . . . . . . . . . . . 89

9 Production Rates for a Lithium-Cooled Lattice . . • • • • • 90

10 Production Rates for a Fast Blanket . . . . . . . . . . . . . 91

B-1 COBRA-IV Input Data for TCT Hybrid Converter . . . . . . • . . B-4

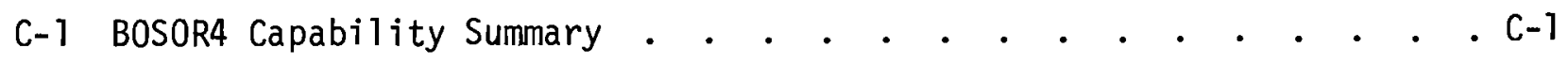


- 


\section{ABSTRACT}

The conceptual design of a tokamak fusion-fission (hybrid) reactor, which produces electric power and fissile material, has been performed in a cooperative effort between Princeton's Plasma Physics Laboratory (PPPL) and Battelle's Pacific Northwest Laboratories (PNL). PPPL, who had overall project lead responsibility, designed the fusion driver system. Its core consists of a tokamak plasma maintained in the two-component torus (TCT) mode by both $D$ and $T$ beams and having a single null poloidal divertor. The blanket concept selected by PPPL consists of a neutron multiplying converter region, containing natural Uranium Molybdenum (U-Mo) slugs followed by a

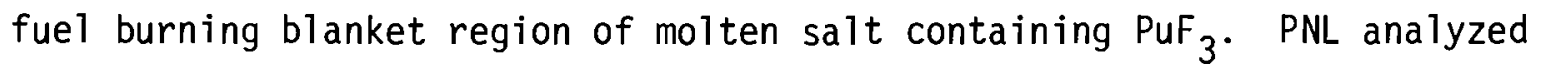
this concept to determine its structural, thermal and hydraulic performance characteristics.

An adequate first wall cooling method was determined, utilizing low pressure water in a double wall design. A conceptual layout of the converter region tubes was performed, providing adequate helium cooling and the desired movement of U-Mo slugs. A thermal hydraulic analysis of the power-producing blanket regions indicated that either more helium coolant tubes are needed or the salt must be circulated to obtain adequate heat removal capability. 
5

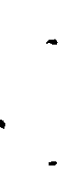

9

" 


\section{INTRODUCTION}

Benefit from nuclear technology depends on effectively using neutrons produced by nuclear reactions. Commercial nuclear fission power reactors produce electricity by using the energy released in neutron-induced fission. Similarly, fusion power will result from using the energy of neutrons produced in the fusion of light nuclei (i.e., the $14 \mathrm{MeV}$ neutron released in the D-T reaction).

Coupling fission and fusion processes has potential advantages. (Several possibilities are reviewed in Reference 1.) Such concepts propose surrounding the fusion plasma with a blanket of fissile and/or fertile material. Systems which utilize the fusion-produced neutrons to ultimately produce fission energy are generally referred to as fusion-fission (hybrid) systems. Hybrid reactors are of interest for several reasons. Compared to pure fusion reactors, they have:

- better utilization of $14 \mathrm{MeV}$ neutrons

- simpler and/or more efficient blanket design because power profile can be flattened

- longer first wall life because low temperature and pressure coolants can be used

- less stringent fusion technology requirements.

Previous hybrid studies $(2-20)$ at PNL have covered a range of applications. The objective of this cooperative study with Princeton Plasma Physics Laboratory (PPPL), was to develop a conceptual design for a system capable of producing electic power and fissile material based upon the Two Component Torus (TCT) concept. (21)

The Tokamak Fusion Test Reactor (TFTR) ${ }^{(22)}$, which will be the first magnetic confinement fusion device to operate with a DT plasma and produce large quantities of neutrons, uses the TCT concept for plasma heating and containment. While the concept is expected to yield a near-Lawson plasma, it is not expected to extrapolate to a net exporter of electrical power as a 
pure fusion reactor would. One possibility for using this technology commercially, however, is to design a hybrid system, which uses the neutrons from the TCT device, to breed fissile material for use in fission reactors and to produce some power directly. Thus, the intitial design guidelines of this studv were: 1) optimize production of fissile material, consistent with the requirement that a tritium breeding ratio in excess of one is obtained; 2) constrain the technology for constructing a machine to that available in the early 1990s; and 3) minimize the capital costs. The second and third guidelines subsequently had to be relaxed to achieve the first.

This report is organized so that the summary is independent of the rest of the report, since this section will be included in PPPL's Conceptual Design Report for the TCT-Hybrid. However, the reader should refer to the other sections and appendices to gain a more thorough understanding of PNL's work on this project, since much of it is important to blanket engineering in general. 


\section{SUMMARY CONCLUSIONS AND RECOMMENDATIONS}

Preconceptual scoping studies were performed on the major components of the TCT Hybrid blanket. To do this, a case was taken from the parametric neutronic studies, which identified the configurations of general interest and the desired volume fractions of materials and approximate thermal loadings. The overall blanket and shield configuration considered is shown schematically in Figure 1. The three components of the overall blanket that needed preconceptual scoping studies were the radiation shield (first wall), the neutron multiplier region (converter) and the burner-moderator region (blanket). The studies and resultant recommendations that will help in selecting a mechanically viable TCT Hybrid blanket design are summarized below.

\section{HYBRID SALT BLANKET \& SHIELD}

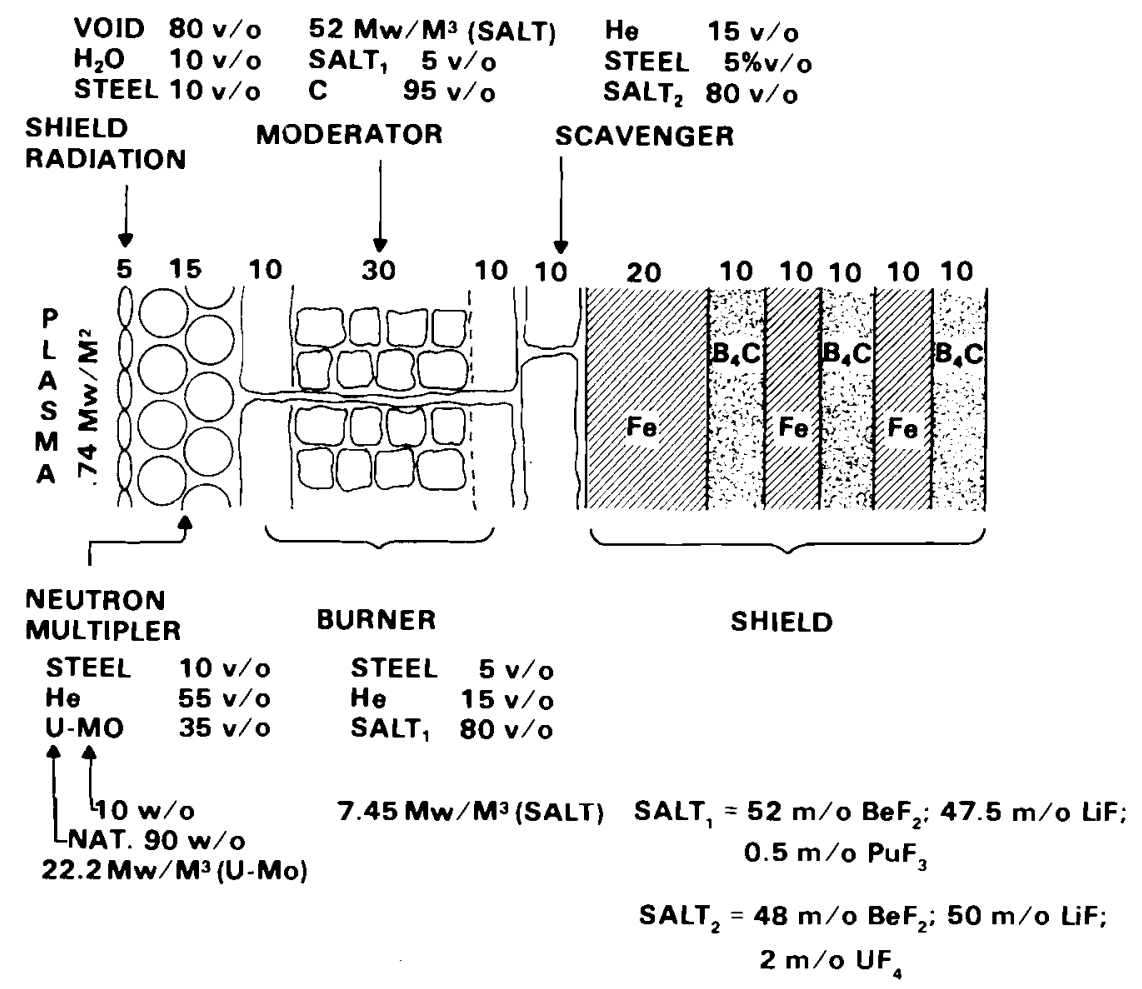

FIGURE 1. Hybrid Salt Blanket and Shield 


\section{FIRST WALL}

One question necessary to consider in a preconceptual study was whether cr not the first wall should be the primary vacuum barrier or more simply a radiation shield to protect the converter pressure tubes from direct thermal loading by the plasma. Considerable incentive exists to make it the primary vacuum vessel since its location (compared to alternatives) eliminates many ccolant line penetrations. If a stable structure with adequate 1 ife requires more coolant and stainless steel than the volume fractions shown in Figure 1 , it would seriously affect the hybrid's neutronic performance. Alternative vacuum barrier locations would then have to be considered.

The BOSOR4 computer code ${ }^{(23)}$ was used to perform stability analyses on a toroidal chamber with approximate major and minor radii of interest, i.e., $\mathrm{R}=8.15 \mathrm{~m}, \mathrm{r}=1.6 \mathrm{~m}$. A wall thickness of about $0.525 \mathrm{in}$. was required to keep the vacuum chamber from collapsing under two atmospheres pressure. Two first wall concepts were then designed (Figure 2). The single wall concept of Figure 2 (b) is relatively easy to fabricate but cannot meet the desired 10 vol\% of structural material. The wall itself would be 27 vol\% of the $5 \mathrm{~cm}$ region. The double wall concept of Figure 2(a) was then evaluated; it has the same stability characteristics as a solid wall but requires much less structural material.

\section{FIRST WALL CONCEPTS}

(a)

DOUBLE WALL

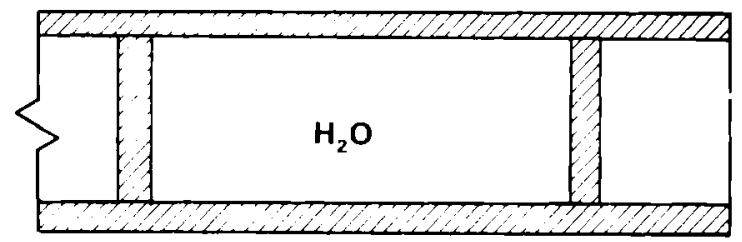

(b) SINGLE WALL

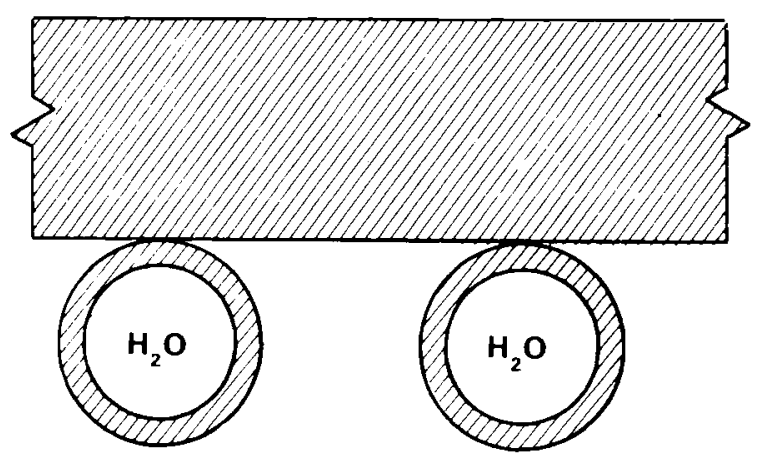

FIGURE 2. First Wal1 Concepts 
The maximum spacing of the ribs in the double wall concept primarily depends on the coolant pressure. In selecting a coolant and coolant pressure, low temperature, low pressure water can be used, which will minimize the structural material required and extend wall life considerably. This is due to the fact that thermal loading on the first wall does not affect overall plant energy balance (less than $1 \%$ of the plant output). For this evaluation, 30 psia water was used.

The flow channel was designed to follow the minor circumference of the toroidal chamber as shown in Figure 3(a). A neutron wall loading of $0.74 \mathrm{MW} / \mathrm{m}^{2}\left(0.1258 \mathrm{MW} / \mathrm{m}^{2}\right.$ therma 1$)$ was used with a relative power distribution along the flow channel as shown in Figure $3(\mathrm{~b})$. The resulting temperatures (referenced to the coolant inlet) are shown in Figure 4. Stability analyses using the BOSOR4 code confirmed the ability of the local channel to handle the 30 psia coolant pressure. The maximum spacing of the ribs coupling the inner and outer walls was set at $4 \mathrm{in}$.

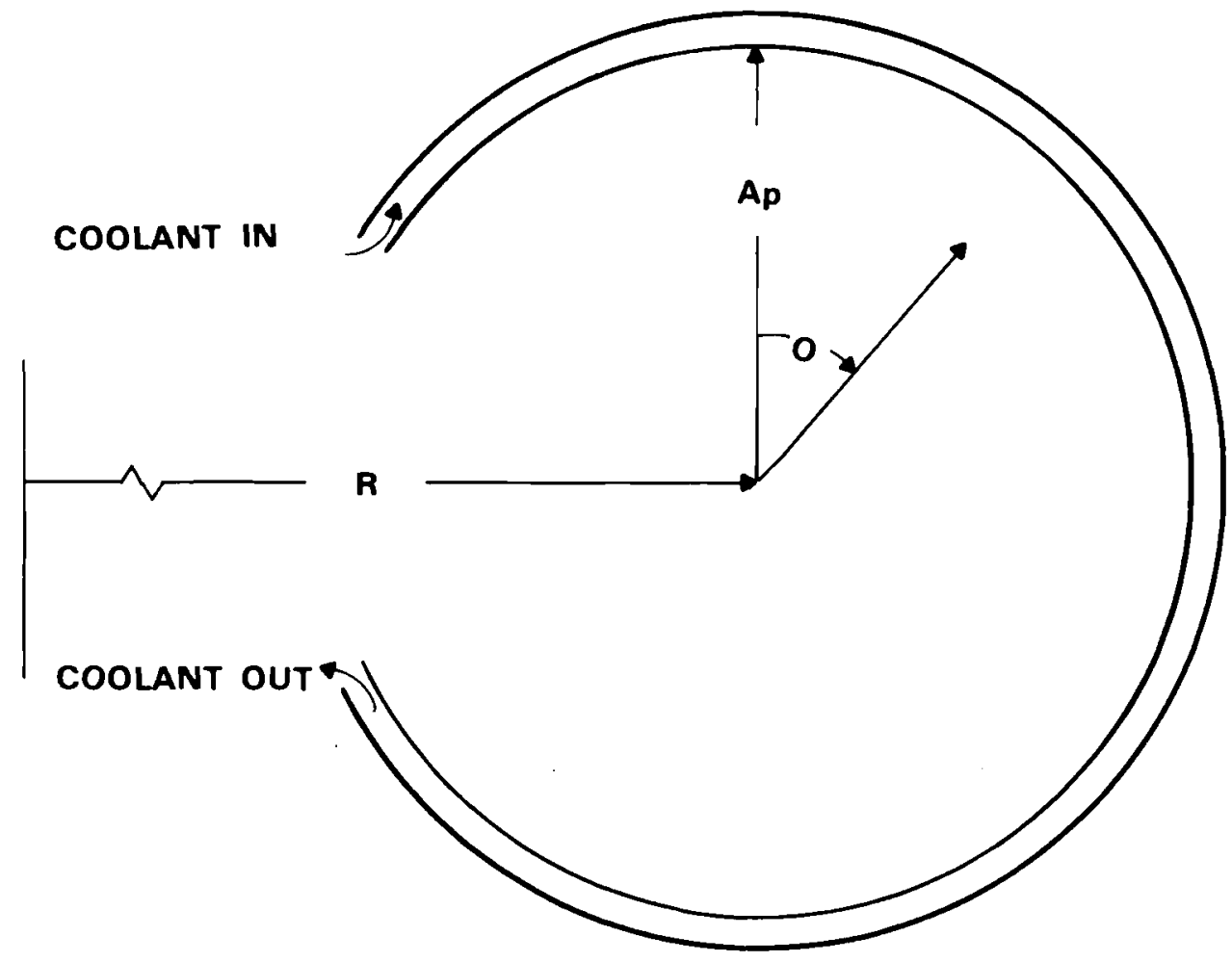

FIGURE 3(a). Characterizations of First Wall Coolant Flow Path 


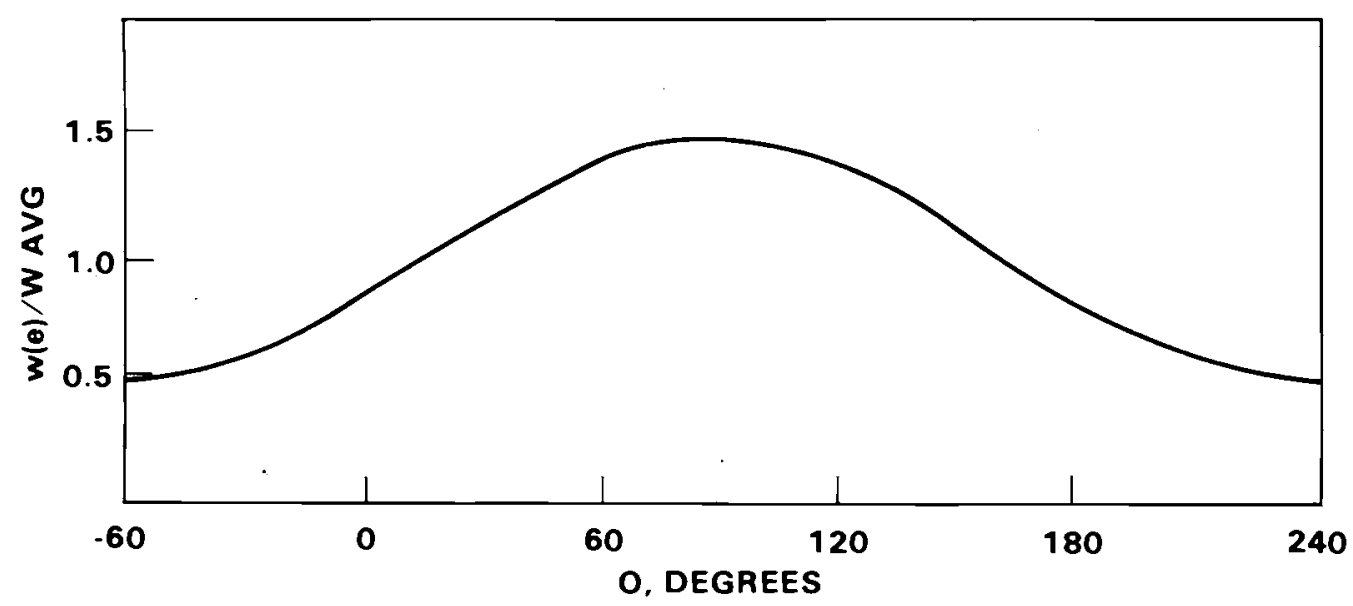

FIGURE 3(b). Normalized Wall Load Around Minor Circumference

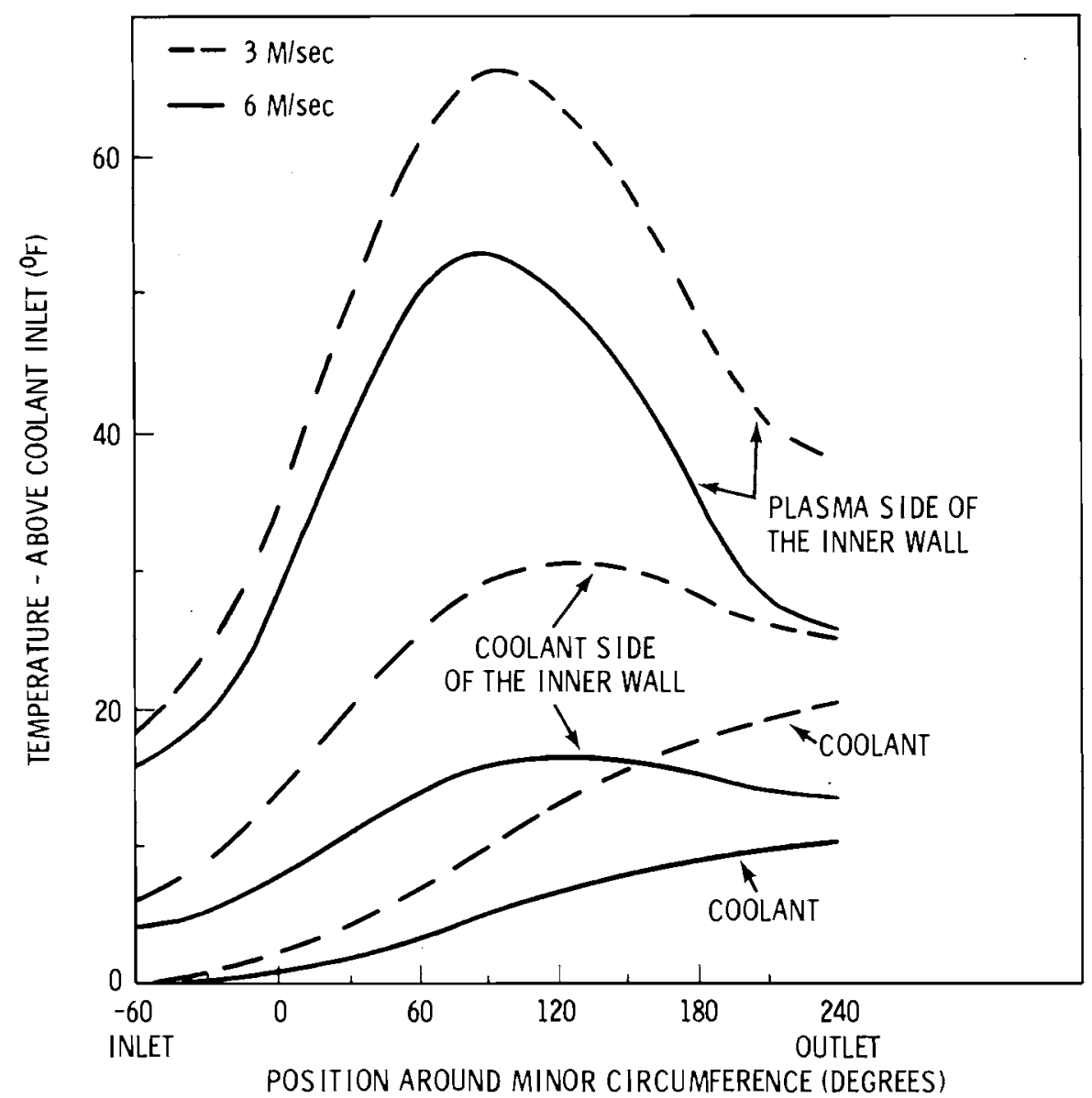

FIGURE 4. TCT Hybrid First Wall Operating Temperature (Double Wa11 Concept) 
Critical first wall stresses at different times in the operating cycle were established using AXISOL, an axisymmetric finite element code. (24) Figure 5 shows the maximum stresses for a full operating load of 14.7 psi vacuum load, and $30 \mathrm{psi}$ in the coolant channel and temperature gradients corresponding to a neutron wall loading of $0.74 \mathrm{MW} / \mathrm{m}^{2}$. Several potential failure modes were examined using the stress results to estimate the potential life of the double wa11. The following conclusions resulted:

- Irradiation Swelling

Since the 316 stainless steel (SS) operating temperature will be well below $350^{\circ} \mathrm{C}$, no irradiation-induced swelling is expected to occur in the life of the plant.

- Tensile Strength

The structure experiences the maximum stress intensity on the outer surface of the outer wall at the junction with the stiffener:

$$
\mathrm{S}_{\text {MAX }}=9956 \mathrm{psi}
$$

From the ASME Boiler and Pressure Vessel Code, Section VIII, Division 2, the allowable stress intensity for 316 SS (reference 17, Table AMA-1) for $100^{\circ} \mathrm{F}-200^{\circ} \mathrm{F}$ is given as:

$$
\mathrm{SM}=20 \mathrm{ksi}
$$

For secondary loading, a factor of 3 is permissible for the allowable stress instensity. Negligible degradation of tensile properties for 316 SS at typical TCT hybrid fluences is expected. Thus, tensile strength does not limit the structure life.

- Plastic Cycling (Ratcheting)

If stresses exceed the yield during the operational cycles, it is possible that incremental plastic growth could occur with each cycle. Since stresses are well below the yield at all times in this structure, it is noi possible for plastic cycling to occur.

- Creep

The creep rupture characteristics of 316 SS indicate that creep is not a problem below $500^{\circ} \mathrm{C}$. Thus, creep rupture does not limit the structure life. 
- Crack Growth

It was assumed that a crack of semicircular shape existed in the 0.1 inch thick shell. The crack radius initially was 0.01 inches. A simple stress intensity factor was used:

where

$$
\text { S.I.F. }=\sigma \sqrt{\pi \mathrm{C}}
$$

$$
\begin{aligned}
\sigma & =\text { maximum stress } \\
& =20,000 \mathrm{psi} \text { (with a factor }=2.0 \text { ) }
\end{aligned}
$$$$
\mathrm{c}=\text { semicrack length }
$$$$
=0.01 \text { inches }
$$

Using an extrapolation of data for $20 \%$ cold-worked 316 SS at a much higher temperature than the operating temperature, computations indicate that it would take several decades for this crack length (and depth) to increase by $10 \%$. Thus, crack growth does not threaten the structure's integrity, nor is it likely to induce leaks.

- Fatigue

The maximum stress intensity due to thermal cycling is:

$$
\mathrm{S}_{\text {MAX }}=6590 \mathrm{psi}
$$

With a concentration factor of 5 , this amounts to a cyclic strain of less than $0.1 \%$. Comparison of this strain with data of irradiated SS indicates the structure has infinite fatigue life.

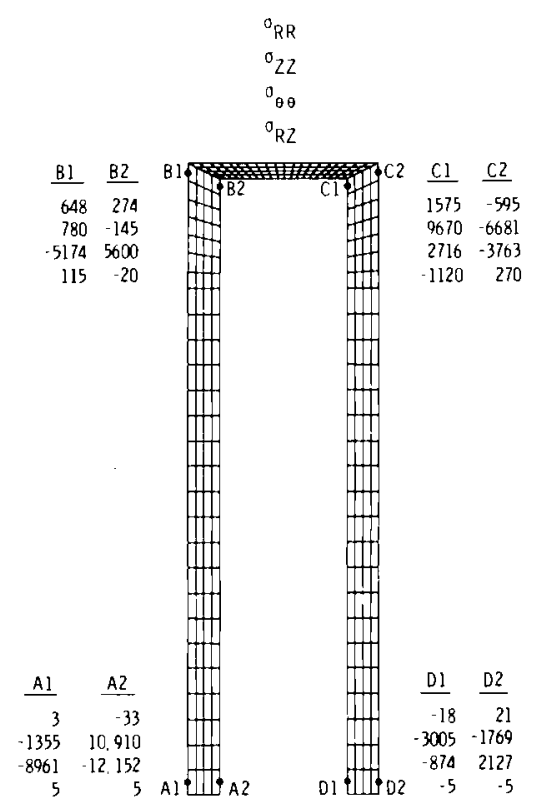

FIGURE 5. Maximum Stress Component Operating Conditions 
The feasibility of fabricating a toroidal vacuum chamber using the double wall concept was briefly examined. A method of fabricating a $30^{\circ}$ segment of the toroidal chamber has been determined, involving stretch forming the components (i.e., innermost wall and integral rib and outermost wall plates) and then TIG or $E$ beam welding them together. Figure 6 shows the resulting wall cross section. The assembly method allows adequate weld quality control inspections. Although the fabrication would be relatively expensive for thin section stainless steel, the long life should compensate for the expense.

\section{TOROUS WALL CONSTRUCTION}
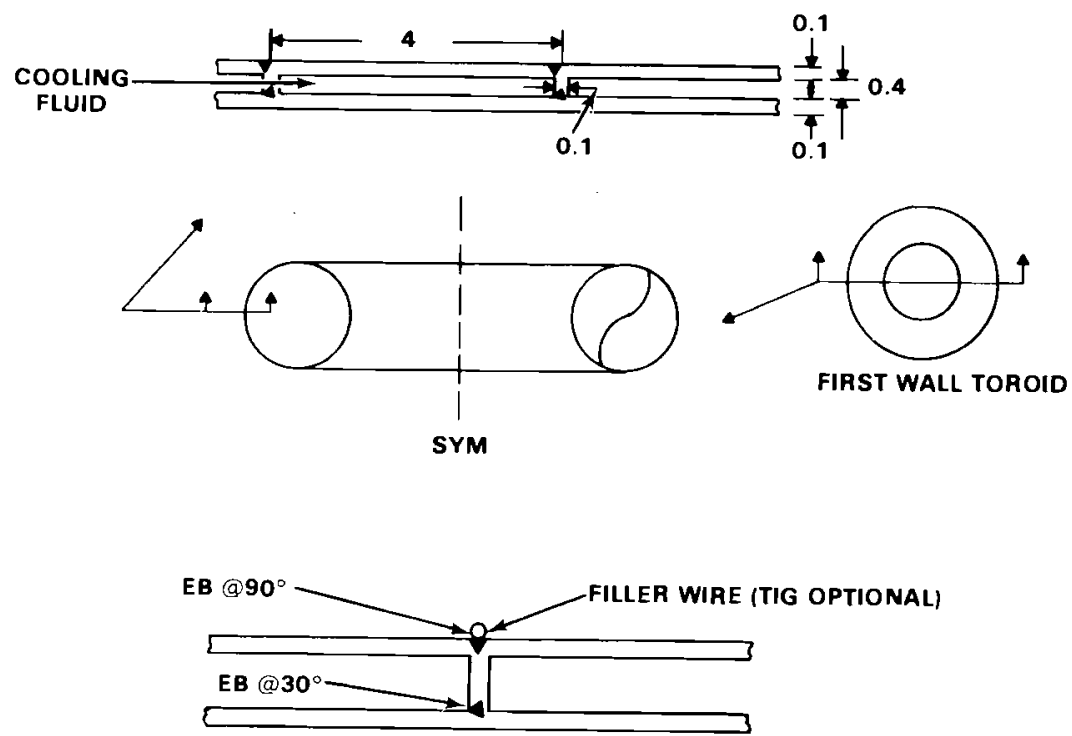

FIGURE 6. TCT Hybrid First Wall Fabrication (Double Wall Concept)

From this brief study, it was concluded that a double wall structure cooled with low pressure water should be used as a basis for the conceptual design of the TCT Hybrid first wall. The first wall could also serve as a vacuum barrier with adequate life. Although this study was based on a toroidal chamber, the basic concept would be adaptable to either a double or single wall diverter design. A different fabrication method would be considered for these designs, however. 


\section{CONVERTER REGION}

The ${ }^{238} U$ in the converter region provides neutron and energy multiplication, due to fast fission, $(n, 2 n)$ and $(n, 3 n)$ reactions of the 14 MeV fusion neutrons, and ${ }^{239} \mathrm{Pu}$ production due to neutron capture in the ${ }^{238} \mathrm{U}$. In contrast, the burner-moderator portion of the blanket in Figure 1 breeds tritium from neutron reactions with lithium and produces power due to ${ }^{239} \mathrm{Pu}$ fissions. It thus appears desirable, from a neutronics viewpoint, to separate the fuel cycle of these two regions. The pressure tube converter fueled with U-Mo slugs or spheres would provide the fuel cycle flexibility desired in the plutonium producing converter. The objectives of this study were to adjust the initial U-Mo slug dimensions and the length of the pressure tube to maintain peak U-Mo temperatures below $900^{\circ} \mathrm{C}$, where an undesirable phase transition takes place.

Uniform coverage of the plasma chamber by the pressure tubes is critical. Since a poloidal diverter will probably be used in the TCT Hybrid, most of the preconceptual effort was directed at evaluating a horizontal pressure tube layout. This type of layout provides better coverage of the poloidal diverter geometry but does sacrifice flexibility in fueling the converter region.

The converter region used in the thermal hydraulic analyses is described schematically in Figure 7 . In sizing the fuel slug, the inner and outer radii were simultaneously changed to maintain a constant fuel cross section. Inlet conditions of helium at $50 \mathrm{~atm}$ and $579^{\circ} \mathrm{F}$ were used for the coolant. Sensitivity studies were performed on slug size, pressure tube length and coolant conditions. The following parameters are recommended as a conceptual design basis:

$$
\begin{array}{ll}
\text { U-Mo dimensions } & \\
\text { Inner diameter } & 1.15 \mathrm{in} . \quad(2.92 \mathrm{~cm}) \\
\text { Outer diameter } & 2.47 \mathrm{in.}(6.27 \mathrm{~cm}) \\
\text { Helium } & \\
\text { Pressure } & 700 \mathrm{psi}(47.6 \mathrm{~atm}) \\
\text { Inlet temperature } & 579^{\circ} \mathrm{F} \quad\left(304^{\circ} \mathrm{C}\right) \\
\text { Outlet temperature } & 80^{\circ} \mathrm{F} \quad\left(466^{\circ} \mathrm{C}\right) \\
\triangle \mathrm{P} & 10 \mathrm{ps} \text { i }(0.68 \mathrm{~atm}) \\
\text { Pumping power } & 2 \% \text { of converter thermal power }
\end{array}
$$


Pressure tube dimensions

$\begin{array}{llll}\text { Inner diameter } & 2.84 & \text { in. } & (7.21 \mathrm{~cm}) \\ \text { Outer diameter } & 3.05 \mathrm{in} . & (7.75 \mathrm{~cm}) \\ \text { Length (maximum) } & 24 & \mathrm{ft} & (7.32 \mathrm{~m})\end{array}$

The thermal hydraulic evaluation was made on a reactor operating at $0.74 \mathrm{MW} / \mathrm{m}^{2}$ average neutron wall loading and circumferential power peaking factor of 1.5. The assumed operating cycle was $1000 \mathrm{sec}$ on, $100 \mathrm{sec}$ off. The thermal response of the converter slugs in a $16 \mathrm{ft}$ channel during the operating cycle is shown in Figure 8.

\section{CONVERTER GEOMETRY}

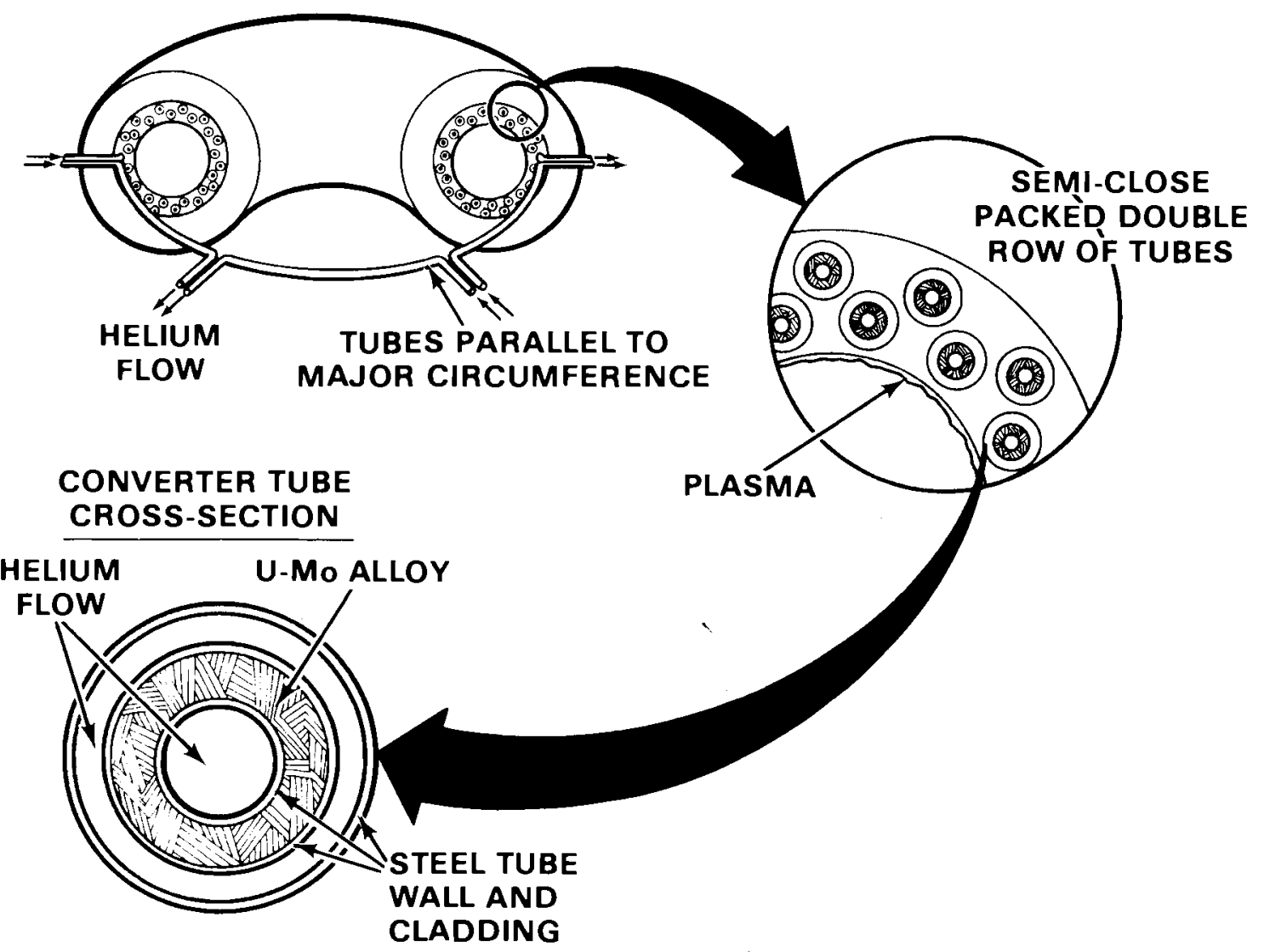

FIGURE 7. Converter Geometry 


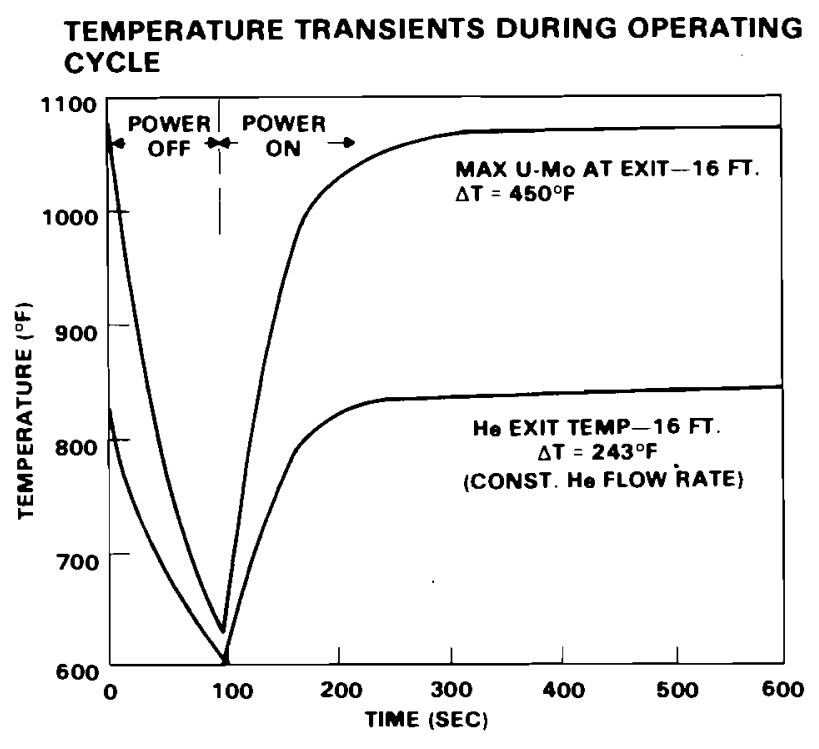

FIGURE 8. Temperature Transients During Operating Cycle

The structural response of the U-Mo slugs to the operating cycle and startup cycle was determined using AXISOL. The following results were obtained:

Load Case 1 - Startup Cycle

Maximum Fuel Stress Intensity $=6060$ psi

Major components of this stress intensity were hoop and longitudinal tensile stresses near the inner cladding. A major source of stress was the radial temperature gradient causing the outer, hotter fuel to pull the cooler, inner fuel outward and longitudinally. This stress is approximately one-third of the yield stress of the fuel at operating temperature.

Maximum Clad Stress Intensity $=22,290$ psi

Major components of this stress intensity are plastic compressive strains in the cladding due to the bulk temperature rise and the difference in clad 
and fuel coefficients of thermal expansion. Maximum effective strain is approximately 0.00323 , which is nearly four and one-half times the yield strain at operating temperature. This value is within the elongation bounds of the material, but a detailed cyclic strain history analysis would be necessary to determine if the cladding would ultimately undergo elastic action for this loading cycle.

A simplified strain history tracing from the single cycle analysis performed indicates significant plastic action into the second cycle due to the radial temperature gradient. The bulk temperature rise from room temperature to around $1100^{\circ} \mathrm{F}$ can be shown to cycle elastically, resulting in cladding tensile stresses of approximately $27 \mathrm{ksi}$ (RT yield = $30 \mathrm{ksi}$ ) on cool down.

The cyclic life of the cladding can be roughly approximated by using the ASME Boiler and Pressure Vessel Code (BPVC) fatigue curves with a stress based on the effective strain and the modulus at temperature. This "elastic" stress level indicates a fatigue life near 1000 cycles, adequate for the short life of a fuel slug. Incremental plastic deformation, or ratcheting, has not been examined at this analysis level.

Load Case 2 - Operating Cycle

Maximum Fuel Stress Intensity $=4062$ psi

This completely elastic stress intensity primarily results from the radial temperature gradient and is in the same location as the startup cycle peak fuel stress.

\section{Maximum Cladding Stress Intensity $=18,940$ psi}

This stress intensity indicates slight inelasticity, but effective strain is much less than twice yield strain at temperature, indicating elastic cycling starts immediately for the operating cycle. Effective strain is 0.00094 , which, with the modulus at temperature, can be used to approximate fatigue life for the operating cycle strain traverse. This elastic stress indicates a fatigue 1 ife of $10^{6}$ cycles, adequate for a short-term pellet cladding. 
A potential concept of a horizontal converter tube layout for a $R=8.15 \mathrm{M}$, $r=1.6 \mathrm{M}$ plasma, using a single null diverter is shown on Figures 9 and 10 . The pressure tubes run a full $60^{\circ}$ arc; however, the bayonet joints every $30^{\circ}$ allow disassembly of the vacuum vessel and converter into $30^{\circ}$ segments. To refuel the converter region, the horizontal layout would probably require blanket disassembly; however, more knowledge about magnet design, diverter openings and neutral beam ports would be required for developing a specific disassembly procedure.

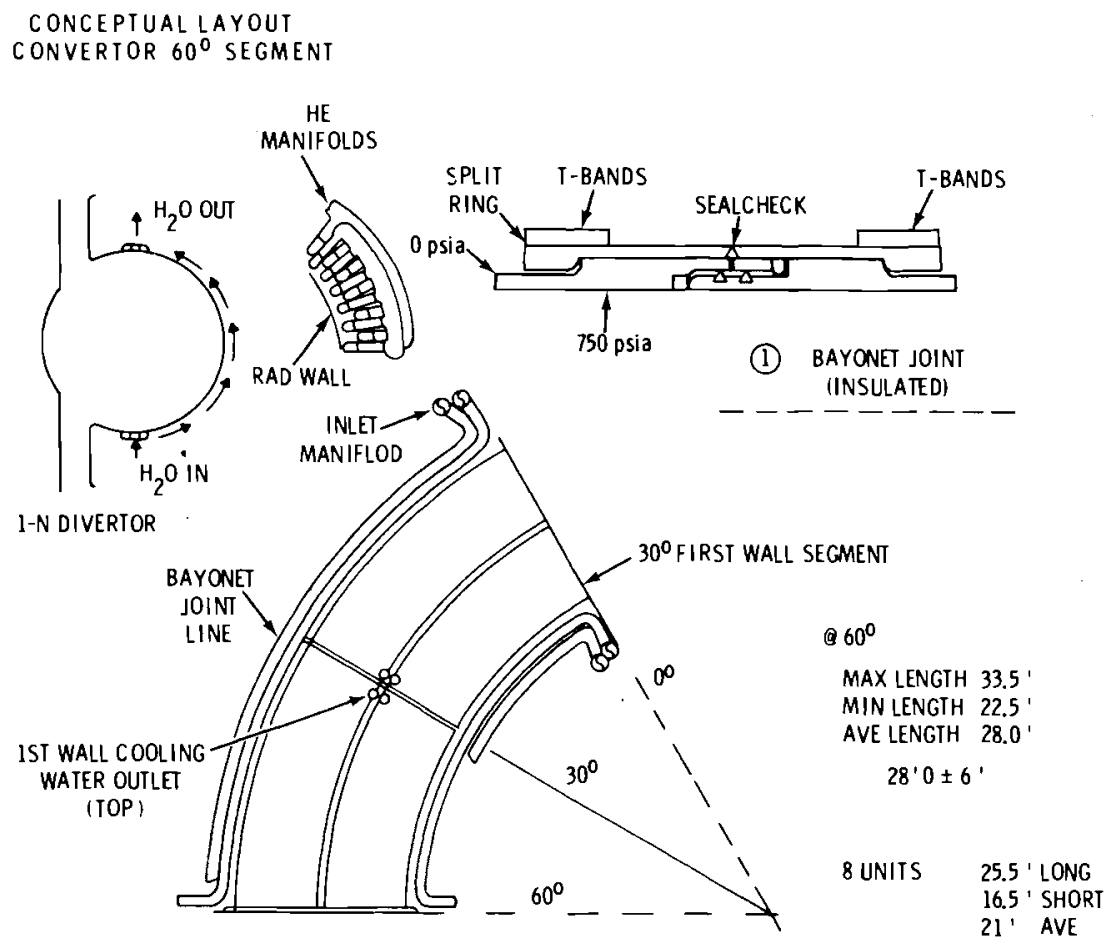

\section{FIGURE 9. Converter $60^{\circ}$ Segment}

Adequate plant availability would result only if the converter fuel has a long residence time. The burnup effects due to fission product buildup and retention in the fuel, appear to physically limit the U-Mo slug life; U-Mo alloys have proved dimensionally stable to 10,000 MWD/MT. In the TCT Hybrid converter region, this would give approximately a 3-4 year life. If, however, fuel cycle economics dictate a shorter converter fuel residence 
time, a vertical tube layout is recommended. Perhaps the U-Mo should be in spherical form for easier fuel handling, although fabrication of clad U-Mo spheres would require development.

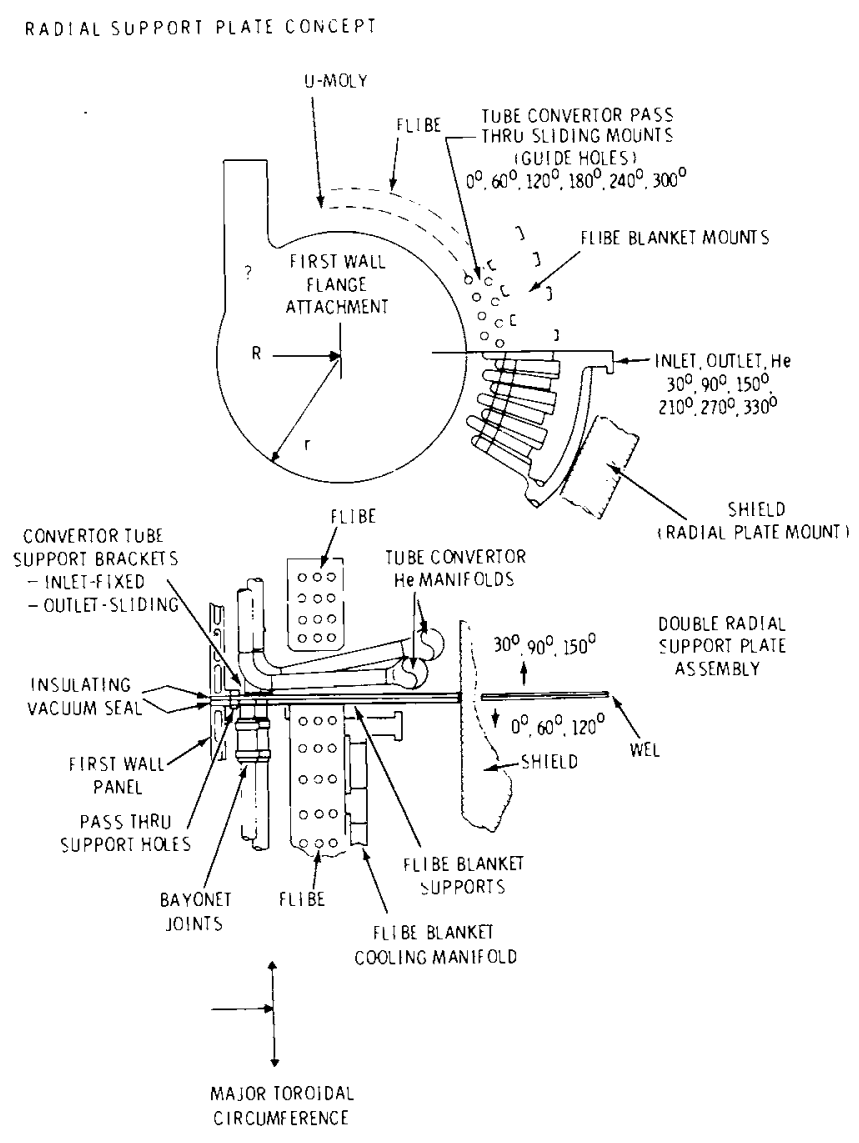

FIGURE 10. Radial Support Plate Concept

\section{BURNER AND MODERATOR REGION}

The blanket burner and moderator were analyzed as a single unit (Figure 11). The burner consisted of 5 v01\% $316 \mathrm{SS}, 15$ vol\% He, and 80 vol\% salt. The moderator consisted of 5 vol\% salt and 95 vol\% graphite. The composition of the salt is 52 mole $\% \mathrm{BeF}_{2}, 47.5$ mole $\% \mathrm{LiF}\left(0.83 \mathrm{a} / \mathrm{L} \mathrm{Li}^{6}\right), 0.5 \mathrm{~mole}^{6} \mathrm{PuF}_{3}$. This composition resembles the molten salt, flibe. The power generated in the salt in the burner region is $7.4 \mathrm{MW} / \mathrm{m}^{3}$ and $52 \mathrm{MW} / \mathrm{m}^{3}$ in the salt in the moderator region (negligible power is generated in the graphite). 


\section{SCHEMATIC OF BURNER AND MODERATOR}
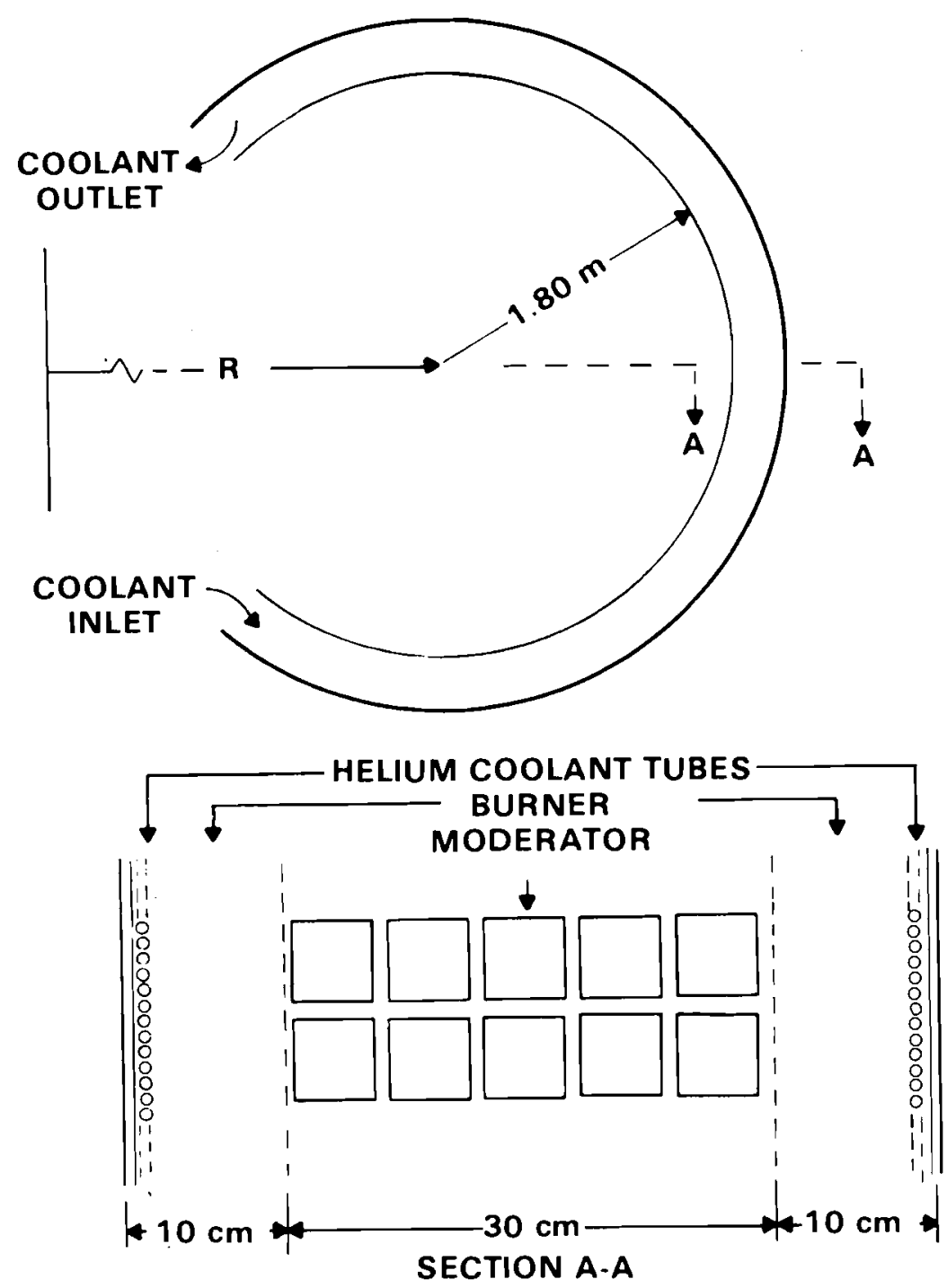

FIGURE 11. Schematic of Burner and Moderator

In designing the heat removal system for the burner-moderator region, transfer of the heat to the helium system in the blanket appeared desirable, as this has two beneficial effects. First, if the salt remains in the blanket during the power-off portion of the cycle, it acts as a thermal storage medium. This minimizes the thermal shock to the structural materials, piping, etc. Secondly, not removing the energy with the salt would eliminate the development of large molten salt pumps. Only a processing stream flow to remove the tritium would be required; this can be accomplished with MSRE pumps. 
The question then becomes whether the heat can be removed from the moderator region and still maintain acceptably low $\left(600^{\circ} \mathrm{C}\right)$ graphite-salt interface temperatures. The concept shown in Figure 11 would be the most acceptable from the neutronics standpoint and perhaps from a fabrication standpoint.

A two-dimensional code was written to analyze the heat transfers in the blanket. It included the appropriate power generation in each region, conduction in the moderator, conduction and natural convection in the burner, and heat transfer to the bank of helium coolant tubes. The code was also equipped to handle phase changes in the salt since the heat of fusion is substantial and a region of permanently, solid salt is undesirable. Thermophysical properties were permitted to be temperature dependent. Average thermophysical properties and power generation rate were applied in the moderator region based on volume percentages and structure; however, a lack of complete agreement seems to exist in the literature on the thermophysical properties of this particular salt (notably liquidus temperature and viscosity).

Thermal profiles in the helium coolant, SS tube wall, burner and moderator are shown in Figure 12(a). These profiles represent conditions at the reactor midplane (Section A-A in Figure 11) at the end of a power-on period $(1000 \mathrm{sec})$ and at the end of a power-off period $(100 \mathrm{sec})$. The helium coolant inlet temperature is $350^{\circ} \mathrm{C}$ and outlet temperature is $490^{\circ} \mathrm{C}$ with a nominal pressure of $50 \mathrm{~atm}, 1 \mathrm{~atm}$ pressure drop, and velocity of $100 \mathrm{~m} / \mathrm{sec}$.

The salt and graphite will be in contact in the moderator at temperatures near $1800^{\circ} \mathrm{C}$. Compatibility problems begin to appear above a temperature of approximately $600^{\circ} \mathrm{C}$. This temperature difference cannot be reduced significantly by any reasonable changes in helium velocity or inlet temperature. Note: Natural convection in the salt effectively promotes a nearly isothermal profile except at the SS interface. At this interface, the relatively low thermal conductivity of the salt leads to a very steep thermal gradient.

In view of the excessively high temperatures, another situation was examined where one bank of helium coolant tubes was placed at the burnermoderator interface and an additional bank was placed in the center of the 
moderator. The thermal profile for this case satisfied compatibility requirements for both graphite and SS as shown in Figure 12(b). Unfortunately, introducing additional SS results in excessive neutron absorption, thus yielding inadequate tritium and plutonium production. Using this configuration would require using a tubing material with much lower absorption cross section than SS or higher fissile plutonium enrichment in the burner salt.

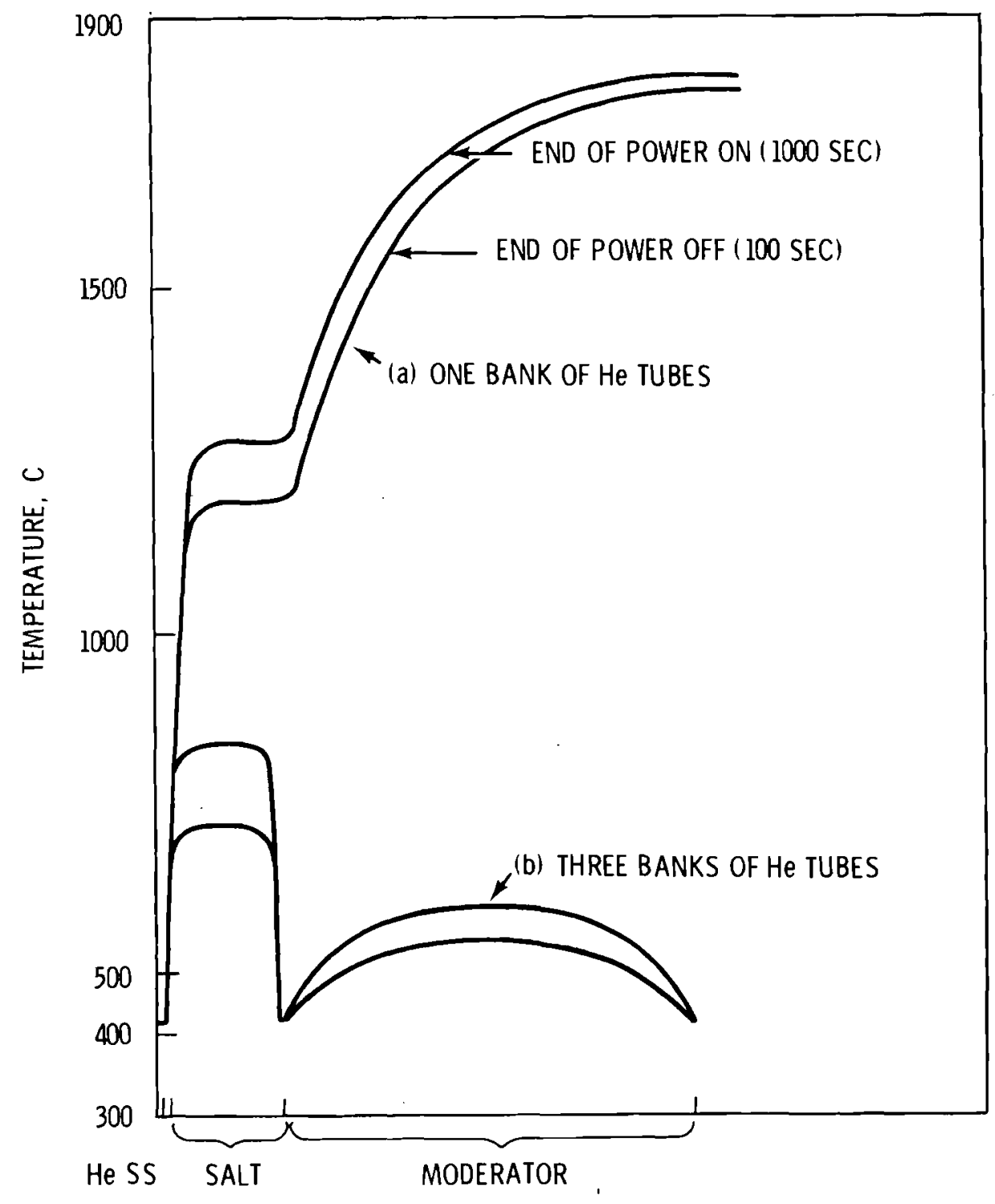

FIGURE 12. Thermal Profile in Burner and Moderator at Mid/Plane 
Neither case considers circulation of the burner salt in the graphite moderator. With the large temperature gradients calculated in Case 1, significant natural circulation would probably occur. To make any meaningful calculations, however, would require spending some time designing discrete channels in the graphite moderator. The channels would have to vary, depending on the orientation of the blanket as it wraps around the plasma chamber. (This effort was beyond the scope of this study.)

It may also be possible to induce forced circulation of the burner salt in the graphite moderator. The process stream for extracting tritium could be brought back into the blanket so that it caused some circulation in that region. More work must be done on laying out the blanket tanks before any meaningful analysis of this concept can be made.

A final situation was briefly examined. The original helium coolant configuration (two rows, one each at the outer face of each burner) was maintained, but the molten salt was pumped through the burner and moderator regions. An average velocity of approximately $10 \mathrm{~cm} / \mathrm{sec}$ is estimated to be sufficient to keep temperatures within bounds. A heat exchanger along with the tritium recovery cycle loop would then be used external to the blanket and shield. This situation could be considered as a last resort since it grossly changes the dynamic characteristics of the blanket heat removal and requires the development of large molten salt pumps.

The analysis did not include magnetohydrodynamic (MHD) effects. MHD effects are expected to be especially noticeable on natural convection currents in the molten salt and, hence, the temperature profile. Transient natural convection velocities of the order of $1 \mathrm{~m} / \mathrm{sec}$ were noted in the absence of MHD forces. Other MHD effects of potential concern are increased pumping losses and corrosion. It is recommended that MHD effects be included in future detailed thermal hydraulic studies. 


\section{ENGINEERING EVALUATION OF BLANKET COMPONENTS}

Preliminary economic studies conducted by PPPL indicated that to be commercially attractive, the TCT Hybrid has to produce considerably more power than is available from the fusion reaction and converter neutron multiplication. To do this, hybrid blankets that use additional fissile material for energy multiplication are being considered. The combinations of materials that neutronically seem to satisfy the requirements for adequate amounts of fissile material, tritium and power pose some interesting engineering problems. The purpose of this study was to identify the applicable design constraints and to determine conceptually how a TCT Hybrid blanket might be cooled and the structural requirements of critical blanket components. The analyses are not exhaustive, nor are the conceptual considerations completely integrated with plasma engineering considerations, but the results will be useful to guide in selecting a design for assessing the commercial viability of the TCT Hybrid concept.

The blanket concept given a preliminary evaluation is shown schematically in Figure 1. The wall loading, power densities, region dimensions and material compositions were taken from the PPPL parametric neutronic studies of salt blankets. (25) The final blanket selected will probably vary in all major parameters, but the case chosen is adequate to begin conceptualizing the components involved.

The three objectives of this study are to: 1) determine an adequate first wal1 cooling method; 2) develop a conceptual layout of the converter region tubes to provide for the desired movement and adequate cooling of the U-Mo slugs of fertile material; and 3) determine an adequate method of cooling the burner and moderator regions (blanket region).

\section{MATERIAL PROPERTIES}

Stainless steel (SS) was selected ${ }^{(8)}$ as the structural material for the first wall and the converter tubes, since it possessed adequate integrity in the presence of the anticpated loadings, and was weldable and capable of being fabricated into forms significant to fusion technology. $(25,26)$ Also, facts have indicated that critical components of a fusion reactor have a satisfactory 1 ifetime when constructed with SS. 
The two most profound effects upon the steels exposed to the fusion reactor irradiation environment are:

- swelling

- lack of ductility.

These effects result from neutron irradiation and consequent atom displacement. The atom realignments produce voids and interstices. Helium bubbles are also generated, which, under certain conditions, can stabilize the voids. Reference 26 discusses the general nature of the irradiation phenomena. Reference 27 also discusses the matter in more depth.

Besides causing a volumetric increase and hardening of the steels, irradiation influences the ultimate and yield tensile strengths, crack growth, fatigue and creep properties of SS. All properties depend to a certain extent upon the amount of accumulated irradiation neutrons $/ \mathrm{cm}^{2}$-year $\left(\mathrm{N} / \mathrm{cm}^{2} \mathrm{yr}\right)$ or displacements per atom/year (DPA/yr), and the prevailing temperature.

This report does not present an exhaustive survey of data on irradiation effects upon SS. The objective was to review those effects that could be significant to the integrity and life of the TCT Hybrid reactor first wall and adjacent structural components. Existing data pertaining to SS were used in subsequent analyses and discussions. The data used pertained mainly to coldworked $316 \mathrm{SS}$, but due to unavailability in some instances, reference was made to related steels.

Volumetric Swelling

Volumetric swelling is a function of the prevailing temperature and the $D P A$, which is regarded as a linear function of the wall loading. The DPA/yr for $1 \mathrm{MW} / \mathrm{m}^{2}$ wall loading on SS is $13.0 .{ }^{(28)}$ Thus, for the TCT Hybrid,

wall response $=0.74 \times 13.0=9.62 \mathrm{DPA} / \mathrm{yr}$.

This approximate value does not consider the energy (MeV) distribution associated with the spectra for the TCT Hybrid reactor. It assumes a uniform spectra of $14 \mathrm{MeV}$, which is conservative as far as loading on the wall is concerned. 
A typical empirical equation for swelling ${ }^{(29)}$ for $20 \%$ cold-worked 316 SS is given below:

Fractional volume change $=\frac{\Delta V}{V_{0}}$

$\frac{\Delta V}{V_{0}}=(0.01) R\left[\phi t+\frac{1}{\alpha} \operatorname{Ln}\left\{\frac{1+\exp [\alpha(\tau-\phi t)]}{1+\exp (\alpha \tau)}\right\}\right]$

$\phi t=$ neutron fluence in units of $10^{22} \mathrm{n} / \mathrm{cm}^{2}$ (E>0.1 MeV)

$R(T)=\exp \left(0.0419+1.498 \Delta+0.122 \Delta^{2}-\right.$

$\left.0.332 \Delta^{3}-0.441 \Delta^{4}\right)$

where

$\Delta=(T-500) / 100$ and $T$ is the temperature in ${ }^{\circ} \mathrm{C}$

$\alpha=2.0$

$\tau($ nominal $)=7.0$

Its range of applicability is $350^{\circ} \mathrm{C}$ to $700^{\circ} \mathrm{C}$.

The function $R(T)$, with $T$ the temperature in ${ }^{\circ} \mathrm{C}$, is shown in Figure 13. This function controls the swelling distribution in the temperature regime. This swelling relation is mainly indicative since it is for a fast fission reactor and not for a fusion reactor.

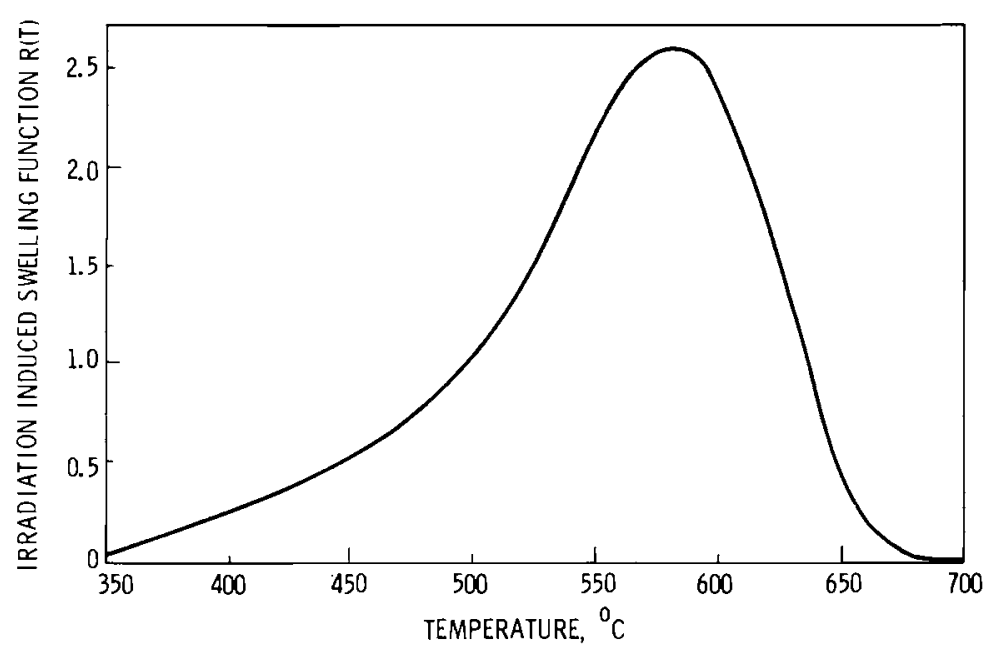

FIGURE 13. Irradiation Induced Swelling Function 
The variation of swelling with fluence for three materials at a fixed temperature is shown in Figure 14. The results indicate that PE-16 has excellent response characteristics in the irradiation environment.

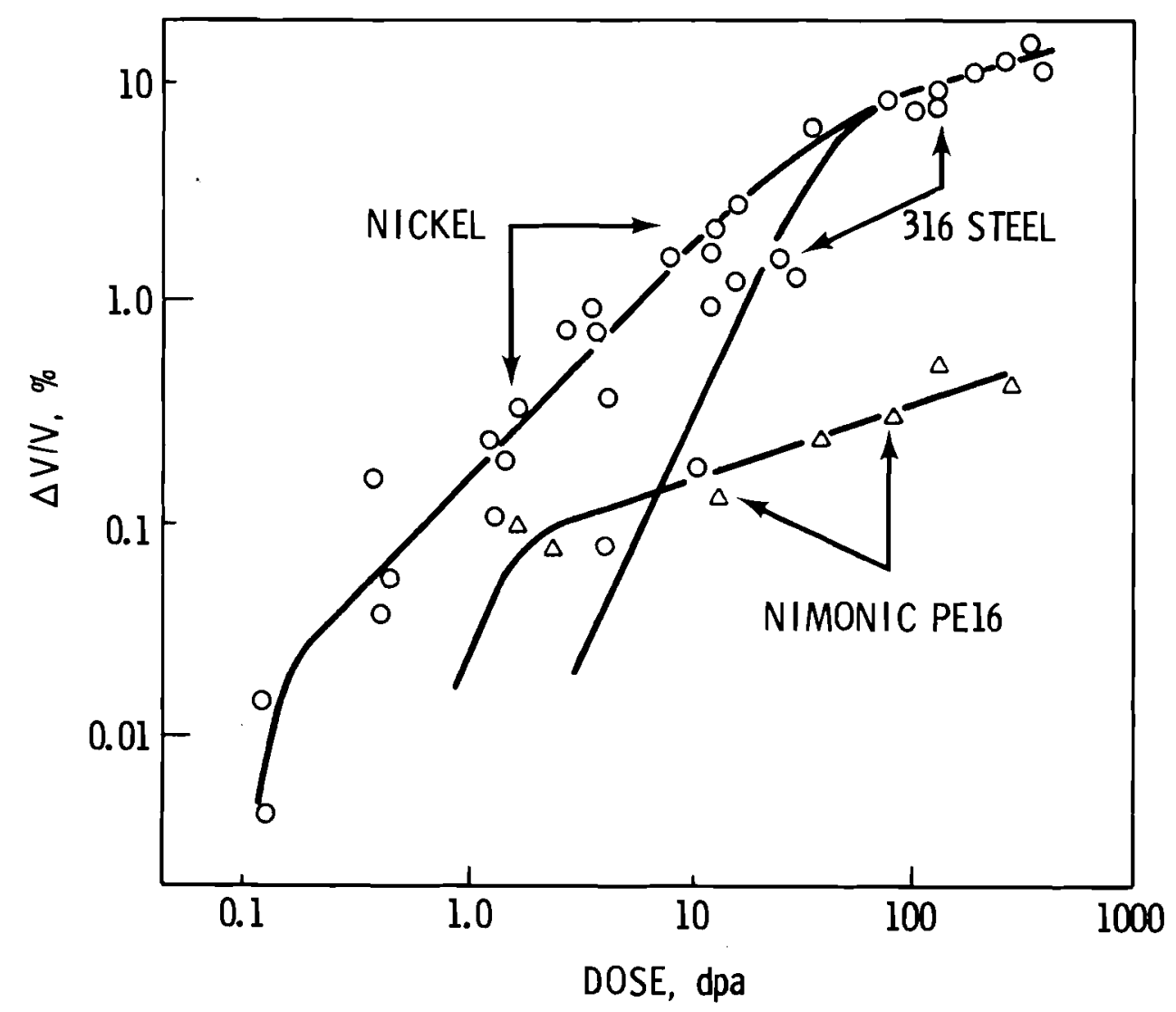

FIGURE 14. Swelling Behavior of $\mathrm{Ni}, 316 \mathrm{SS}$ and PE-16 at $25^{\circ} \mathrm{C}$ with Bombardment by $20 \mathrm{MeV}$ atoms. All materials contain $10 \mathrm{ppm}$ He.(30)

\section{Tensile Strength.}

Irradiation causes failure to occur at a reduced strain value in SS. The reduced ductility with increased fluence is both significant and consistent for some materials. However, the effect of irradiation upon tensile ul timate and yield strengths is not so consistent. 
Figure 15 shows plots of ultimate and yield tensile strengths for unirradiated and irradiated 316 SS specimens. (31) The plots represent both annealed and $20 \%$ cold-worked specimens tested over a limited temperature range. The irradiation was to a fluence of from 5.6 to $8.7 \times 10^{26} \mathrm{~N} / \mathrm{cm}^{2}$.
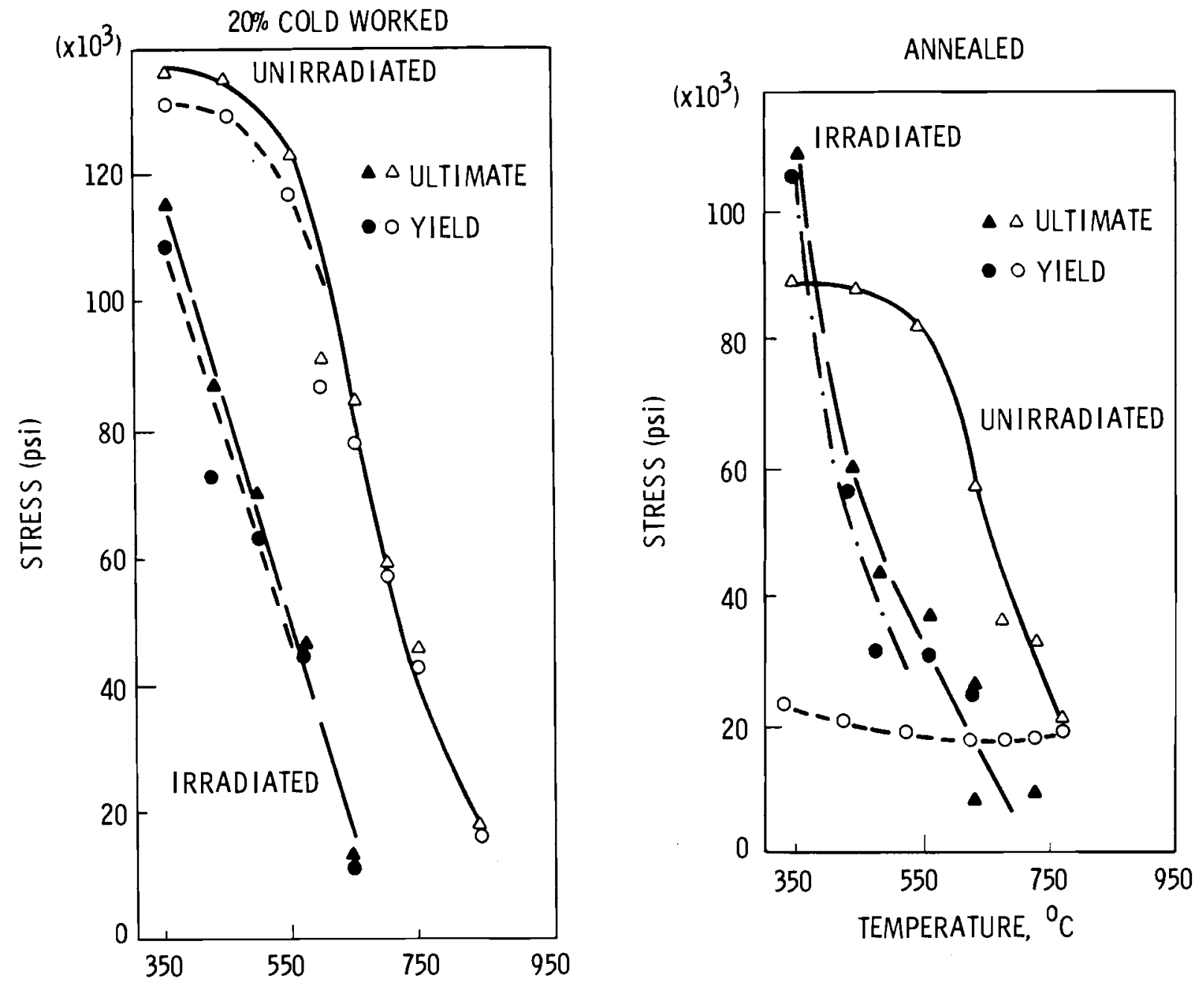

FIGURE 15. The Effect of Irradiation Upon 316 Stainless Steel Tensile Strength(31)

For the specified temperature range, the $20 \%$ cold-worked samples steadily deteriorate in strength whereas the annealed samples initially increase in strength.

\section{Creep Rupture}

Temperatures and irradiation play important roles in the creeprupture behavior of 316 SS. In creep tests at constant temperature 
levels and varying damage levels, increasing damage level corresponds with decreasing rupture 1 ife. (31) To mathematically represent the interrelationship of temperature and fluence upon rupture life, the following empirical equation is developed: (24)

$$
t_{r}=A(t i / \operatorname{tn}) \sigma^{B}
$$

where:

$$
\begin{aligned}
A & =\exp \left\{18+0.02893\left(T \text { 461.6) } \exp \left[-\frac{1}{8.4}\left(\frac{T-461.6}{655}\right)^{8.4}\right]\right\}\right. \\
B & =-5.4+0.014633(T-916) \exp \left[-\frac{1}{4}\left(\frac{T-916}{265}\right)^{4}\right] \\
\left(\frac{t i}{t n}\right) & =\exp \left\{-\frac{3.3}{\exp -\left(\frac{1}{M}\right)}[G-\operatorname{Ln}(\phi t)] \exp \left[-\frac{1}{M} \frac{G-\operatorname{Ln}(\phi t)^{M}}{1.3}\right]\right\} \\
G & =42.9+0.0095 T \\
M & =0.015408(T-870) \text { exp }\left[-\frac{1}{4}\left(\frac{T-870}{300}\right)^{4}\right] \\
t i & =\text { rupture time after irradiation } \\
t n & =\text { unirradiated rupture 1ife }
\end{aligned}
$$

$\mathrm{T}$ is expressed in ${ }^{\circ} \mathrm{F}$, $\phi t$ in units of $\mathrm{n} / \mathrm{cm}^{2}\left(\mathrm{E}_{\mathrm{n}}>0 / 1 \mathrm{MeV}\right)$, and $\sigma$ in $\mathrm{ksi}$ (true, normalized stress.) (a) Limits are: temperature 1000 to $1400^{\circ} \mathrm{F}$, stress to ultimate strength and fluence to $7.0 \times 10^{22} \mathrm{n} / \mathrm{cm}^{2}\left(E_{n}>0.1 \mathrm{MeV}\right)$. Correlations between the equation and actual creep rupture test results are shown on Figure 16.

Creep failure can be predicted for cyclic, or varying, conditions when:

$$
\sum \frac{\operatorname{tn}}{\operatorname{trn}} \geq 1.0
$$

where: $\quad t n=n t h$ time interval

trn = rupture life for the conditions of nth time interval.

\section{Crack Propagation}

The establishment of crack growth potential is necessary for structural integrity and coolant leakage. A fracture mechanics analysis can establish the potential for assumed cracks in critical regions of the structure. Fracture mechanics analyses are discussed in reference 32, particularly for SS.

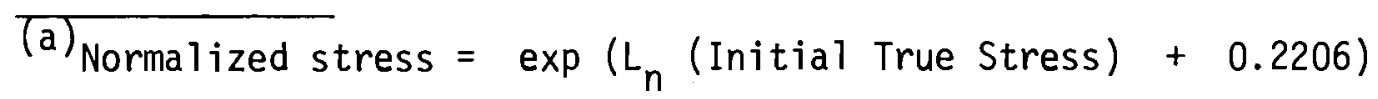


Data show the relationship between stress intensity factor and crack growth rate for various conditions. Also discussed are the temperature effects, neutron irradiation, environment and other factors. It indicates that $20 \%$ cold-worked 316 SS exposed to neutron irradiation has similar crack propagation characteristics as its unirradiated form. Results for a fixed temperature condition are shown on Figure 17. (33) Some crack growth effects of irradiation on 316 SS weldments are shown on Figure 18. ${ }^{(34)}$

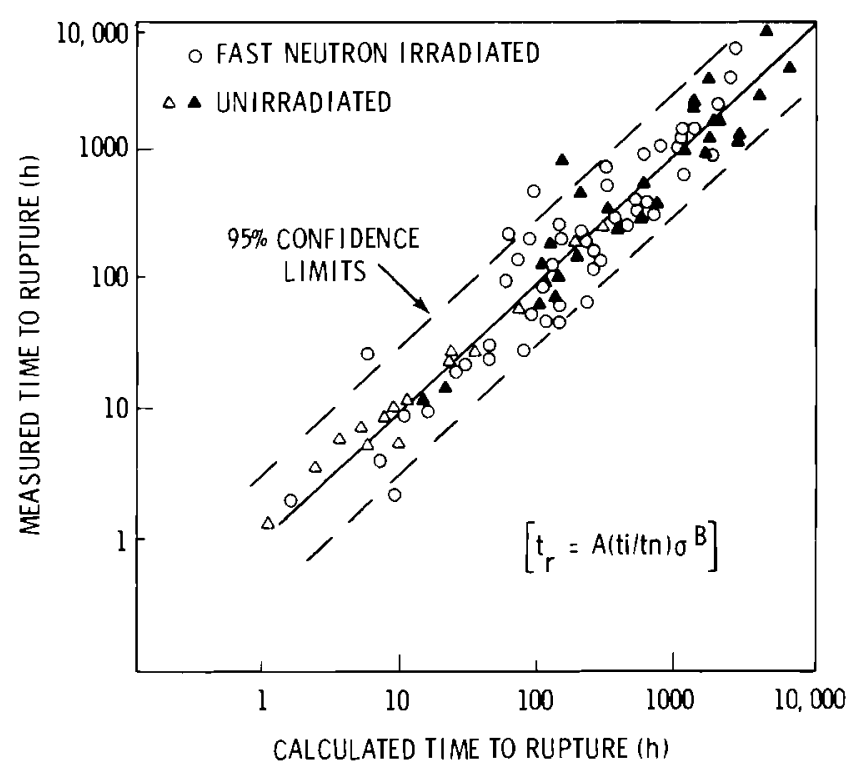

FIGURE 16. Correlation of Rupture Life Tests and Calculated Rupture Life for Annealed 316 Stainless Steel Specimens $(24)$

\section{Fatigue}

Irradiation affects the ductility of 316 SS and it is thus expected that fatigue characteristics would also be affected. Limited irradiation test data is available, but the plots of Figure $19^{(35)}$ substantiate that fatigue resistance is considerably reduced by irradiation. 


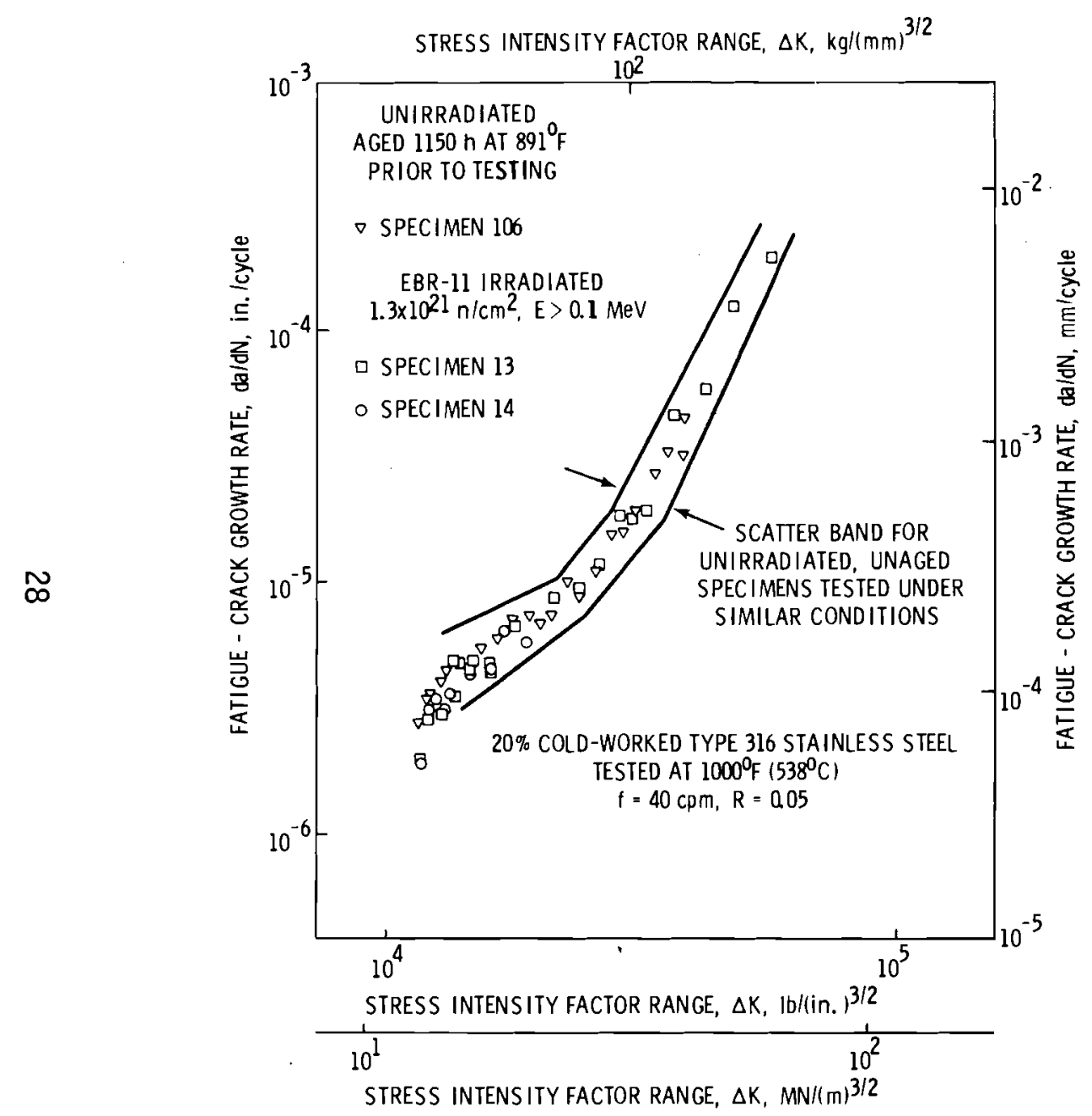

FIGURE 17. Comparison of Crack Propagation Behavior at $1000^{\circ} \mathrm{F}\left(538^{\circ} \mathrm{C}\right)$ of $20 \%$ Cold-Worked Type 316 Stainless Steel in the Unirradiated and Irradiated conditions $(33)$

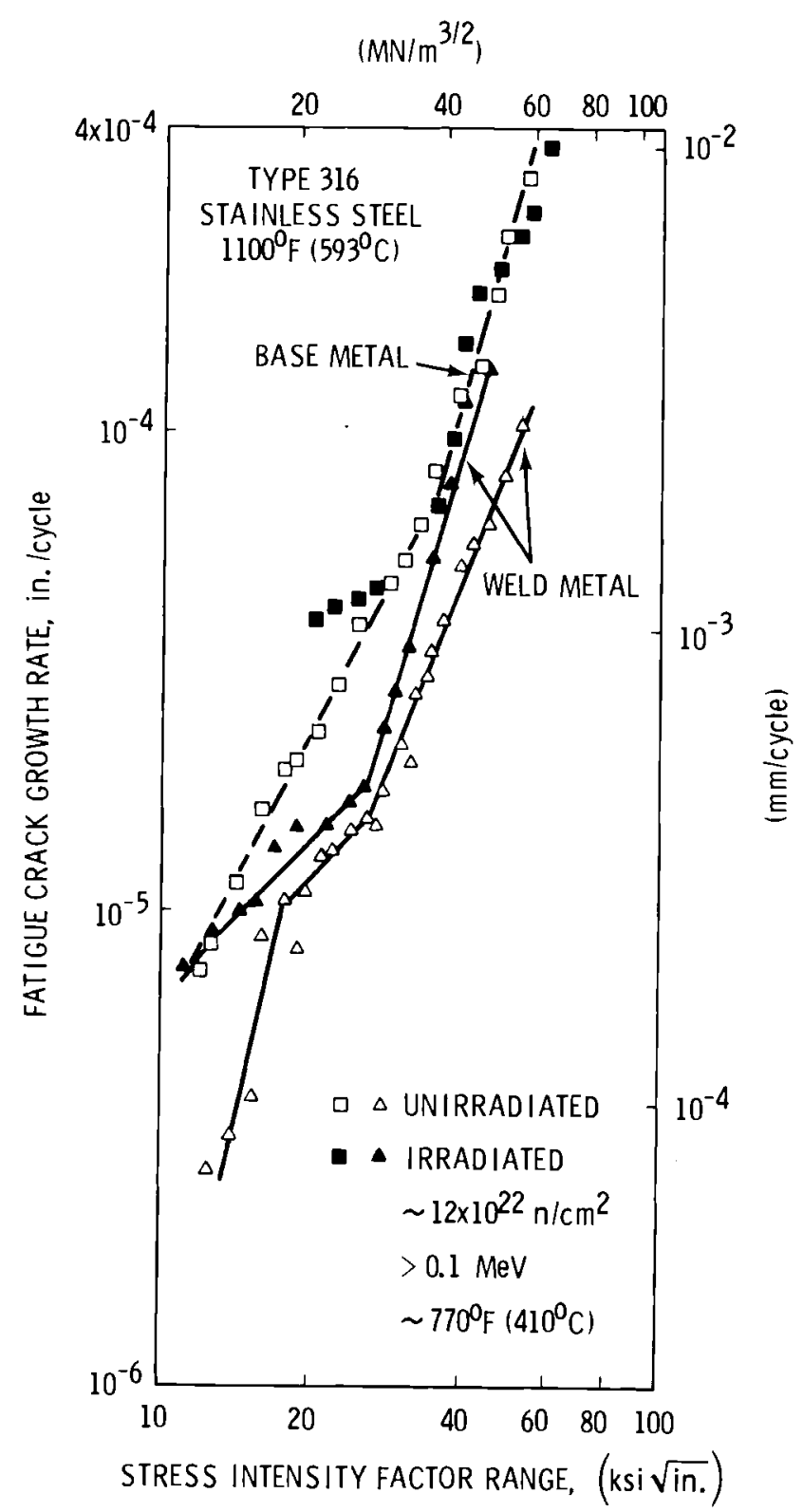

FIGURE 18. Influence of Irradiation on Crack Growth Rate in Type 316 Base and Weld Metals at $1100^{\circ} \mathrm{F}\left(593^{\circ} \mathrm{C}\right)(34)$ 


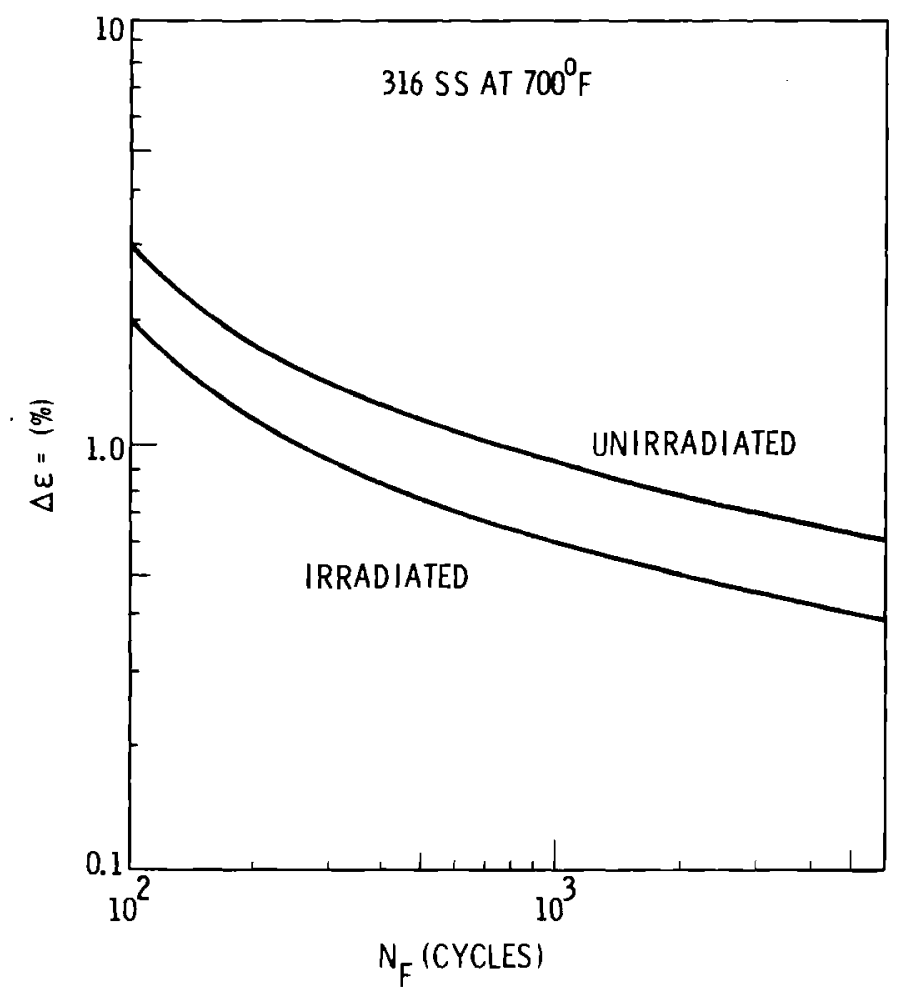

FIGURE 19. 316 SS Fatigue Characteristics

\section{FIRST WALL}

The first wall will provide the vacuum environment for the plasma and will be maintained at near-ambient temperature. It is envisioned as a doublewall structure (Figure 22). Water, under forced circulation between the inner and outer walls, will serve as the coolant.

The double wall concept accomplishes the goal of minimizing the amount of material in the first wall, but at some additional complexity in fabrication. The first wall life should be extended to balance this added complexity. Added wall life may be enhanced by maintaining the wall at relatively low temperatures and nearly isothermal conditions to minimize thermal stresses and fatigue, swelling, and ductility problems. 
Low-temperature water circulating within the double walls would effectively approach the desired isothermal conditions, but the thickness of water through which neutrons must pass should be minimized. One penalty in using low-temperature water is that plant efficiency will be lowered because the first wall thermal load is not used in the power conversion cycle. However, since the blanket multiplication is high $(\sim 23)$, the heat load on the first wall is a small percentage of the thermal power available. Also, the extended wall life and the attendant increase in plant availability will be positive economic factors.

The inner side of the first wall facing the plasma may be coated with a low- $Z$, low sputtering-rate material. The first wall's relatively low temperature should ease thermal expansion mismatch problems. An alternative is the use of a liner (low-Z, low sputtering-rate material), cooled primarily by radiation to the first wall. This will reduce the heat load to the first wall but may complicate fabrication and may also eliminate some candidate materials which must now withstand high temperatures.

Figure $3(a)$ indicates the coolant path around the minor circumference of the first wall. Figure $3(b)$ shows the variation in the wall thermal load around the minor circumference. This variation is meant to suggest a typical reactor and may not correspond exactly to any specific reactor. Calculations were based on average values for walload of $0.74 \mathrm{MW} / \mathrm{m}^{2}$, power absorbed at inner face of first wal1 of $0.17 \times 0.74 \mathrm{MW} / \mathrm{m}^{2}$, and internal power generation for $316 \mathrm{SS}$ of $0.0064 \times 0.74 \mathrm{MW} / \mathrm{m}^{3}$. The inner and outer wall thicknesses are each $0.25 \mathrm{~cm}$. The coolant is $0.05 \mathrm{~cm}$ thick. The remainder of the gap between walls (approximately $0.5 \mathrm{~cm}$ ) is assumed to be filled with a material that has low neutron cross sections and reasonably high thermal conductivity.

Table 1 shows wall temperatures and coolant temperatures and pressure. A11 temperatures are above coolant inlet conditions; the pressures are above the outlet conditions. Two cases are illustrated: average coolant velocities 
of $6.0 \mathrm{~m} / \mathrm{sec}$ and $3.0 \mathrm{~m} / \mathrm{sec}$. The higher coolant velocity naturally leads to lower wall temperatures but with potential higher coolant pressure. Thus, structural and neutronic trade-off could be required. Higher pressures imply more structural material with additional neutron loss. Lower pressures imply larger temperature swings between the on and off portions of a power cycle; thus, structural life may be shortened.

\section{TABLE 1. First Wal1 Temperatures and Coolant Pressures}

\begin{tabular}{|c|c|c|c|c|c|c|c|c|}
\hline \multirow[b]{3}{*}{ O. DEGREES } & \multicolumn{7}{|c|}{ AVERAGE COOLANT VELOCITY OF $6.0 \mathrm{~m}$ SEC } & \multirow{3}{*}{$\begin{array}{c}\text { COOLANT } \\
\text { PRESSURE } \\
\text { PSI }\end{array}$} \\
\hline & \multicolumn{3}{|c|}{ INNER WALL TEMPERATURES. $C$} & \multirow{2}{*}{$\begin{array}{c}\text { COOLANT } \\
\text { TEMPERATURE, } \\
\text { C }\end{array}$} & \multicolumn{3}{|c|}{ OUTER WALL TEMPERATURES. C } & \\
\hline & $\begin{array}{l}\text { PLASMA } \\
\text { SIDE }\end{array}$ & AVERAGE & $\begin{array}{l}\text { COOLANT } \\
\text { SIDE }\end{array}$ & & $\begin{array}{l}\text { COOLANT } \\
\text { SIDE }\end{array}$ & AVERAGE & $\begin{array}{l}\text { CONVEATER } \\
\text { SIDE }\end{array}$ & \\
\hline 60 & 16.0 & 9.9 & 3.7 & 0.0 & 0.3 & 0.7 & 09 & 49.3 \\
\hline 30 & 19.7 & 12.4 & 5.0 & 0.5 & 0.9 & 1.4 & 1.6 & 43.5 \\
\hline 0 & 28.7 & 18.3 & 7.6 & 13 & 1.8 & 2.4 & 2.8 & 38.3 \\
\hline 30 & 39.8 & 25.6 & 10.9 & 2.3 & 3.1 & 3.9 & 43 & 337 \\
\hline 60 & 49.0 & 31.8 & 14.1 & 3.7 & 4.5 & 5.6 & 6.1 & 29.7 \\
\hline 90 & 52.9 & 34.7 & 16.0 & 50 & 5.9 & 7.0 & 76 & 263 \\
\hline 120 & 510 & 34.2 & 16.8 & 65 & 7.4 & 8.4 & 89 & 22.5 \\
\hline 150 & 45.1 & 30.9 & 16.3 & 7.7 & 84 & 9.3 & 9.7 & 18.9 \\
\hline 180 & 36.1 & 25.7 & 15.0 & 87 & 9.3 & 99 & 102 & 14.4 \\
\hline 210 & 28.6 & 21.3 & 13.9 & 9.5 & 9.8 & 10.3 & 105 & 9.2 \\
\hline 240 & 26.0 & 19.9 & 13.7 & 10.0 & 10.3 & 10.7 & 10.9 & 3.4 \\
\hline \multicolumn{9}{|c|}{ AVERAGE COOLANT VELOCITY OF $3.0 \mathrm{~m}$ SEC } \\
\hline .60 & 187 & 126 & 6.4 & 0.0 & 0.6 & 0.9 & 1.1 & 14.9 \\
\hline 30 & 235 & 162 & 8.8 & 1.1 & 17 & 22 & 24 & 12.6 \\
\hline 0 & 346 & 242 & 13.5 & 26 & 3.5 & 41 & 44 & 10.9 \\
\hline 30 & 484 & 342 & 196 & 46 & 5.9 & 68 & 72 & 99 \\
\hline 60 & 603 & 43.1 & 254 & 73 & 8.9 & 99 & 10.4 & 9.4 \\
\hline 90 & 66.1 & 48.0 & 29.2 & 10.0 & 11.6 & 127 & 133 & 9.2 \\
\hline 120 & 64.5 & 48.8 & 30.5 & 13.0 & 14.5 & 155 & 160 & 89 \\
\hline 150 & 59.2 & 45.0 & 30.4 & 154 & 16.7 & 175 & 179 & 8.4 \\
\hline 180 & 49.5 & 39.1 & 28.4 & 17.5 & 18.4 & 19.0 & 193 & 7.4 \\
\hline 210 & 41.3 & 341 & 26.6 & 189 & 19.6 & 200 & 202 & 5.7 \\
\hline 240 & 38.7 & 32.6 & 26.4 & 20.0 & 20.6 & 20.9 & 21.1 & 3.4 \\
\hline
\end{tabular}

Under pulsed operation the temperature in portions of the first wall will reach steady state relatively quickly. The response time is estimated at 10 seconds. As a first approximation, therefore, the time variation in temperatures and gradients would be the same as those given in Table 1 .

First Wall Structural Analysis

This section describes the steps taken to perform initial sizing and integrity evaluations of the first wall. Major loadings due to pressure, temperature, radiation and magnetism were reviewed and applied to the structure if they were deemed significant. Because of the uncertainity that exists in the major configuration items (diverters, beam ports) and time available, an exhaustive analysis of the structure could not be done. The stress levels are believed to be representative and, therefore, meaningful in assessing the integrity and life of the structure. 
Reference 23 portrays the sequential arrangement of the tckamak hybrid components of the first wall converter. The major radii of the toroidal shape were later proposed as:

$$
\begin{aligned}
& R=320.866 \mathrm{in} .(8.15 \mathrm{~m}) \\
& A=62.99 \mathrm{in} .(1.6 \mathrm{~m})
\end{aligned}
$$

\section{Single Wall Thickness}

The basic shape of the first wall is a toroid. (25) It will possess many openings of structural significance to accomodate diverter flow and beam ports. These openings and their necessary reinforcements will enhance the stiffness of the first wall she11. Thus, to assess the general stability of the first wall, which contained the plasma vacuum, on the assumption that it was a uniform thin shell, was considered conservative. The criterion of general stability was used to arrive at the initial value of wall thickness. An iterative procedure was adopted ${ }^{(36)}$ to establish the minimum shell thickness to prevent a general instability due to an external pressure of 29.4 psi (safety factor = 2). The solution, based on a series expansion method, indicated that a shell thickness of 0.525 in. was required.

Since this recognized only two modes of instability, a more stringent study was made, using a computer program BOSOR4 ${ }^{(23)}$ which is outlined in Appendix E. This program is based upon she11-of-revolution theory and is capable of solving complex configurations under a variety of loading conditions.

BOSOR4 solves for buckling loads by recognizing two distortion categories:

1) Poloidal (Vertical or Meridional) Plane - A typical cross section is defined by a number of analysis points and their interconnecting shel1 elements. Such a view is presented in Figure 20 by 42 points and elements. Each point is able to move independently but is subject to the elastic constraints of the shell elements. 


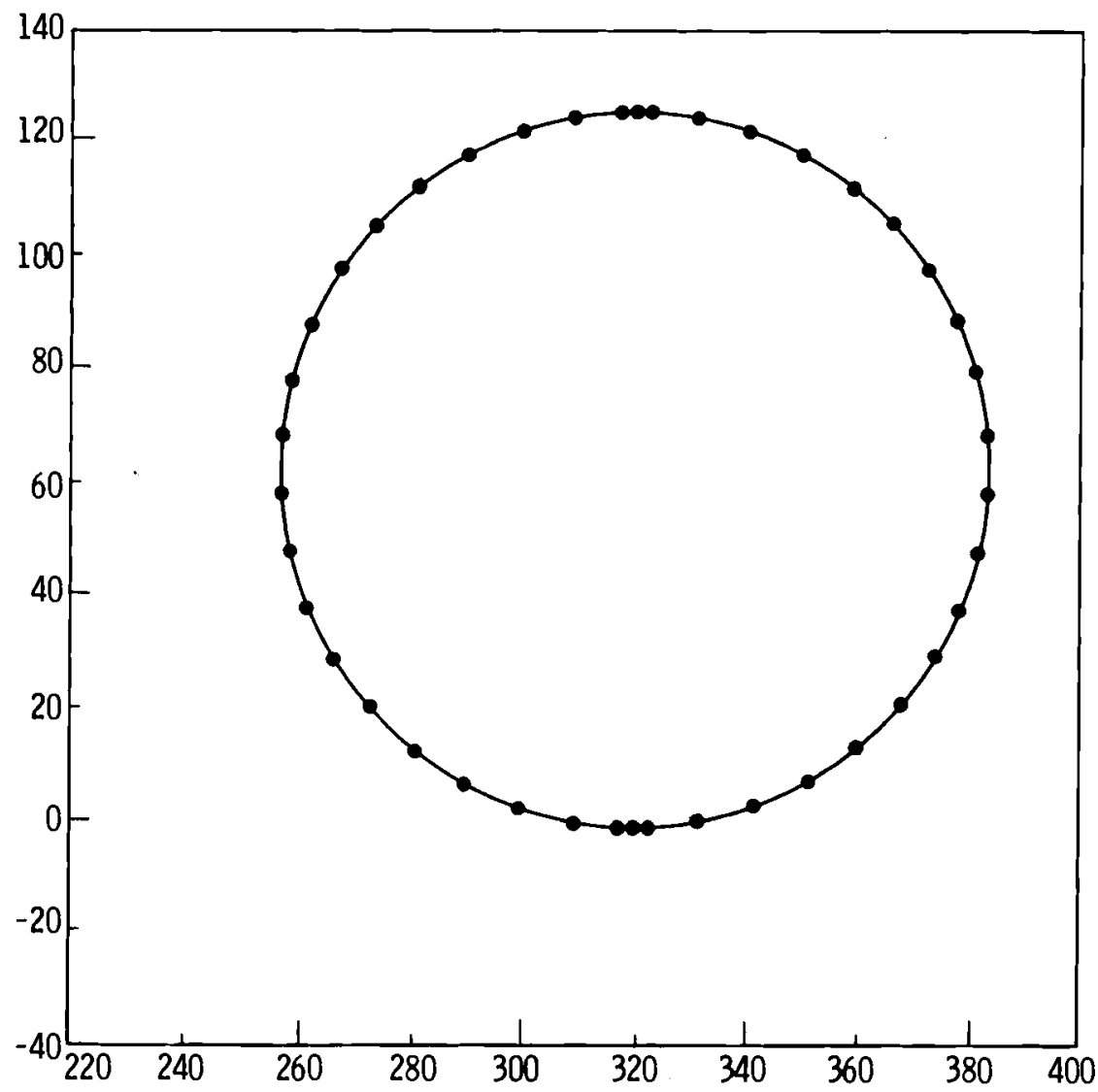

FIGURE 20. Meridional Section of Single-Wal1 Toroid, BOSOR4 Analysis

2) Circumferential Plane - Each point's motion is assumed to vary about the symmetry axis as a cosine function. The function is controlled by a parameter $N$, a simple integer.

Using several values of $N$, many buckling pressures were computed for each value and for a shell thickness of 0.525 in. Figure 21 gives the lowest pressures and the corresponding distorted shape of the poloidal cross section. $N=0$ implies a uniform circumferential deformation. The BOSOR4 solution indicated that a slight increase in the $0.525 \mathrm{in}$. thickness should be used to resist general collapse under two atm external pressure. 
TOROID BUCKLING STUDY BOSOR 4 ANALYSIS

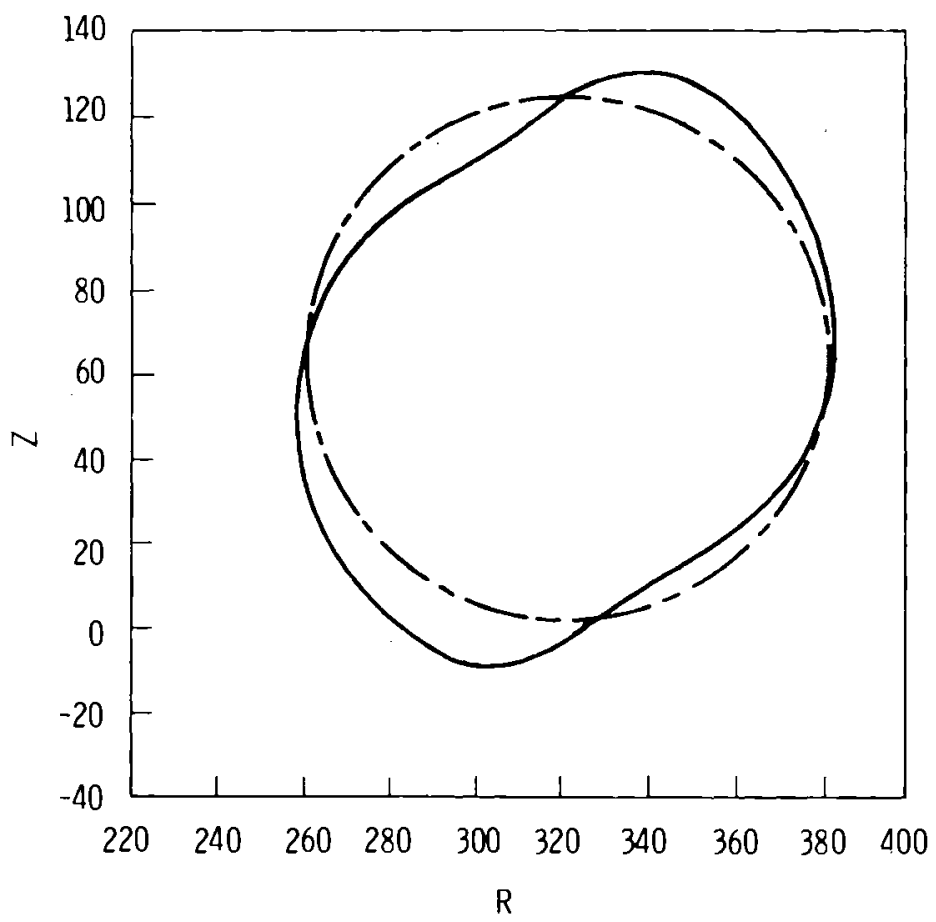

A. $N=0$

BUCKLING

PRESSURE $=27.5 \mathrm{pSi}$

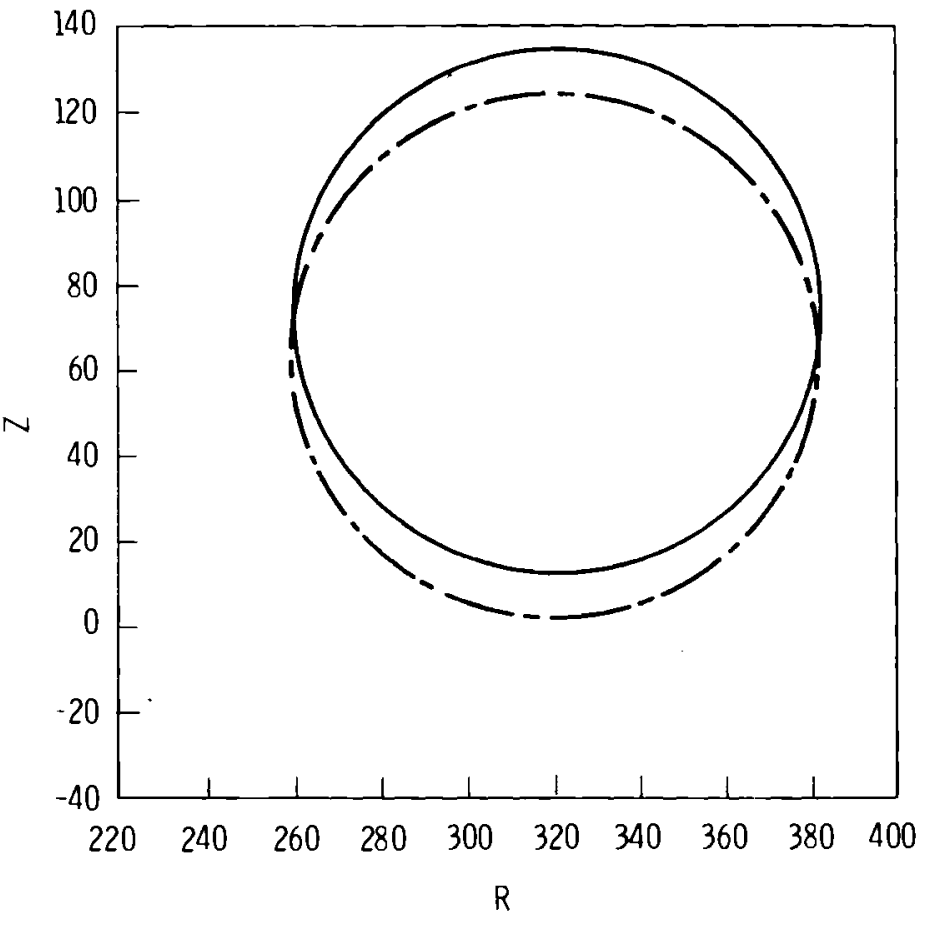

B. $N=1$

BUCKLING

PRESSURE $=29.9 \mathrm{pSi}$

FIGURE 21. Toroid Buckling Study BOSOR4 Analysis 


\section{Double Wall Thickness}

The first wall shell was formulated as a double wall for cooling purposes. The two walls will be separated and stiffened by a system of meridional stiffeners. This arrangement would permit coolant to flow down and around the plasma chamber and maintain a low temperature in the wall.

The double wall dimensions were derived on the basis that the two thin walls would provide a flexural rigidity equivalent to that of the single wa11. Spacing and thickness details are given on Figure 6.

It was assumed that the two-wall configuration satisfied the general stability criterion. The tctal thickness across the two walls is less than one-hundredth of the minor radius; thus, together they still conform to thin shell structural behavior. However, localized effects of the two-wall configuration were considered significant and will be discussed later.

It had been expected that localized stresses could be evaluated using a three-dimensional model that recognized sheil curvatures due to major and minor radii. The approach was to be based upon the ANSYS finite element program $^{(23)}$ and would represent a small sector of the shell encompassing two stiffeners and the two walls. An enlarged diagram of one of the walls is shown on Figure 23. Two such walis were to have been formulated and elastically connected with stiffener elements.

The boundary conditions for the shell sector were to have required that no motions could occur across the radially-oriented meridional planes at each sector end. Unfortunately, the precise manner of applying the program to reflect such boundary conditions was not established until after it was decided to pursue another approximate and simpler approach.

ANSYS was considered in place of BOSOR4 for such a detailed analysis because BOSOR4, developed upon the assumption of axisymmetric uniformity, cannot represent discrete stiffeners in the plane of the axis symmetry. The simplified approach used to establish localized effects is best understood by referring to Figure 22 . The assumption was made that the major radius $(R=320.866 \mathrm{in.})$ had become infinite. This reduced the toroidal 
shell to a cylinder of radius 62.99 in. The localized interactions between the two walls and the stiffeners could then be evaluated in detail with a finite element program using the assumptions of axisymmetry. The AXISOL program was used $\left({ }^{3}\right)$ which is distinguished from BOSOR4 in that it is not confined to shell elements. It uses triangular and quadrilateral finite elements that permit the analyst to use as much detail across a wall as deemed necessary to represent local stress gradients.

DOUBLE WALL CONCEPT

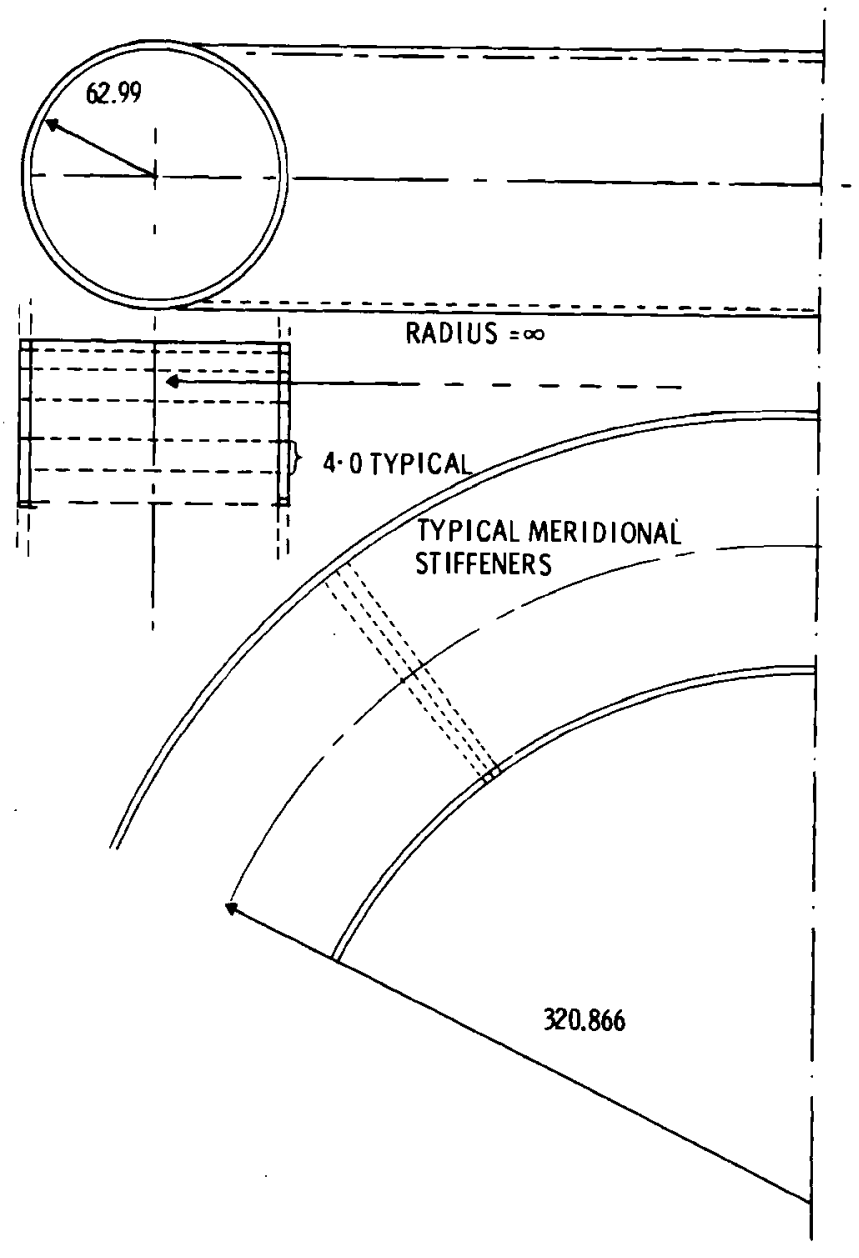

FIGURE 22. Double Wall Concept 


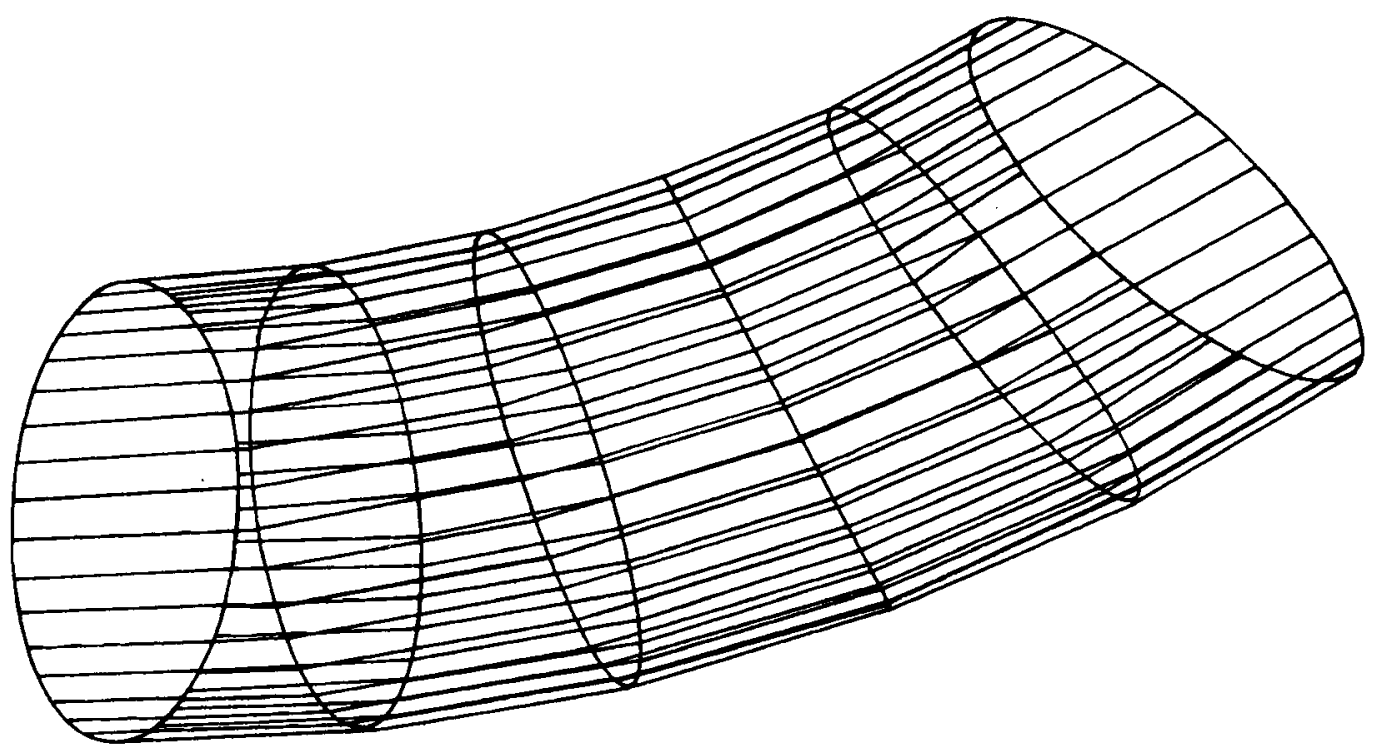

FIGURE 23. A Sector of the Toroidal First Wall ANSYS Geometry Model

\section{Wa11 Loading Conditions}

The following conditions were assumed to apply to the front wall for structural analysis purposes.

\section{Pressure:}

Inner surface - vacuum (0 psi)

Outer surface - ambient (14.7 psi)

Between walls - coolant pressure (30 psi)

\section{Temperature;}

Inner wa11 - $136^{\circ} \mathrm{C}$

Outer wal1 - $121^{\circ} \mathrm{C}$

These are average temperatures. The gradient through the stiffener was linear.

Neutron Flux:

Wa11 loading - $0.74 \mathrm{MW} / \mathrm{m}^{2}$

Flux

$-9.70 \times 10^{20} \mathrm{n} / \mathrm{cm}^{2} \mathrm{yr}$

DPA/yr

- 9.62 (reference 28) 


\section{Magnetic Flux:}

No attempt was made to assess the extent of magnetic field pressures. Operating Cycles:

The plasma was assumed to be in an operating mode for 1000 seconds and in a down mode for 100 seconds. This cycle was repeated continously.

Integrity Analyses:

The following analyses were aimed at identifying stress levels in the basic two-wall shells. Since no definitions of openings or supports currently exist, such complexities could not be analyzed.

\section{Shell Local Stability Analys is}

The general stability criterion discussed earlier was used to define the flexural characteristics of the main shell. This was later transformed into a two-wall assembly with meridional stiffeners to accommodate a coolant system between the walls. The coolant was assumed to be pressurized and this pressure, combined with the vacuum and thermal effects, was considered a potential cause of inner wall buckling.

To analyze the local stability of the shell inner wall between stiffeners, a BOSOR4 computer model was formulated (Figure 24). Because BOSOR4 cannot represent discrete meridional stiffeners, a cylindrical section was used that embraced two and one-half channels between stiffeners. Also, symmetry about the midpoint of one channel was assumed by applying rotational boundary constraints so that the model represented five channels. It was assumed that removing one plane of curvature (making the section cylindrical instead of toroidal) was conservative. The member eight was given a pressure loading equivalent to the overall compressive effect of the $1 \mathrm{~atm}$ pressure upon the toroidal shell. To transmit this load evenly to the two walls, member eight was made much stiffer than the other members. 
SHELL SECTION (INFINITE MAJOR RADIUS) BOSOR 4 LOCAL STABILITY ANALYSIS

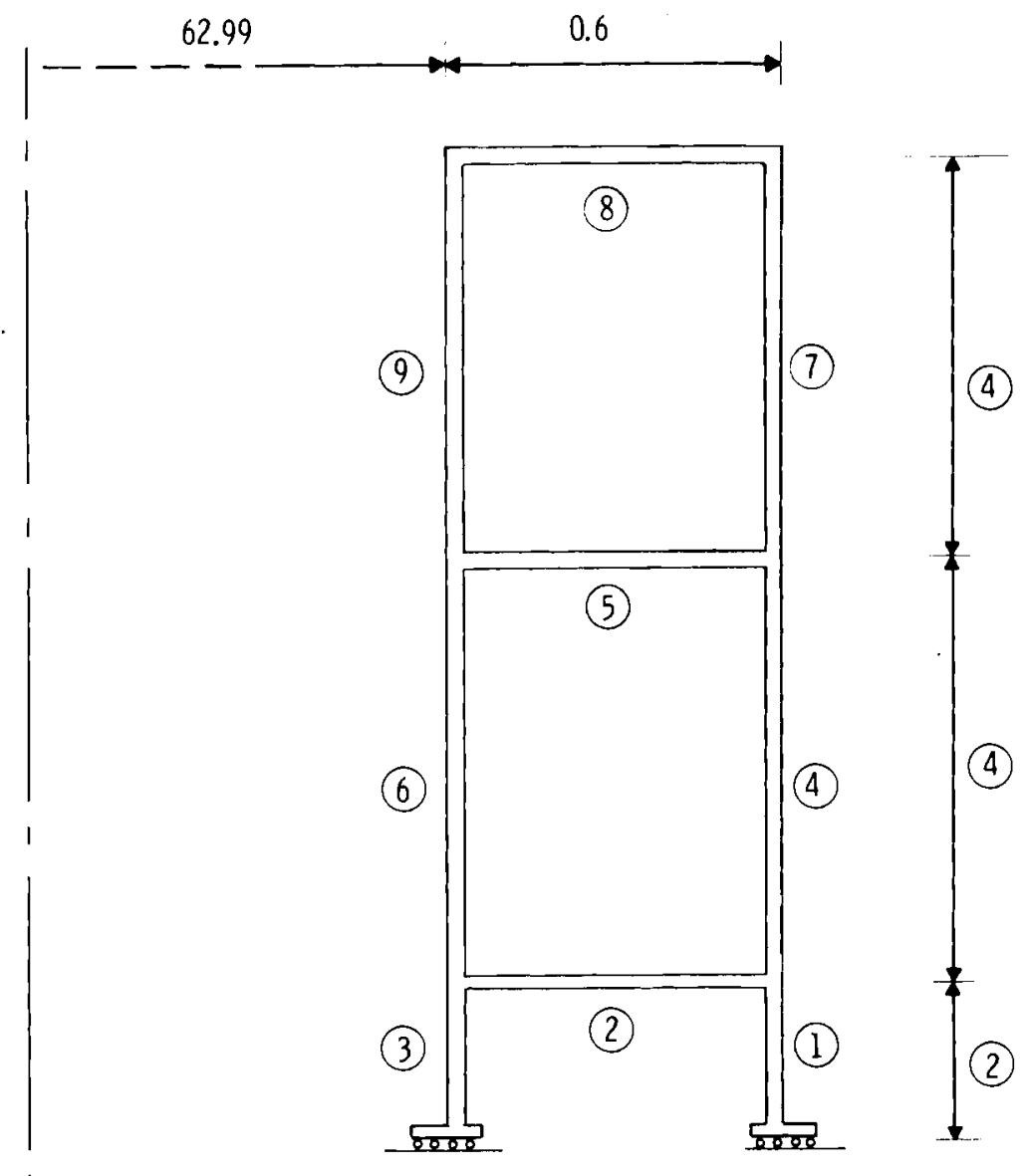

FIGURE 24. Shel1 Section (Infinite Major Radius) BOSOR4 Local Stability Analysis

Several circumferential modes of distortion (N) were analyzed and their corresponding values given in Figure 25. It can be seen that the lowest value is 4.45 , corresponding to $N=42$. This is the lowest factor by which the operational pressure must be multiplied to cause the system to become unstable. The shape of the structure in this mode of instability is shown in Figure 26. 


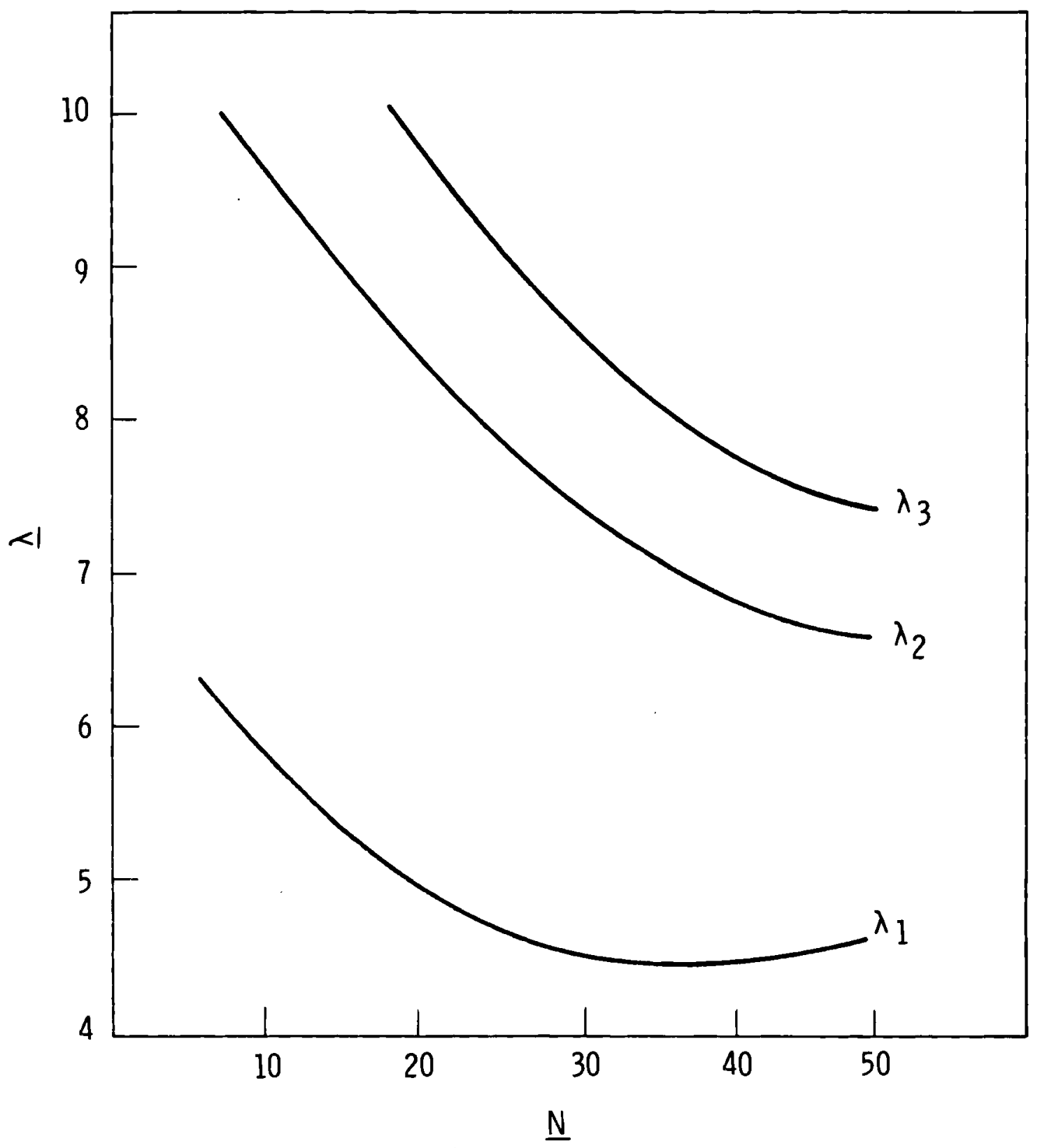

FIGURE 25. Variation of Buckling Eigenvalues $\lambda$ with Circumferential Wave Number $\mathrm{N}$ 


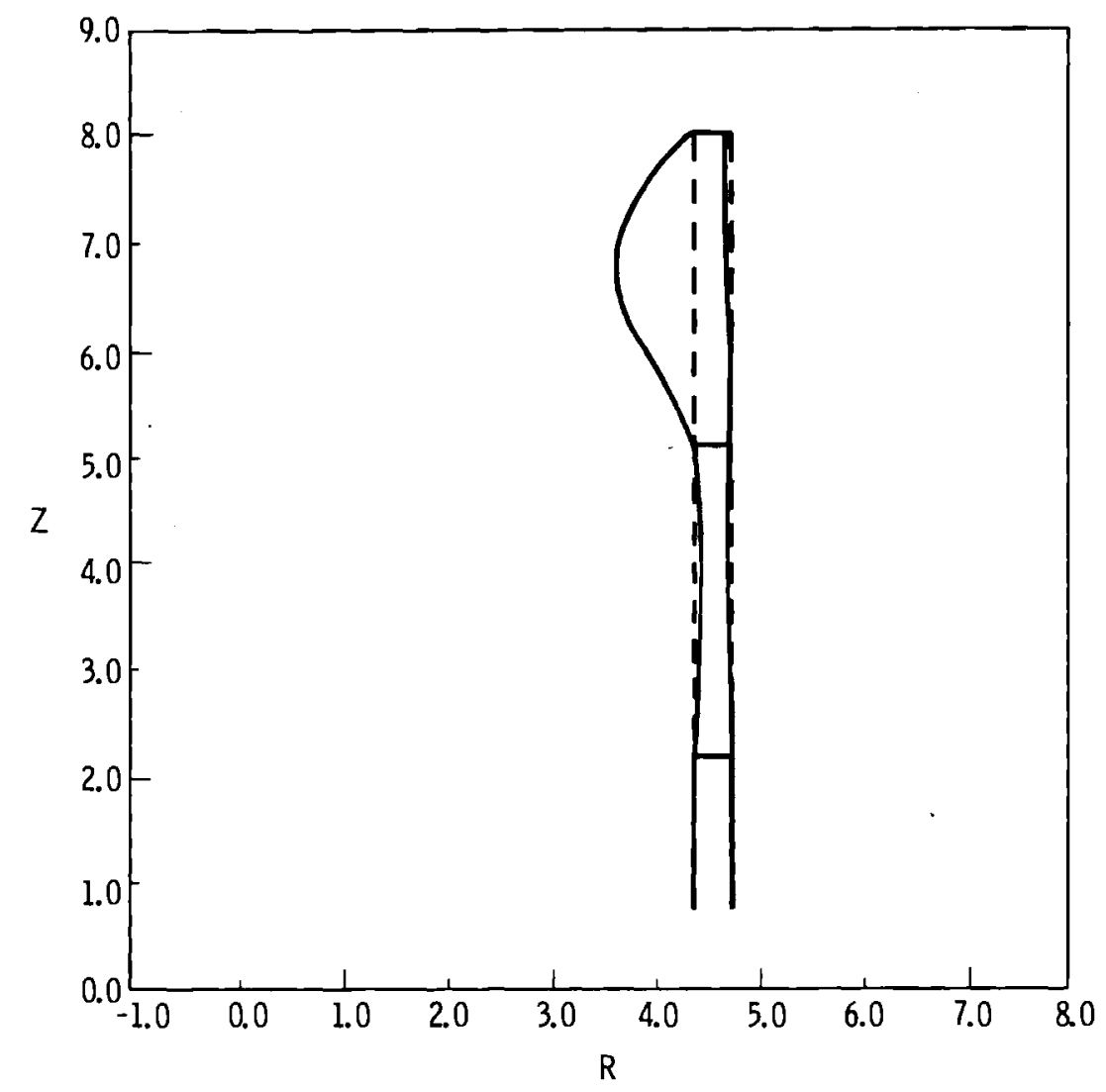

FIGURE 26. Local Buckling of Coolant Channel BOSOR4 Analys is

It was concluded from these conservative results that the two-wa11 she11 was adequately stable for the predicted conditions.

\section{Pressure and Thermal Stress Analyses}

To evaluate representative stresses on the first wall due to operating conditions, an infinite major radius assumption was used. This permitted an axisymmetric model of a half channel section to be formulated using the AXISOL finite element program. ${ }^{(37)}$ The model's inner surface was located at a radius from the axis of symmetry equal to the minor toroidal radius. Using an infinite major radius yields hoop stresses that are not as large as those for a toroid with a noninfinite radius. Therefore, the hoop stresses $\sigma_{H}$ produced by the cylindrical model were factored to make them comparable to hoop stresses for a toroid. This procedure is still approximate and does not guarantee the correct distribution. 
Figure 27 shows the finite element grid for the section analysis. Only half of a coolant channel was analyzed because of the symmetry of the loading. Rotations were constrained at each end of the structure but radial and axial motions were permitted. The stiffener elements comprised half the stiffener thickness because of symmetry. The surfaces of elements lying in the midplane of the actual stiffener geometry were constrained to stay within a radial plane while being free to displace axially.

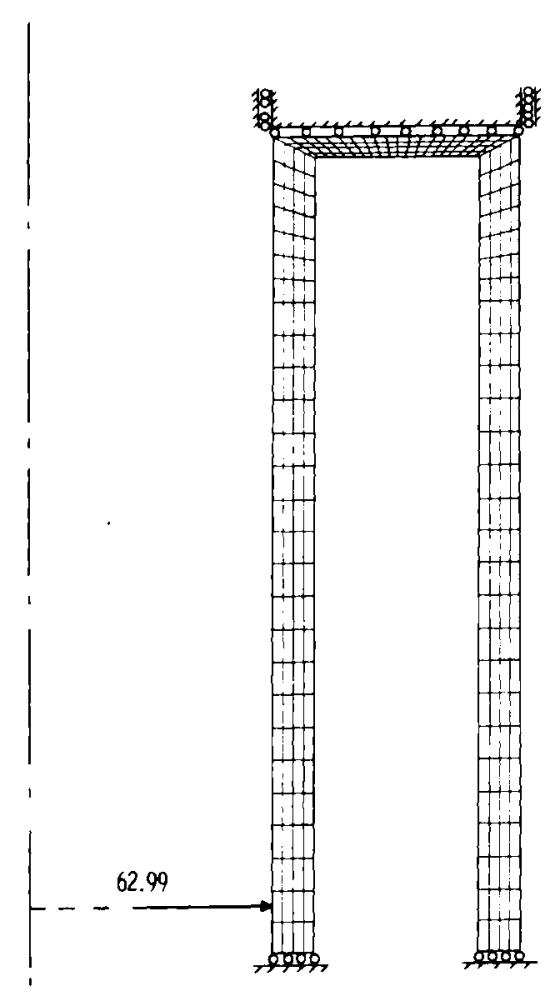

FIGURE 27. Two Wall Section AXISOL Analysis

Three cases were analyzed using the load conditions specified earlier:
a) Operating:
1. al1 pressures
2. full temperature gradient
b) Shutdown
3. coolant pressure oniy

In case 1 the stiffener was additionally loaded with a uniform pressure of $798 \mathrm{psi}$ to simulate the compressive effect of the 1 atm ambient pressure upon the toroid. 
The following results were obtained:

a) Operating stresses (case 1 and case 2 combined)

Figure 5 gives the resultant components.

b) Temperature stresses (case 2 onty)

Figure 28 gives the components.

c) Shutdown stresses (case 3 oniy)

Figure 29 gives the maximum shear contours.

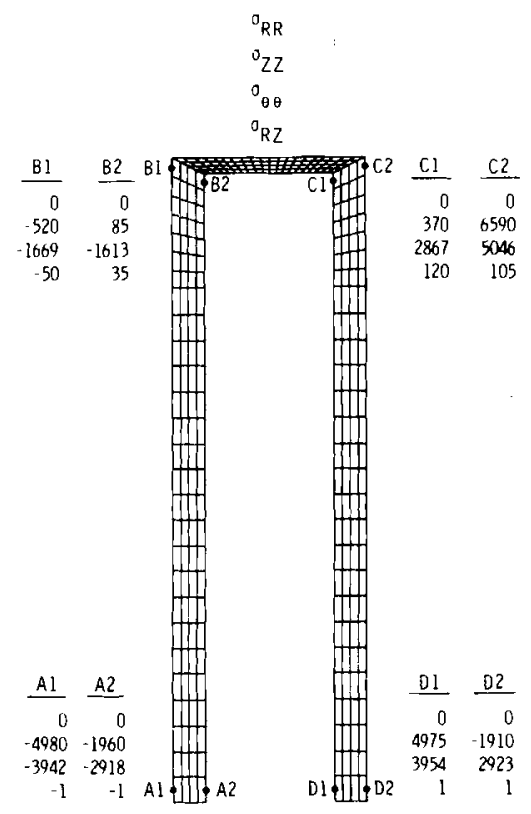

FIGURE 28. Maximum Stress Components Temperature Stresses

To account approximately for the toroidal configuration, the following maximum factor ${ }^{(38)}$ was used upon the hoop stresses:

$$
k=\frac{2 R-A}{R-A}=\frac{2 \times 320.866-62.99}{320.866-62.99}=1.12
$$

First Wall Failure Modes

To assess the first wall life under the predicted operating conditions, the following possible failure modes were examined. 


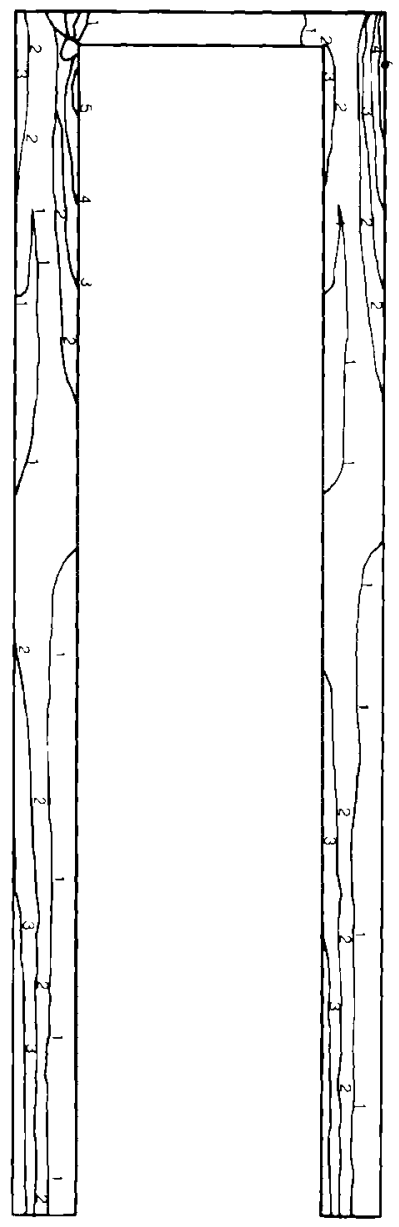

$1=1420 p \mathrm{si}$
$2=2492 \mathrm{ps}$
$3=3565 \mathrm{psi}$
$4=4638 \mathrm{psi}$
$5=5718 \mathrm{psi}$

FIGURE 29. Two Wall Section AXISOL Analysis

\section{Irradiation Swelling}

The Structural Materials Section (from reference 30) gives the empirical equation for irradiation-induced swelling of $20 \%$ cold-worked 316 SS. The temperature function $R(T)$ shown in Figure 13 portrays the lack of significant swelling below $350^{\circ} \mathrm{C}$. Extensive irradiation does not change this temperature. For these reasons, swelling is not included as a strain in the structural analysis. 


\section{Tensile Strength}

The structure experiences the maximum stress intensity at the outer surface of the outer wall at the junction with the stiffener:

$$
S_{\text {MAX }}=9956 \text { psi }
$$

From the ASME Boiler Pressure and Vessel Code, Section VIII, Division 2, the allowabie stress intensity for $316 \mathrm{SS}^{(39)}$ (Table AMA-1) for $100^{\circ} \mathrm{F}-200^{\circ} \mathrm{F}$ is given as:

$$
\mathrm{SM}=20 \mathrm{ksi}
$$

For secondary loading, a factor of 3 is permissible for the allowable.

Figure 15 shows the degradation of both $20 \%$ cold-worked and annealed 316 SS from temperature and irradiation. The effective irradiation of the plotted data equals several decades of the TCT Hybrid flux. The degradation of the $20 \%$ cold-worked 316 SS is small (<5\%) even at the test temperatures.

Thus, tensile strength does not limit the structure life.

\section{Plastic Cycling (Ratcheting)}

If stresses exceed the yield during the operational cycles, incremental plastic growth could occur with each cycle. However, stresses are below the yield at all times in this structure, and plastic cycling will not occur.

\section{Creep}

The Structural Materials section gives the empirical relations expressing the creep rupture characteristics of 316 SS. They indicate that creep cannot be a problem below $500^{\circ} \mathrm{C}$. Thus, creep rupture does not limit the structure life.

\section{Crack Growth}

It was assumed that a crack of semicircular shape existed in the 0.1 in. thick she11. The crack radius initially was 0.01 in. A simple stress intensity factor from reference 21, page 2.1, for $(F(a / b)=1.0)$ was used:

$$
\begin{aligned}
\text { S.I.F. } & =\sigma \sqrt{\pi \mathrm{C}} \\
\sigma & =\text { maximum stress } \\
& =20,000 \text { psi (with a factor }=2.0) \\
c & =\text { semicrack length } \\
& =0.01 \text { inches }
\end{aligned}
$$


Extrapolating from the data in Figure 17 for $20 \%$ cold-worked 316 SS, which is at a much higher temperature than the operating temperature, it would take several decades for this crack length (and depth) to increase by $10 \%$. Thus, crack growth does not threaten the integrity of the structure, nor is it likely to induce leaks.

\section{Fatigue}

The maximum stress intensity due to thermal cycling is:

$$
S_{\text {MAX }}=6590 \text { psi }
$$

With a concentration factor of 5 this amounts to a cyclic strain of less than $0.1 \%$. From the data in Figure $19^{(35)}$ it can be seen that even with heavy radiation, the structure has infinite life.

\section{Fabrication Considerations}

The first wall, a stiffened double wall structure, contains cooling fluid in its void and sustains the vacuum loading for the reactor as a toroidal membrane. It sustains a sizeable internal wall heat load that is removed by the cooling fluid, and exists in a severe radiation environment that may modify its structural properties.

Due to the well-developed fabrication technoiogy associated with 316 SS, it has been selected as the first wall material. Other analyses have verified $i$ ts adequacy with respect to thermal loadings and stability and have shown that swelling in the first wall's operating range is not a significant problem for the anticipated life cycle. Embrittlement considerations will require careful attention and the highest standards of quality control to prevent flaws and fracture prone features. The critical impact of first wall integrity requires that, if possible, an existing technology be utilized in determining its feasibility.

The toroidal first wall is a complex structure with circular ribs paraliel to the major radius. These connect two thin sheet membrane walls 
of varying curvature in two directions (see Figure 6). The overall size of the structure dictates that it be segmented for fabrication, maintenance and access.

Cooling water flow will enter the first wall channels at the bottom and exit near the top. The location of the first wall coolant headers dictates the location of the major circumferential parting line, as the inlet manifolding can be included with the additional material for the flanging, aiding in its cooling. Radial segments will be $30^{\circ}$ arcs, resulting in 24 segments, with 12 for the outside curvature and 12 for the inside curvature. The $30^{\circ}$ segments were selected so that the segment flanges would coincide with the first wall supports, which consist of major radial double plates attached to the structural shield wall. These plates also support the fission blanket tubes and manifolding and the flibe blanket structure. The $30^{\circ}$ arc segment results in two curved panels approximately $10 \mathrm{ft} \times 14 \mathrm{ft}$, making them a manageable size and simplifying the fabrication jigging, which should be quite precise.

A design approach to the feasibility of first wall structure fabrication has been formulated that would permit inspection of the internal rib welds, especially at the inside wall stiffener interface, where maximum stress would act on the fillet. First the inner wa11, a 1/10 in sheet (Figure 30) will be stretch-formed over the appropriately curved segment mold. Forming four or more subsegments to proper curvature might be economical. These could be butt-welded, planished and inspected carefully, with final finish forming done on the assembled sheet. Thus, a smooth internal surface could be formed for later antisputtering coatings.

The rib and outer wall sections would form a unit based on a single rib and a single wal1 span (see Figure 31 ). This would result in an angle section which could easily be press-braked from flat stock. While in the flat configuration, the long radius arc, necessary to account for the narrowing of the rib channels toward the center of the torus, could be precut. These long light ribs, approximately 4 in. $x 1 / 2$ in. $\times 61 / 2 \mathrm{ft}$ could then be stretch-formed to the minor toroidal radius in a flexible form that would preserve the rib shape. 


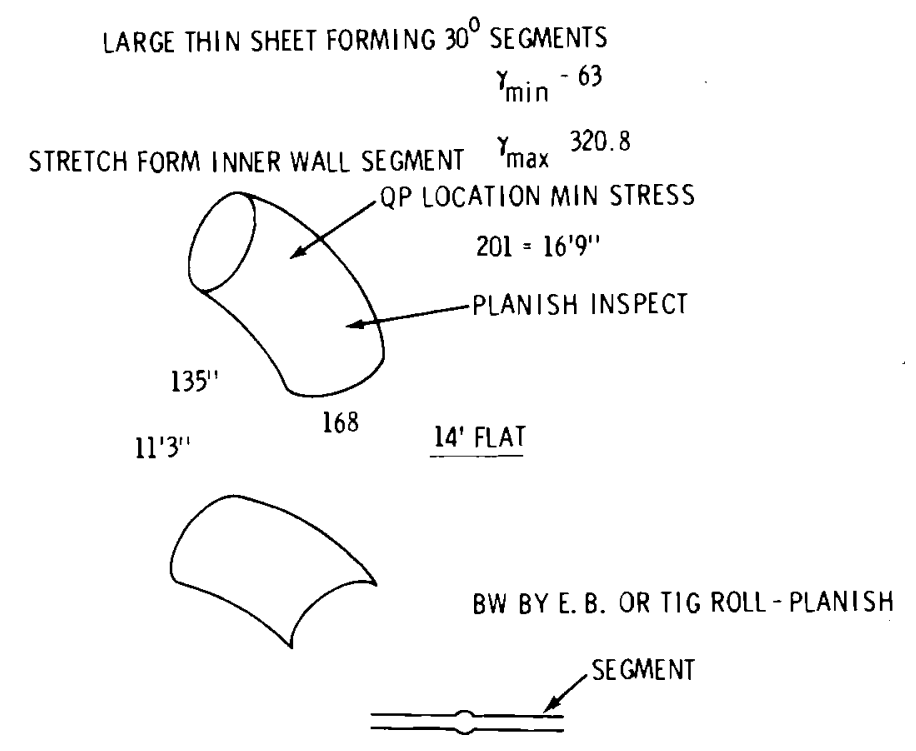

FIGURE 30. Large Thin Sheets Forming $30^{\circ}$ Segments

The inner wall could then be trimmed and flanged and the ribs welded to the inner wall one at a time. After the first wall has been placed, it can be examined from both sides visually without great difficulty and is open enough for radiographic inspection on an intermittent basis. Then, the outer wall long-angle leg can be welded to the rib bend from the outside, enclosing the cooling channel.

This process seems prohibitively expensive for such a light fabrication, but it is felt that integrity assurance at the fillets is justified for such a critical component. The resistance of this structure to fatigue and fracture will be almost directly determined by the quality of the rib wall intersection welds. These considerations in the severely embrittling radiation environment have a definite effect on the fusion reactor's operational life. First wall replacement could require too many shutdowns and compromise the economics of the reactor. 

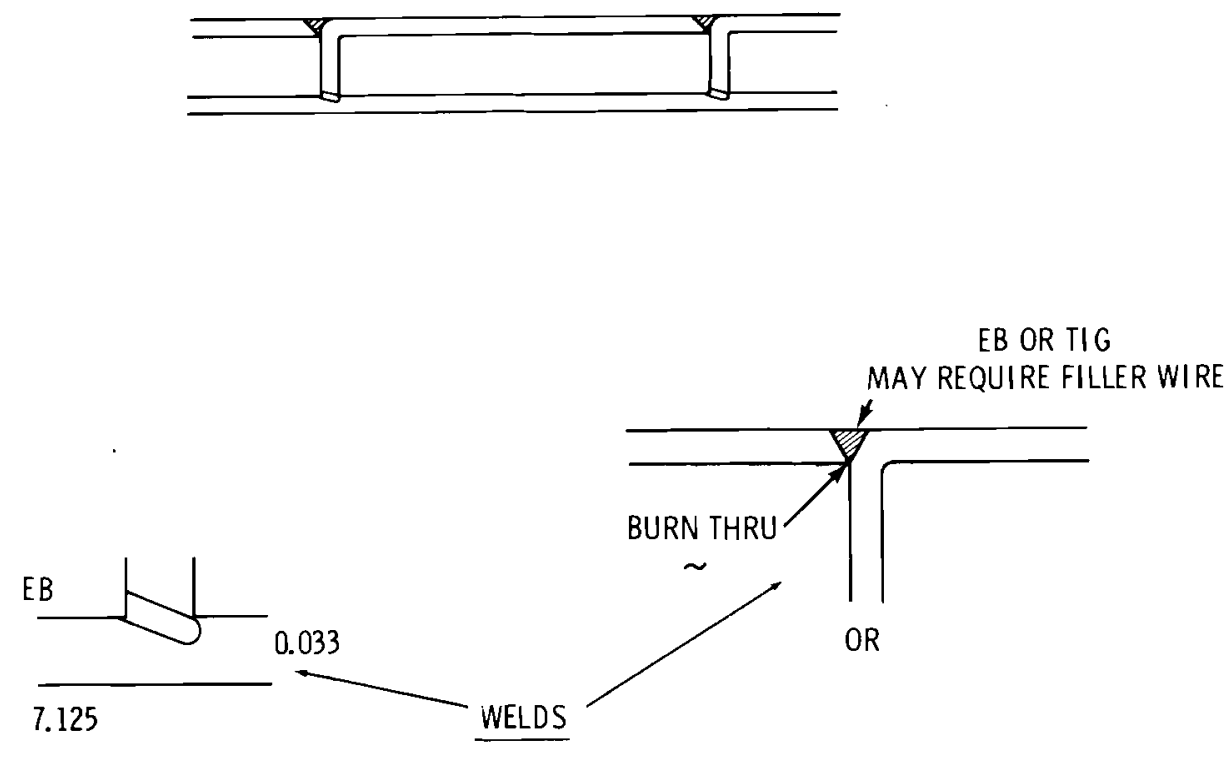

FIGURE 31. Welds

Small penetrations in the first wall structure can be fabricated once the general structure of a segment has been completed (Figure 32). Reinforcing doubler plates can be added outside the penetration to distribute the membrane discontinuity to a sufficient number of ribs. The intercepted coolant channels can be bypassed by a circumferential channel around the penetration integral with the top doubler plate.

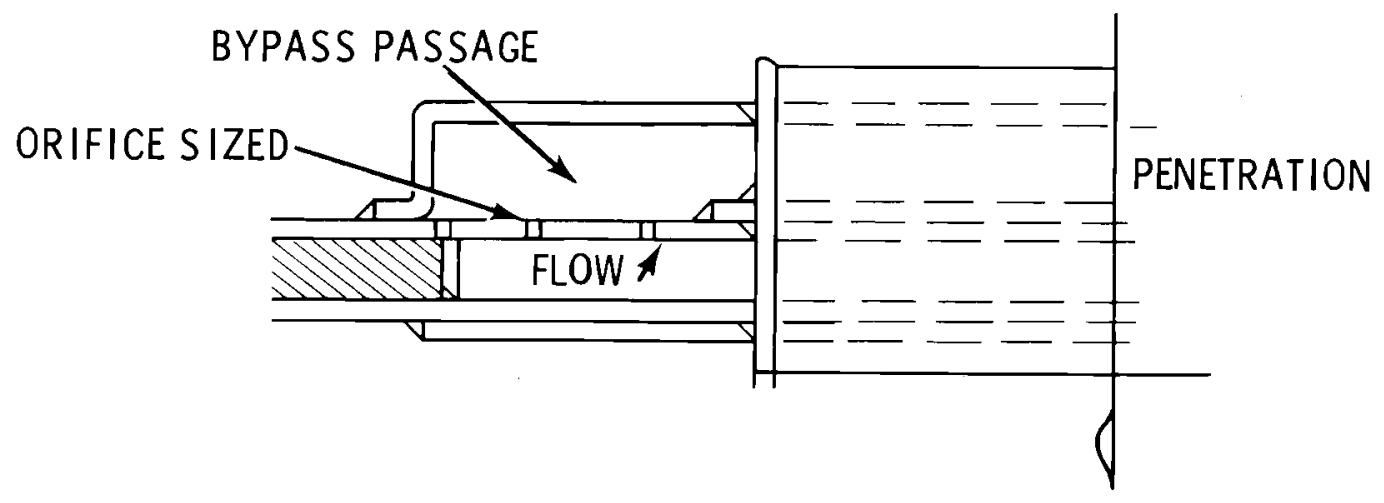

FIGURE 32. Penetration 
Neutral beam ports can be made to coincide with flanging and the intercepted channels manifolded around the opening. Diverter channels may require extensive redesign of the internal segments, but detail design will have to await more specifics. The diverter area may also present some special fabrication problems.

\section{Welding Processes}

The stiffened double wall structure has special welding requirements resulting from its severe operating environment.

Fatigue. A highly stressed first wall region is near the wall stiffener junction. Possibly, due to jigging errors or imprecise control of the welding process, many crack-like details could be created. This may adversely affect the fatigue life of the structure, especially in an embrittling radiation environment.

Inspectability. Welds by the spot or roll process result in fused beads or seams of parent material between two contacting surfaces. In this application, the rib welds would be extremely difficult to examine visually and the geometry of the rib wall intersection would create problems for nonvisual techniques. Quality control will be difficult.

Weld Placement. At least one side of the rib welds would have to be welded blind along a long circular arc, through a sheet with curvature in two directions. Precise directional control for this weld would be difficult. This would increase reliability problems and possibly compromise quality control.

Spot and roll welding appear to be ideal methods of fabricating such a structure, in that no filler is required and the "internal" location of the rib welds could be accommodated. However, this method does have some inherent shortcomings (Figure 33 ).

of the precise methods available for welding structural material in thin sections, electron beam welding shows certain advantages. In this application, the nonvacuum or partial vacuum process would be necessary due to the large size of the components. The two major advantages for this process are: 
1. ability to make deep, narrow welds with minimum heat input, thus minimizing heat-affected region in the joints. (Embrittling carbide precipitation near the joint would thus be minimized.)

2. superior control over penetration, weld dimensions and properties

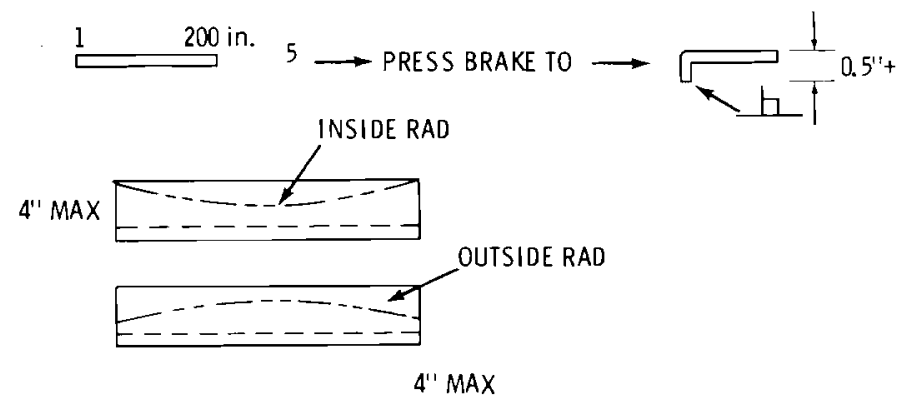

STRETCH FORM TO MINOR R OVER BLOCKS

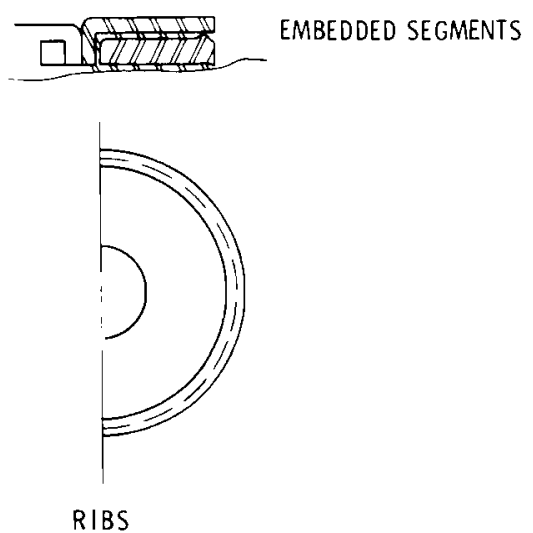

FIGURE 33. Stretch Form to Minor R Over Blocks

Disadvantages exist in the requirements for precise fit-up at assemblies. This disadvantage is minimized in this application, as great precision in fit-up will be required to minimize structural imperfections that could adversely affect the compression membrane stability under the operational vacuum loading. This is a minimum material design that requires precision manufacture. 


\section{CONVERTER REGION}

Most fusion-fission hybrid concepts currently being studied involve modular blanket designs. In a modular design it is very difficult to separate the fuel cycles for the fertile material in the converter and the tritium breeding material in the blanket region. By using pressure tubes filled with the fertile material in U-Mo slugs in the converter and molten salt in the blanket region, the two cycles are conceptually separated.

The large manifolds required to suspend modular blanket designs will require considerable development. The design bases and fabrication technology for large, irregularly shaped, high temperature, high pressure ducts are currently not available, although the pressure tube concept tends to break the design and fabrication problems down into components that do have bases. Since the purpose of current hybrid conceptual design studies is to determine their technical and economic feasibility, it was felt that pressure tube potential should be evaluated. Blanket modules could be adapted to the TCT if the pressure tube-molten salt blanket concept appears relatively unattractive.

The orientation of the pressure tubes around the plasma is very important in achieving the design objectives for the converter region. A vertical orientation would allow for easier flow of fertile material and simpler structural design but would fit best on a vertically elongated plasma. Horizontal orientation fits best around a single null diverter plasma but sacrifices flexibility in removing the slugs of fertile material. The manifolding would have to be removed and fuel handling equipment designed to push the slugs out. This would limit removal of converter slugs to a cycle which had significant down time. Vertical orientation could conceptually allow gravity flow of spherical fertile material for a nearly continuous refueling concept.

Since plasma engineering considerations tend toward selection of a single null diverter for the TCT Hybrid, this preliminary engineering evaluation of the converter region considers only a horizontal orientation of the pressure tubes filled with U-Mo slugs. 


\section{Converter Region Layout}

In this preliminary evaluation, the U-Mo alloy blanket elements are contained in tubes running parallel to the plasma ring along the major circumference of the toroid. These fuel elements are cooled by high velocity helium at 50 atm pressure. Thermal hydraulic considerations with respect to inlet-outlet temperature rises and fuel operating temperature dictate that the maximum tube length be approximately the length of one-sixth of the major circumferential arc.

Using present size ranges selected for fuel assemblies, wall coverage wi11 require approximately 160 tubes around the toroidal minor circumference.

This is based on fuel assembly diameters at the minor circumference which would cover the maximum usable surface area of the uniform toroid. The present concept, using six separate tube manifolds around the major circumference, six neutral beam ports and a single null type diverter, would have a maximum usable surface area for the blanket as follows:

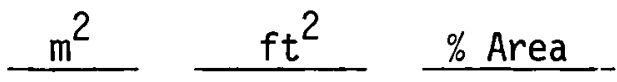

Total toroidal surface area $01.7 \mathrm{~m}$ minor radius

Area Lost:

- cooling tube manifolding and thermal growth
allowance
$-43.8$
$-471-8.7 \%$

- six neutral beam ports approximately $1.2 \mathrm{~m}^{2}$

$-8.6-93-1.6 \%$

- two $20^{\circ}$ arc diverter channels

$-60.7-654-11.1 \%$

- minor penetration and see through loss

$-10.9-118-2 \%$

- total loss

$-124$

$-1336-22.7 \%$

Net wall area

$\underline{423}$

$\underline{4549 \quad 77.3 \%}$ 
The converter region tube and manifolding layouts have been designed without considering major penetrations, such as the diverter and neutral beam ports. The number and specific configuration of these openings has not been finalized. These openings may have significant impact on coolant manifolding, but these problems may be overcome without compromising the general layout.

Converter tubes are arranged in two layers of 80 tubes each about the minor circumference. A $60^{\circ}$ segment compromises a total independent module, supported on three major radial plates fastened to the main shield segment. Three identical modules and three opposite hand modules comprise the total tube converter blanket (see Figure 34 ). This layout concentrates helium inlet and outlet points resulting in three inlet regions and three outlet regions alternating at $60^{\circ}$ intervals about the major circumference at the very outside of the torus major radius.

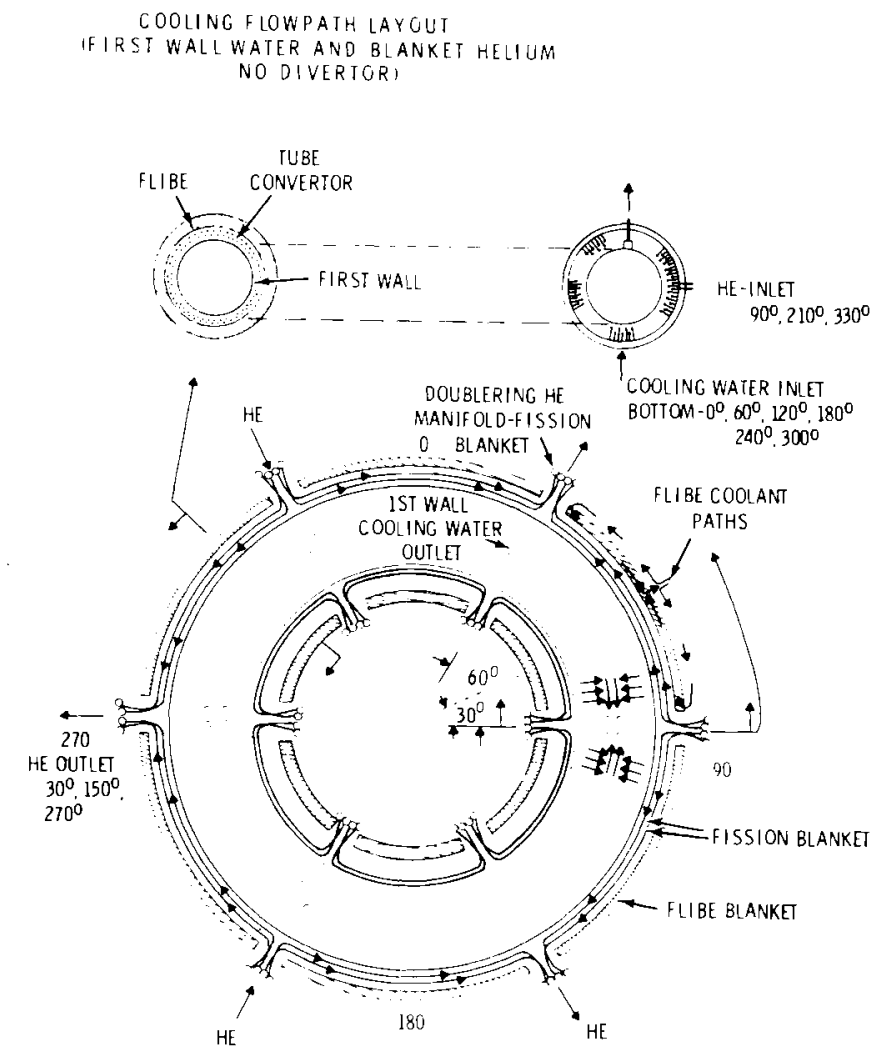

FIGURE 34. Cooling Flowpath Layout (First Wall Water and Blanket Helium, No Diverter) 
Each tube receives coolant from the inlet manifold, at $0^{\circ}$ on the segment (Figure 9). The inlet manifold is a double tube ring that stands outside the flibe blanket. This minimizes wall surface losses in both the tube converter and the flibe blanket by moving most of the manifold heavy fabrication outwards. Also, each tube becomes a separate piping loop with sufficient leg length to minimize thermal expansion constraint. The manifolds are double so that each tube layer has a separate manifold ring. The density of the tubes in this region precludes attaching a 11 tubes to a single manifold without complicating the tube loops with extra smal1 radius elbows. Extra turns on the loops would also result in increased losses of wa 11 area and unbalanced pressure losses in each tube layer. Manifold inlets near the outer torus point balance cooling to the longer tube runs, which are also the most heavily loaded by the radial power distribution.

The tube loop is supported near the inlet (Figure 10) elbow for dead weight loading and is fixed in the direction of its axis along the toroid major circumference. The tube loop has a gradual temperature rise along its gradient and operates around $1000^{\circ} \mathrm{F}$ average. Its thermal growth paralle1 to the axis is around 4 in. maximum and this growth is absorbed by the movement of the outlet manifold, with the inlet manifold's position essentialiy fixed by the inlet elbow supports.

The tube loop long arc is supported midspan where it penetrates the $30^{\circ}$ radial support plate that provides support for the first wall elements. A simple sliding guide provides dead weight support while allowing thermal movement in the tube axial direction.

At this point in the tube run, a bayonet joint in the tube allows disassembiy of the module into two $30^{\circ}$ sections. The bayonet joint assembly takes up a minimum amount of space external to the tube wall so the tube layer arrangement is not disturbed. It has self-energizing gaskets to minimize sealing problems. This joint in the tube run provides access to the fuel assemblies once the segment has been disassembled and allows access to al1 fuel at one plane in the segment. Simple pullers can be used to extract the fuel as the fuel does not have to pass through any discontinuities. 
Near the outlet elbow a sliding support provides dead weight support and absorbs the tube axial thermal growth. The outlet manifold is similar to the inlet double ring manifold, except that its deadweight support attachments to the radial support plate will be detailed to move in the toroid axis direction with the outlet elbows.

Material

The converter tubes will operate in the $800^{\circ}$ to $1200^{\circ} \mathrm{F}$ temperature range. Helium at approximately 750 psi will move through the tubes to cool the contained fuel elements. Total radiation fluence over a tube assembly life time could approach 15 fluence units (unit $=10^{22} \mathrm{n} / \mathrm{cm}^{2}$ ). The primary pressure stress intensity is around $10 \mathrm{ksi}$, using present design dimensions for tube diameter and wall thickness. 316, 321 and 347 series SS meet these requirements and have adequate strength at the operating temperatures to meet the present dimensional requirements. Their operating life would be determined by the total cumulative fluence in their operating environment, as the presently anticipated operating temperature covers the bank in which these typical steels are sensitive to neutron swelling. Adequate life is indicated for the tubes using present concept fluences and existing swelling information.

Careful materials research and testing in this area are required to insure proper tube life. The present concept is based on 316 stainless tubing, but extended life could be obtained for the tube assembly by switching to a swelling preventative alloy such as Nimonic-Pe-16, whose other structural properties are similar to those of 316. Specific precipitates in the matrix of this alloy provide sites for rematching of frenkel pairs of interstitial atoms and vacant interstices, thus greatly minimizing swelling sensitivity.

Converter Thermal-Hydraulic Analysis

The converter or neutron multiplier region studied consists of a bank of tubes containing long hollow slugs of U-Mo alloy cooled by helium gas at $50 \mathrm{~atm}$. The tubes run parallel to the major circumference for a significant fraction of the total distance around the torus. Having chosen two rows of 
tubes in a semi close-packed array, the diameter of the outer pressure tube and the cross-sectional area of the U-Mo slugs in each tube have been fixed by the neutronically desired volume fractions (Figure 7 ).

This analysis has two purposes: 1) to determine the optimum dimensions of the U-Mo slug consistent with the tube diameter cross-sectional area requirements and 2) to determine what fraction of the circumference can be adequately cooled by a single run pipe within the bounds of maximum structural material and U-Mo operating temperatures. The final result must also be compatible with the overall goal of maximum power production.

The analysis was performed in two steps. First, the best U-Mo dimensions were chosen to give the lowest possible U-Mo temperature and equal helium exit temperature from the inner and outer coolant channels. With these dimensions the sensitivity of the exit temperature and pumping power to the length of pipe run was determined for several combinations of operating pressure. The full operating cycle of $100 \mathrm{sec}$ off/ $1000 \mathrm{sec}$ on was considered in both of these steps so that thermal cycle effects could be studied.

The COBRA-IV $(40)$ thermal hydraulics code was selected as the computational tool to perform the calculations. The code was developed at PNL for thermal hydraulic analysis of rod bundle water reactor elements. It solves the transient two-dimensional equations for conservation of mass, momentum and energy for the coolant, coupled with a solution of the two-dimensional heat conduction model for the fuel rods. Some modification was necessary to consider the hollow U-Mo slug geometry and to include the helium state properties in the input.

Selection of U-Mo Slug Radial Dimensions

The best radial dimensions for the U-Mo slug were selected by examining the thermal hydraulic performance of the two coolant channels as the inner diameter was varied. The variation of the flow areas and outer diameter with the inner diameter is shown in Figure 35. The specific cases considered are indicated by a number along the bottom of the figure. Cases 1 and 2 were too extreme to be usable. 
In setting up the input for the COBRA code for the 6 usable cases, no hydraulic connection was made between the two channels. If the U-Mo slugs are not bonded together at the ends, some flow will occur between the channels. However, to model this connection, a flow area and a hydraulic resistance must be assigned. This is impossible to do without a more detailed design. Nevertheless, ignoring any interchannel communication is conservative and valid for a sensitivity study.

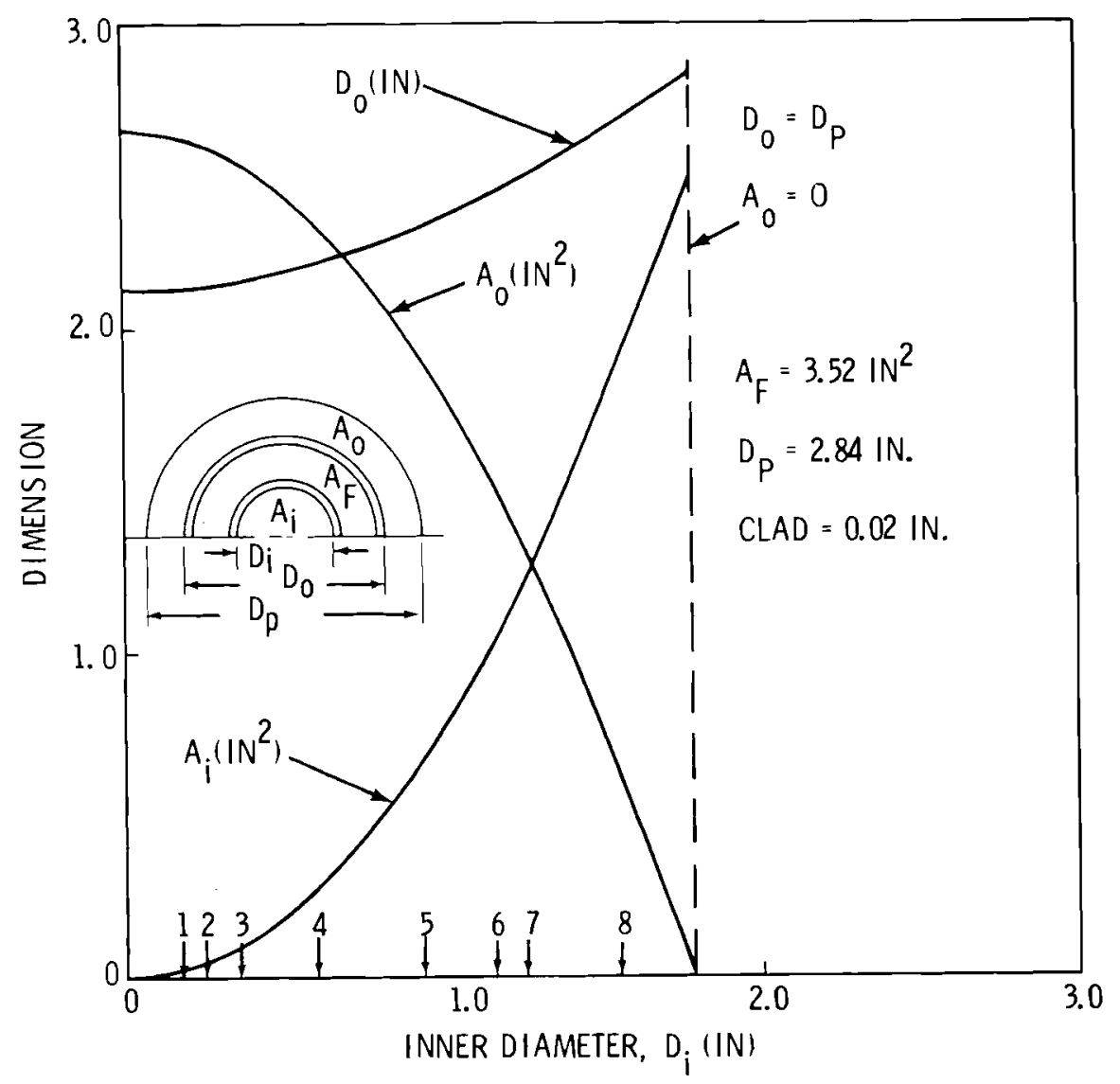

FIGURE 35. Flow Area Variation With Inner Diameter

The operating conditions used are listed as the base case in Table 2 below. All inlet conditions and the pressure head were uniformly applied to both helium channels. An axially uniform power density of $22.5 \mathrm{MW} / \mathrm{m}^{3}$ 
was applied to the U-Mo. This is $50 \%$ higher than the average to account for peaking around the minor circumference. The base inlet temperature was selected to keep the maximum SS temperature just below $1100^{\circ} \mathrm{F}$, which is about $1 / 2$ its melting point and significantly below typical high temperature gas-cooled reactor (HTGR) temperatures. (41)

The exit temperatures of the two helium channels, the maximum U-Mo temperature at the exit end, the average exit temperature, and the pumping power as a fraction of the thermal power are all plotted against the inner diameter in Figure 36. The maximum average exit temperature, minimum pumping power and point of equal exit temperatures all occur at approximately $D_{1}=0.92 \mathrm{in.}$, but the minimum U-Mo temperature appears near $1.15 \mathrm{in}$. from the competing effect of a thinner cross section. Since the pumping power is slightly higher at the latter diameter, it would be tempting to choose 0.92 in. as the optimum value. Consider first, however, the hypothetical case where either one of the channels becomes blocked.

TABLE 2. Range of Operating Conditions Considered in Sensitivity Analysis

\begin{tabular}{|c|c|c|c|c|}
\hline Quantity & Base & High & Low & $\operatorname{HTGR}^{(a)}$ \\
\hline Pressure & 750 & 1000 & 500 & 700 \\
\hline Inlet Temperature $\left({ }^{\circ} \mathrm{F}\right)$ & 579 & - & 419 & 760 \\
\hline Pressure Head $(p s i)^{(b)}$ & $3-24$ & $4-32$ & - & 8.4 \\
\hline Tube Length $(f t)$ & 16 & 32 & - & 23 \\
\hline $\begin{array}{l}\text { Surface Heat Flux } \\
\left(\text { BTU/hr-ft }{ }^{2}\right)\end{array}$ & 61,500 & - & - & 45,000 \\
\hline
\end{tabular}

(a) Ft. St. Vrain FSAR $(41)$

(b) High pressures are for $32 \mathrm{ft}$ length

In this case, one or the other of the channels must carry the entire heat load without structural damage. When the tentatively selected "optimum" dimensions are subjected to these conditions, the cladding in the outer 
channel may exceed the melting point if this channel is blocked as shown in Figure 37. If the inner channel is blocked, though, the outer channel is quite able to carry the load without exceedingly high temperatures anywhere. By increasing the inner diameter to $1.254 \mathrm{in.,}$ the situation is reversed. Figure 38 shows that blocking the inner channel now produces the higher temperature, though it is not nearly as high as with the former dimensions.

\section{TEMPERATURE AND PUMPING POWER VARIATION WITH INNER DIAMETER}

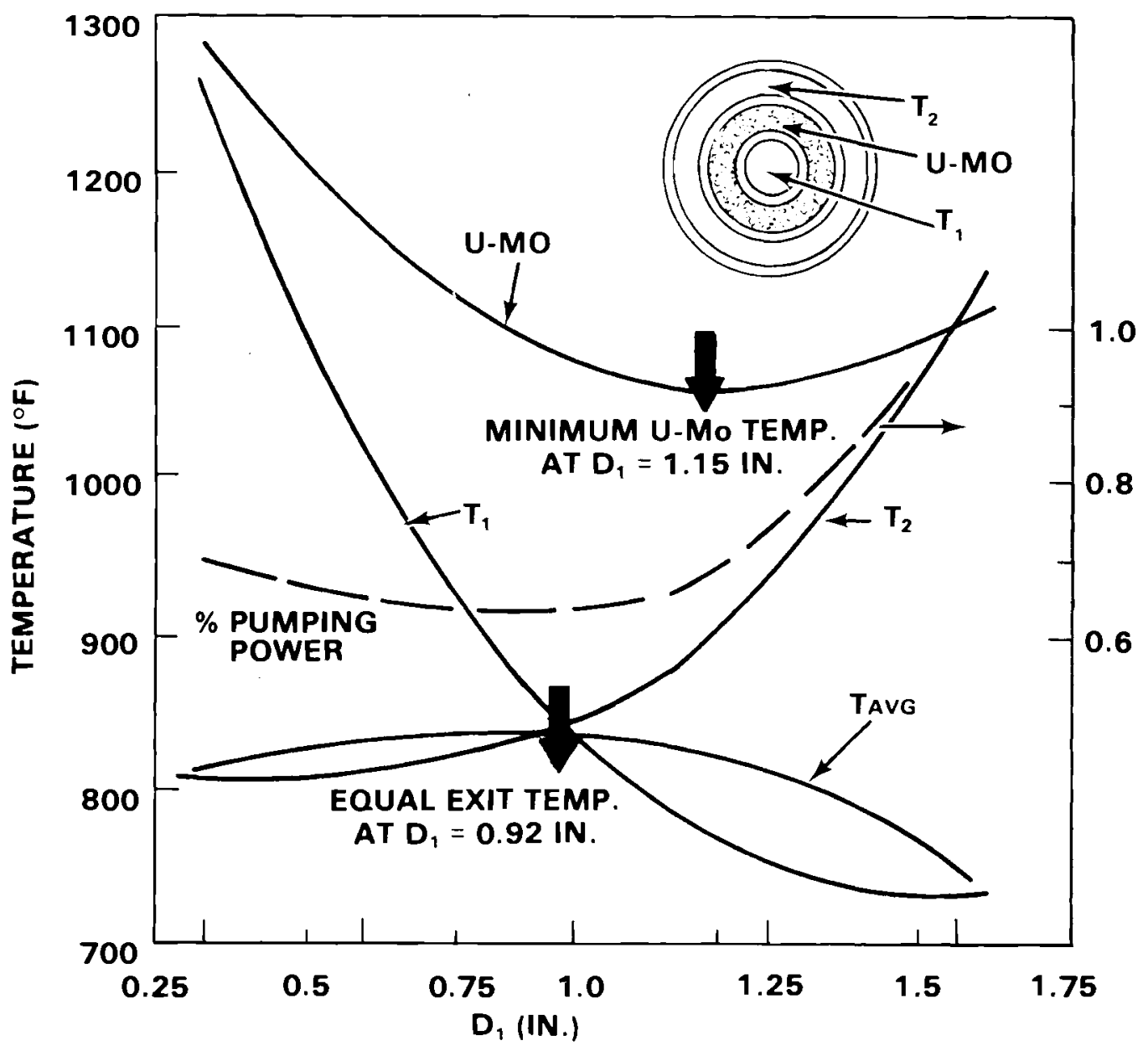

FIGURE 36. Temperature and Pumping Power Variation with Inner Diameter 


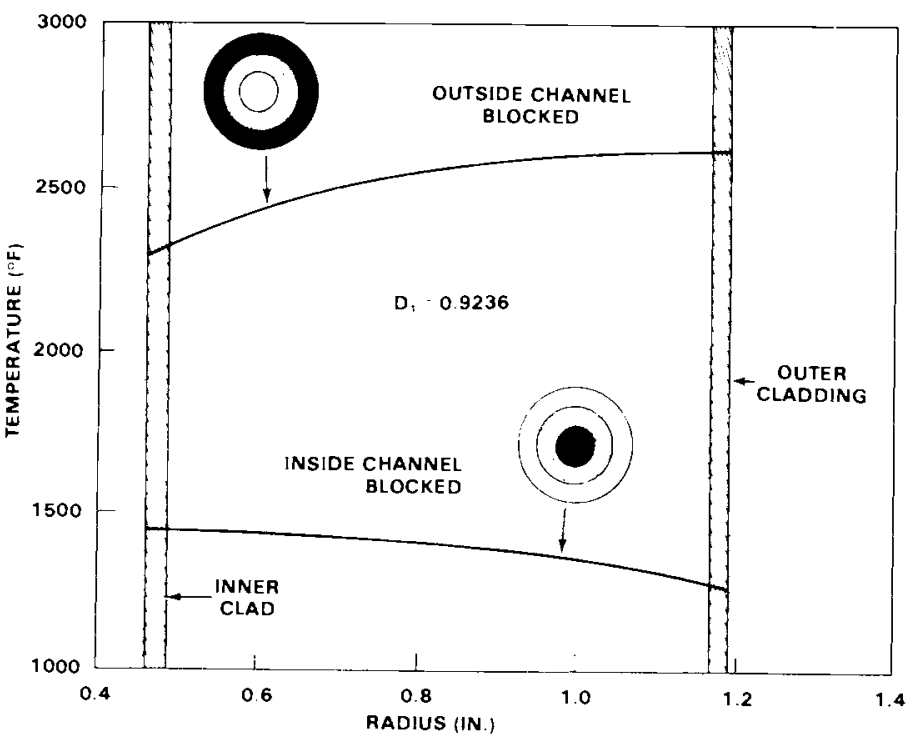

FIGURE 37. U-Mo Radial Temperature Distributions with Blocked Channels -- $D_{1}=0.9236$

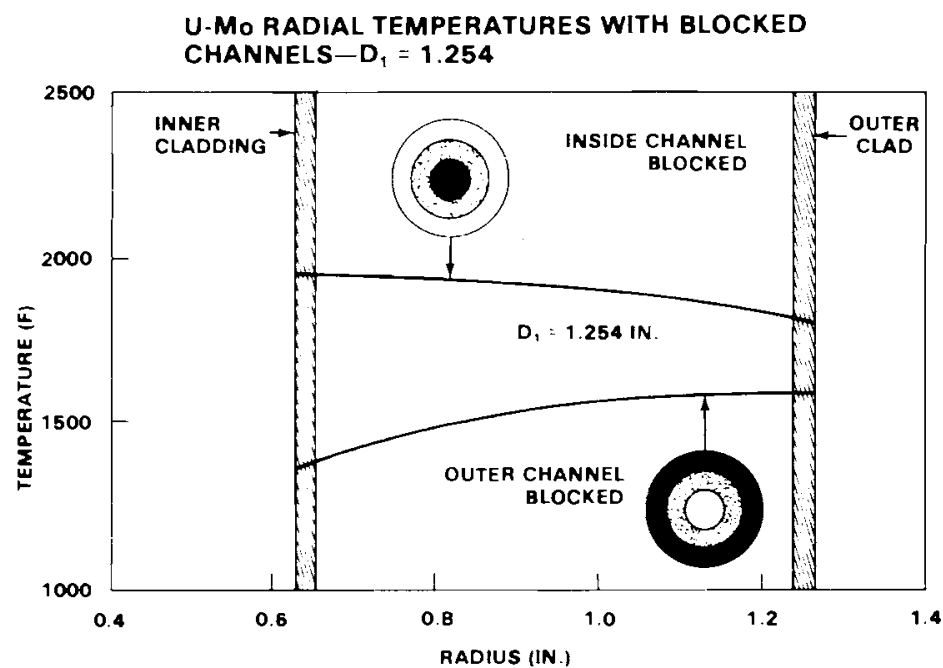

FIGURE 38. U-Mo Radial Temperatures with Blocked Channels

$D=1.254$ 
If this type of off-normal condition is a criterion for choosing the best diameter, then one ought to choose the value that produces the same maximum temperature for blockage of either channel. By interpolation, the proper value should be 1.15 in. which corresponds exactly to the dimension of minimum U-Mo temperature in Figure 36. With SS pressure tube in contact with the outer channel, however, even the lowest outside wall temperature attainable with the outer channel blocked (about $1600^{\circ} \mathrm{F}$ ) is probably too high for the tube to hold the 750 PSIA operating pressure. A different material is probably required for the tube wall.

In summary, for the given fuel cross-sectional area and pressure tube diameter, the inner U-Mo slug diameter which gives equal helium exit temperature is $0.92 \mathrm{in.;}$ that for minimum U-Mo temperature is $1.15 \mathrm{in}$. It is reasonable to conclude that a value between these two points is probably the best all-around dimension. For other cross sections and clad thicknesses it may be possible to correlate the inner diameter with

$$
0.51<\frac{D_{1}}{D_{\max }}<0.64
$$

where $D_{\max }$ is the inner diameter resulting in a zero outer helium channel area. It is given by:

$$
D_{\max }=\sqrt{\left(D_{p}-2 t_{c}\right)^{2}-\frac{4}{\pi} A_{f}-2 t_{c}}
$$

where $D_{p}$ is the pressure tube, I.D, $t_{c}$ is the clad thickness and $A_{f}$ is the fuel cross-sectional area.

Determining Tube Length

Because of the many factors and constraints to be considered, determining a "best" value for the maximum tube run is not practical. Instead, this study will present the effects of varying tube length and attempt to define a desirable design range. The effects of pressure, temperature and pressure head changes are also considered. The range of variation in these parameters is summarized in Table 2. Typical HTGR values are shown in the right hand column for comparison. Five cases were run for each of two tube lengths. In each case one parameter was varied while the others were held constant. 
Since the maximum helium temperature is 1 imited to about $900^{\circ} \mathrm{F}$ by the steel, the flow rate was increased linearly with length to maintain a nearly constant helium exit temperature near this value for the best thermal efficiency possible. Therefore, the results of this study show what operating conditions are required to achieve a limiting exit state, rather than the variation of the exit state with changes in operating conditions.

The main results of this sensitivity study are shown in Figure 39, where the quantities of interest are plotted against tube length. The top of the figure shows that the goal of constant exit temperature was not achieved exactly, although it remained below $900^{\circ} \mathrm{F}$ in the base case. The exit temperature rises about $40^{\circ}$ from 16 to $32 \mathrm{ft}$, which is about $13 \%$ of the total axial temperature rise. The pressure head would have to be increased about $25 \%$ at the $32 \mathrm{ft}$ length for a constant exit temperature with a consequent $45 \%$ increase in pumping power. The other curves are, therefore, somewhat nonconservative.

The velocity is far below sonic conditions at $300 \mathrm{ft} / \mathrm{sec}$ and, of itself, presents no problems. Therefore, with the maximum temperature fixed, the quantities limiting tube length are the pressure head and the pumping power required.

The questions to address are: 1) what is the maximum pressure head which can reasonably be expected using current technology compressors and 2) what fraction of the reactor thermal output can be tolerated to run the compressors? As Figure 39 shows, a typical HTGR operates with a 10 pressure drop across the core, which would limit the length to about 23 feet (less than $1 / 8$ the major circumference). However, a modified HTGR design ${ }^{(42)}$ proposed for use with a direct cycle gas turbine was to run with a 40-50 psi core pressure drop at 1000 psia, while a Gas-Cooled Fast Reactor design ${ }^{(43)}$ predicted a pressure drop of more than 70 psi at over i300 psia. Thus, the maximum pressure head may not be a severe limitation. About 24 psi is required for a 1/6 circumference run in the TCT Hybrid. 
PUMPING POWER, HEAD AND VELOCITY VS. TUBE

LENGTH FOR CONSTANT EXIT TEMPERATURE

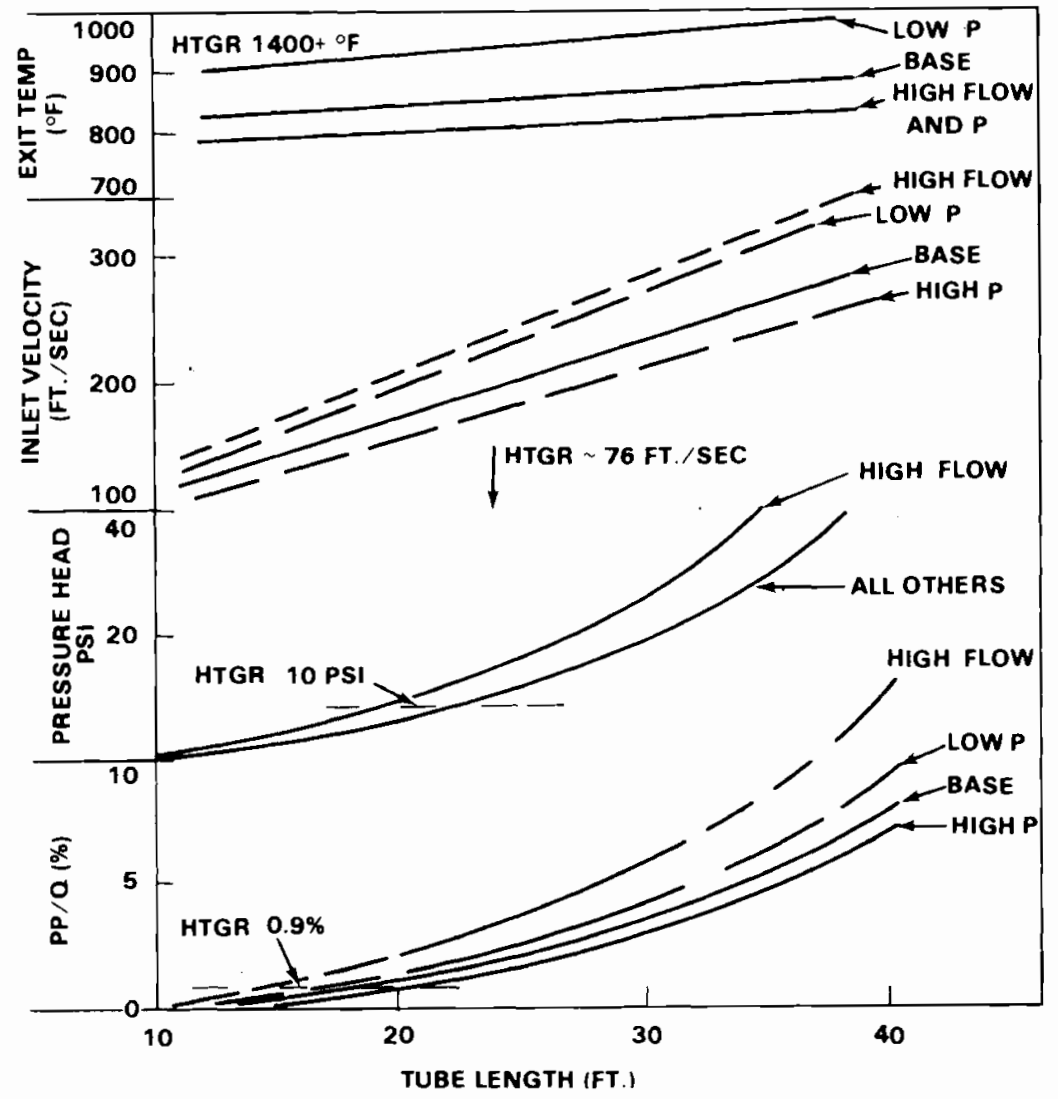

FIGURE 39. Pumping Power, Head and Velocity Versus Tube Length for Constant Exit Temperature

The pumping power as a percentage of the total rate of thermal energy deposited in the coolant is shown in the lower set of curves in Figure 39. The actual load on the system is about three times greater than indicated because 1) the power is figured for the core only, ignoring losses in the rest of the system, 2) thermal power is being produced $90 \%$ of the cycle but pumping power is required all the time, and 3) power to run the circulator/ compressor is produced by a turbine using thermal power at not more than $40 \%$ efficiency. Accordingly, the $5 \%$ power required for the 32-ft length takes a considerable portion of the plant's usable output. The HTGR, in contrast, manages with less than $1 \%$ power and water-cooled fission reactors require much less yet. Although $32 \mathrm{ft}$ of tube run would be entirely feasible, a reduction to less than $24 \mathrm{ft}$ brings the pumping power down to a high, but probably acceptable, level. 
Variation of the flow rate or operating pressure/temperature does not alter this conclusion. The effect of increased flow rate (by increasing the head) and system pressure are shown in Figures 40 and 41 , respectively. In Figure 40, some improvement in pumping power can be attained by reducing the head if a small increase in exit temperature can be tolerated. The system pressure would have to increase significantly to achieve any benefit. The effects of inlet temperature variations are not plotted since they would merely be the inverse of the pressure effect in Figure 40.

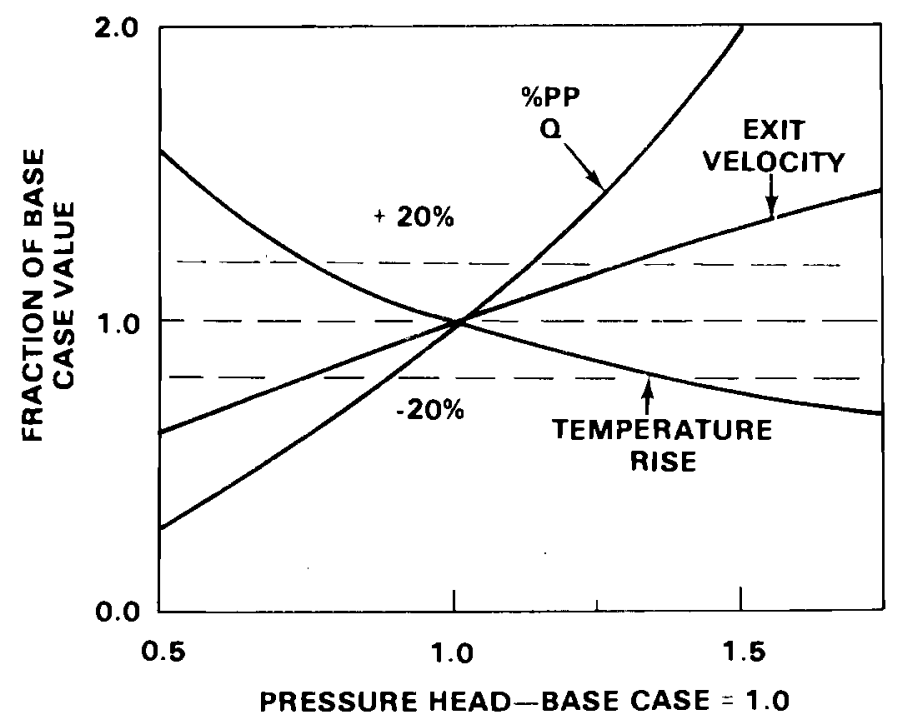

FIGURE 40. Pressure Head Base Case

In summary, given the SS temperature 7 imit and the HTGR operating conditions, it is possible to cool a $1 / 6$ circumference run of tube. However, in order to remain clearly within presently attainable technology, a $1 / 8$ to $1 / 12$ section should be chosen unless the exit temperature limit can be raised by a different choice of material.

\section{Transient Operation}

The cyclic mode of operation necessary for many fusion concepts makes it particularly difficult to extract thermal power efficiently. The most 
important considerations are probably the thermal stress and fatigue in structural components and the ultimate temperature/pressure fluctuation at the turbine-generator inlet. It is possible that the high thermal inertia of the graphite/salt regions will even out the blanket exit temperature to a great extent, but the converter tubes are upwind from this region and will feel the full power fluctuation. Figure 8 shows the helium exit temperature and maximum U-Mo temperature through the first half of a normal cycle. After $600 \mathrm{sec}$ conditions are essentially constant.

The only conclusion to be drawn from the $450^{\circ} \mathrm{F}$ temperature drop in the U-Mo is that it should be reduced. It was found by trial and error that the helium flow rate must be reduced to almost zero during the off-cycle to maintain the high temperatures. This suggests that the converter should be valved off completely during this time and the helium flow diverted through thermal ballast. Further investigation must await a firmer design.

\section{PARAMETER VARIATION WITH PRESSURE}

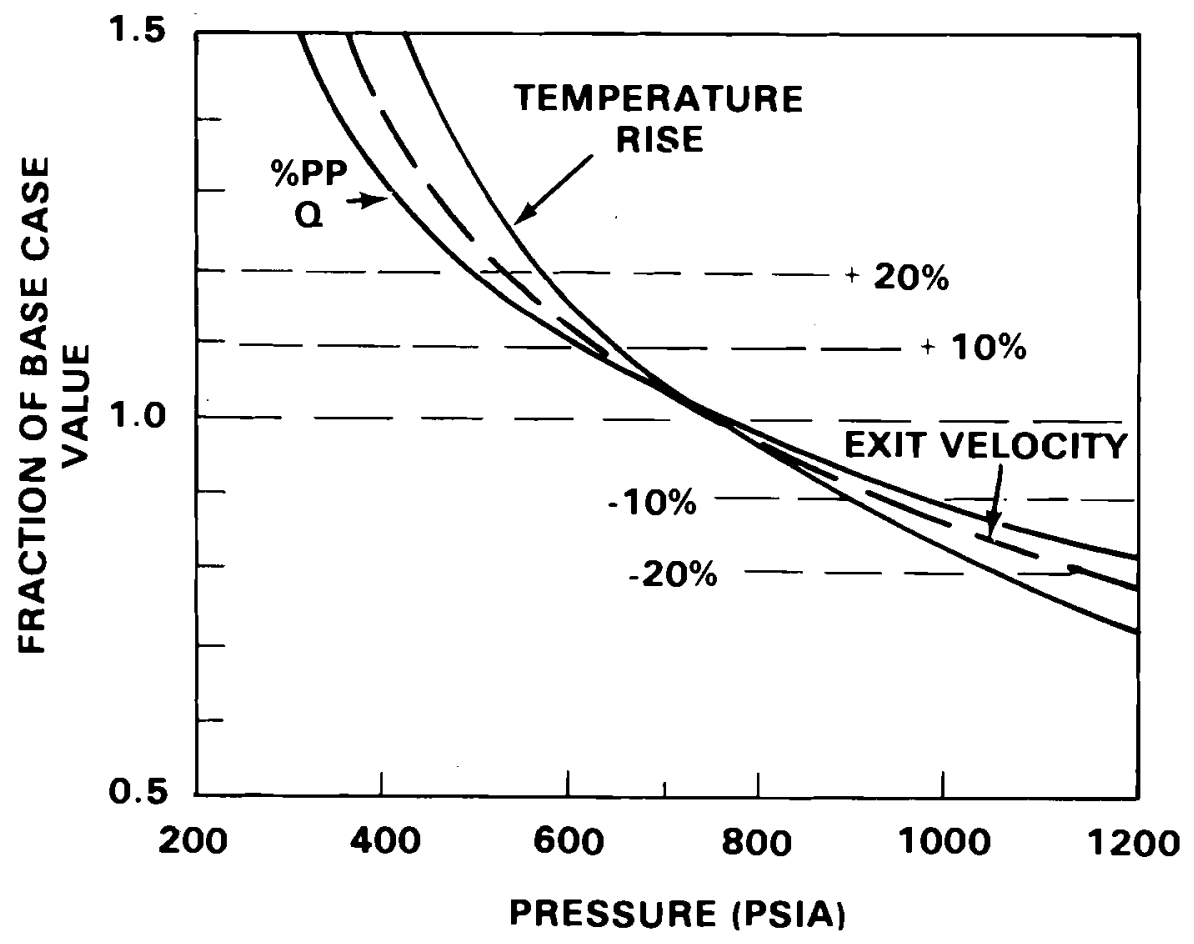

FIGURE 41. Parameter Variation With Pressure 
A more detailed design must also be available before a meaningful study of off-normal or accident conditions can be undertaken. For information, however, the converter heat capacity is such that the U-Mo temperature rises about $10^{\circ} \mathrm{F} / \mathrm{sec}$ at ful1 power and about $1 / 10$ that under a reasonable estimate of decay heat with no cooling.

\section{Fuel Slugs Stress Analysis}

A general stress analysis of the fuel slugs in the tube converter was done to determine the feasibility of using stainless clad cylindrical U-Mo alloy fuel in the fission blanket. Stresses and strains caused by both startup and operating cycles were calculated for the thermal loadings. Thermal loadings used were the worst case results of the thermal hydraulic studies.

\section{Fuel Siug Geometry}

The fuel slug's basic shape is a thick-walled cylinder of appropriate length to fit the curvature of the converter tubes. The uranium alloy is clad uniformly with a $20 \mathrm{mil}$ skin of SS in the present concept. Cooling flow is directed both inside and outside the cylinder surface. Specific dimensions for this analysis are shown on Figure 42 . These dimensions are the result of optimized thermal hydraulic studies. Length for the fuel slug was initially conceived to be near $2 \mathrm{ft}$, but curvature clearance considerations may dictate a shorter slug length.

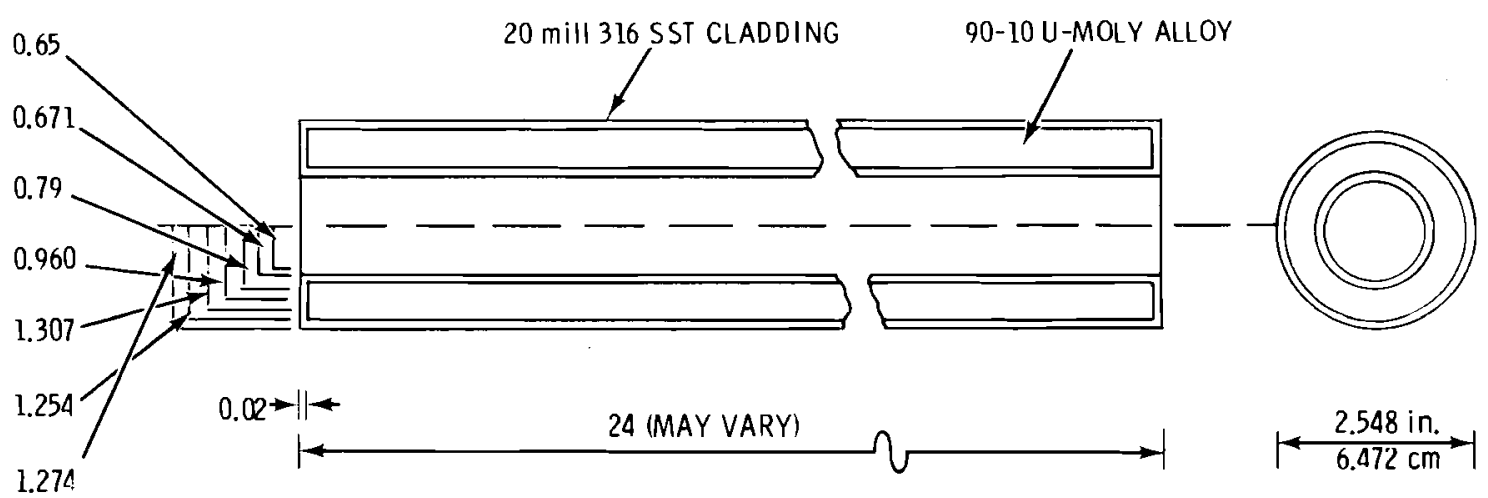

FIGURE 42. Standard Fuel Element Geometry 


\section{Loadings}

Primary loadings of the fuel slugs were stresses due to temperature rise and thermal gradients. The slugs are contained in a nearly uniform pressure field so pressure loadings were not considered. Long-term effects, such as creep and radiation damage, were not explicitly considered.

The thermal hydraulic studies resulted in a series of transient gradients throughout a normal operating cycle of a $1000 \mathrm{sec}$ burn followed by a $100 \mathrm{sec}$ power-off phase with helium cooling operating throughout.

This mode of operation defines two cyclic loading cases. The first is a startup cycle from room temperature to the peak operating temperature. Peak operating temperature for this analysis, using the transient results, may not yield in the maximum stressed condition if there is no significant gradient through the fuel and cladding. Therefore, a search through the transient was performed to find a peak internal temperature in the fuel in conjunction with a maximum temperature difference between the inside of the fuel and the outer cooling surface of the cladding. This situation occurs shortly after the 1000 sec burn ceases: before the maximum internal temperature changes but after the significant surface cooling has taken place (Figure 43). Thus, the startup cycle is defined as the thermal stresses induced by raising the clad fuel slug from room temperature to the severest high temperature gradient.
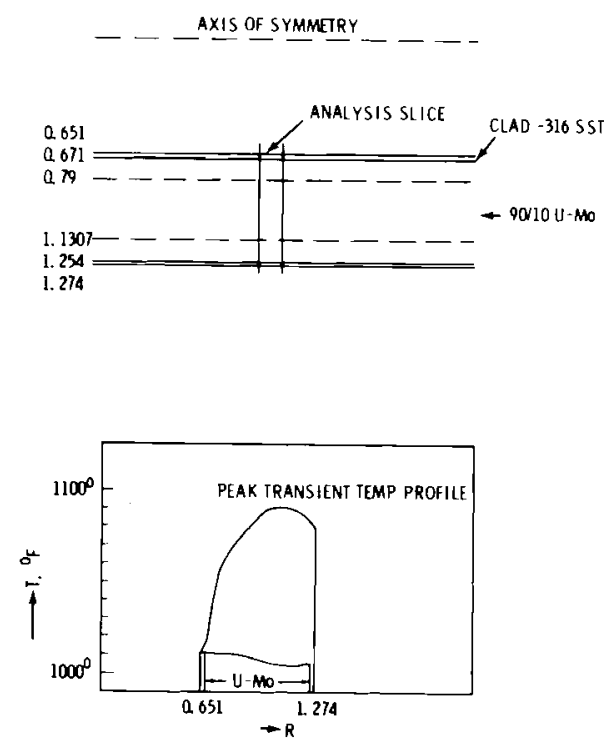

FIGURE 43. Analysis Model Section 
The second cycle is the operating cycle. At the end of the power-off, coolant-on $100 \mathrm{sec}$ of the cycle, fuel temperature has fallen near the temperature of the helium coolant and the through thickness temperature profile is nearly flat, indicating no significant gradient. The most severe stressing condition for this cycle is the thermal traverse from this steady cooled condition to the thermal stressing peak defined for the startup cycle.

The load cases examined in this analysis are:

Load Case 1 - Startup Cycle

$70^{\circ}$ to peak transient gradient (fuel at $1100^{\circ} \mathrm{F}$, outside cladding at $1000^{\circ} \mathrm{F}$.

Load Case 2 - Operating Cycle $800^{\circ}$ to peak transient gradient

Assuming a one-year operating life for the fuel slug translates into approximately 28,000 operating cycles for an operating year. Startup/shutdown cycles would probably number less than 10 over the same period.

\section{Material Properties}

\section{Stainless Steel}

Material properties for $20 \%$ cold-worked 316 stainless cladding material were derived from the ASME BPVC Section III properties tables and verified in the higher temperature ranges by using values from the Liquid Metal Fast Breeder Reactor Materials Handbook. Material properties were given as a function of temperature. Properties over the temperature range were:

\begin{tabular}{|c|c|c|c|}
\hline & & $\Delta T\left(F^{\circ}\right)$ & Value \\
\hline$E$ & Young's modulus & $300^{\circ}-1100^{\circ}$ & 26.8 to $23.6 \times 10^{6} \mathrm{psi}$ \\
\hline$v$ & Poisson ratio & $300^{\circ}-1100^{\circ}$ & 0.33 \\
\hline & $\begin{array}{l}\text { Coefficient of } \\
\text { thermal expan- } \\
\text { sion }\end{array}$ & $300^{\circ}-1100^{\circ}$ & 9.47 to $10.12 \times 10^{-6}$ in. $/$ in. ${ }^{\circ} \mathrm{F}$ \\
\hline & ield stress & $300^{\circ}-1100^{\circ}$ & 23.3 to $17.3 \times 10^{3} \mathrm{psi}$ \\
\hline
\end{tabular}


Uranium Molybdenum Alloy

The metal alloy selected for the fuel material is of uranium molybdenum composition. Weight percentage is around $90 \%$ uranium, $10 \%$ molybdenum. The heat treatment selected was a seven-day soak at $900^{\circ} \mathrm{C}\left(1650^{\circ} \mathrm{F}\right)$ followed by water quench. Typical properties were selected from the existing literature and are tabulated and shown in Figure 44. (Note that the coefficient of thermal expansion is considerably less than that of stainless steel.)

Analysis Method

The AXISOL code was used to analyze a radial section of the fuel slug. The code is well suited to this particular analysis due to the axisymmetry of loading and geometry. The thermal hydraulic studies ignored edge effects on the temperature distribution in the fuel slug, giving the gradients in terms of radial coordinates only. Thus, based on this input, reasonable stresses could be obtained near the midsection of the slug cylinder where the different materials at different temperatures are constrained to displace together. Integral bonding between the cladding and fuel was assumed for both thermal analysis and stress analysis.

0ther features used were the temperature mapping option and the elastoplastic analysis option. A bilinear stress-strain curve was used in the plastic analysis with effective modulus corrections made at each iteration based on effective strain (Figure 45). The procedure is not inherently stable, but it has been shown to converge very rapidly when inelastically restricted to small areas of a structure that is generally responding elastically.

Analys $\underline{\text { is }}$ Results

Preliminary AXISOL analysis indicated that yield stress was generally exceeded in the cladding compression. The U-Mo appeared to respond elastically except in the region immediately adjacent to the cladding. 


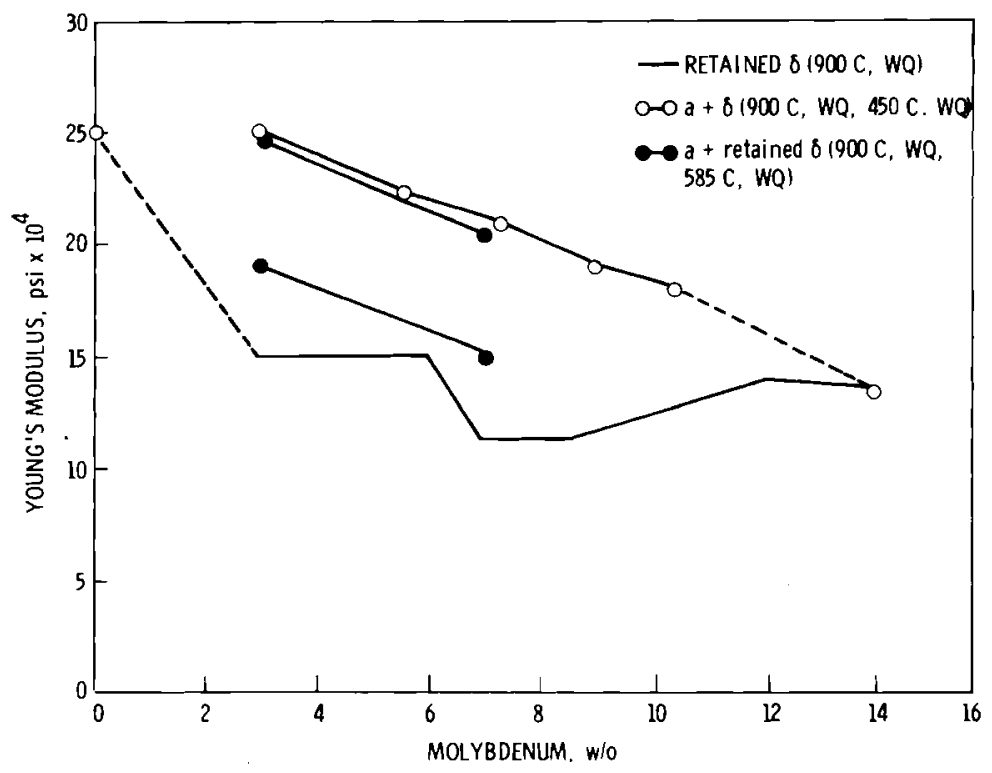

FIGURE 44. Relation Between Young's Modulus and Composition of Uranium-Molybdenum Alloys

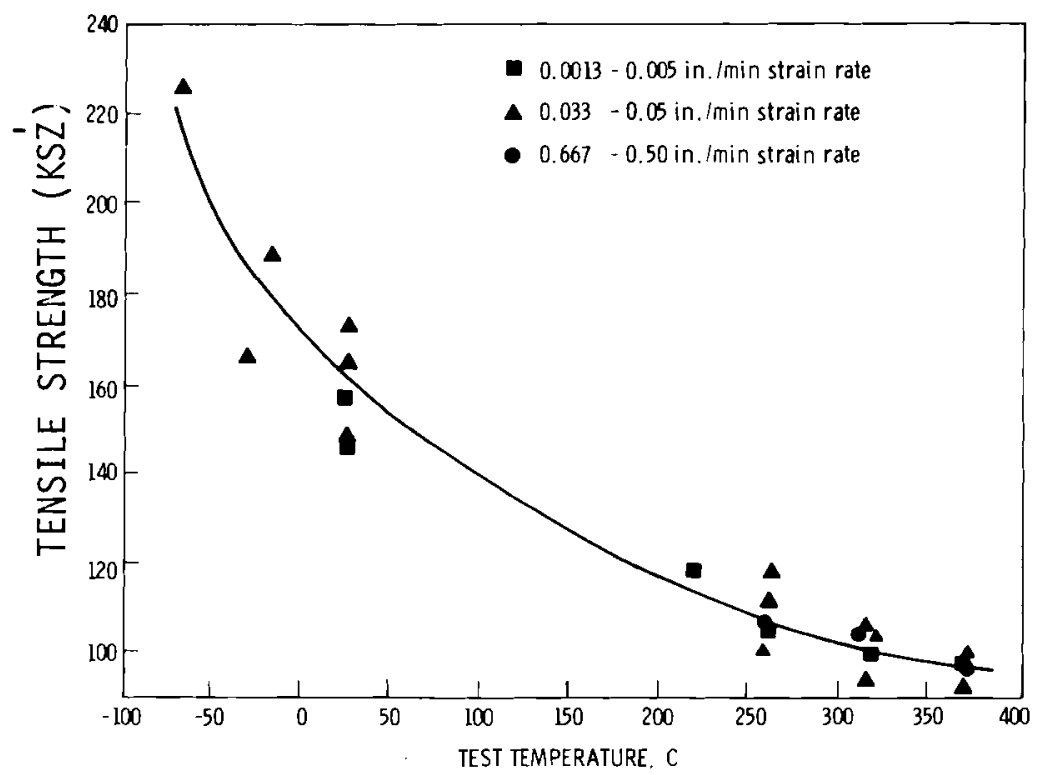

FIGURE 44. (cont.) Tensile Strength of Uranium-12 Wt\% Molybdenum Alloy 


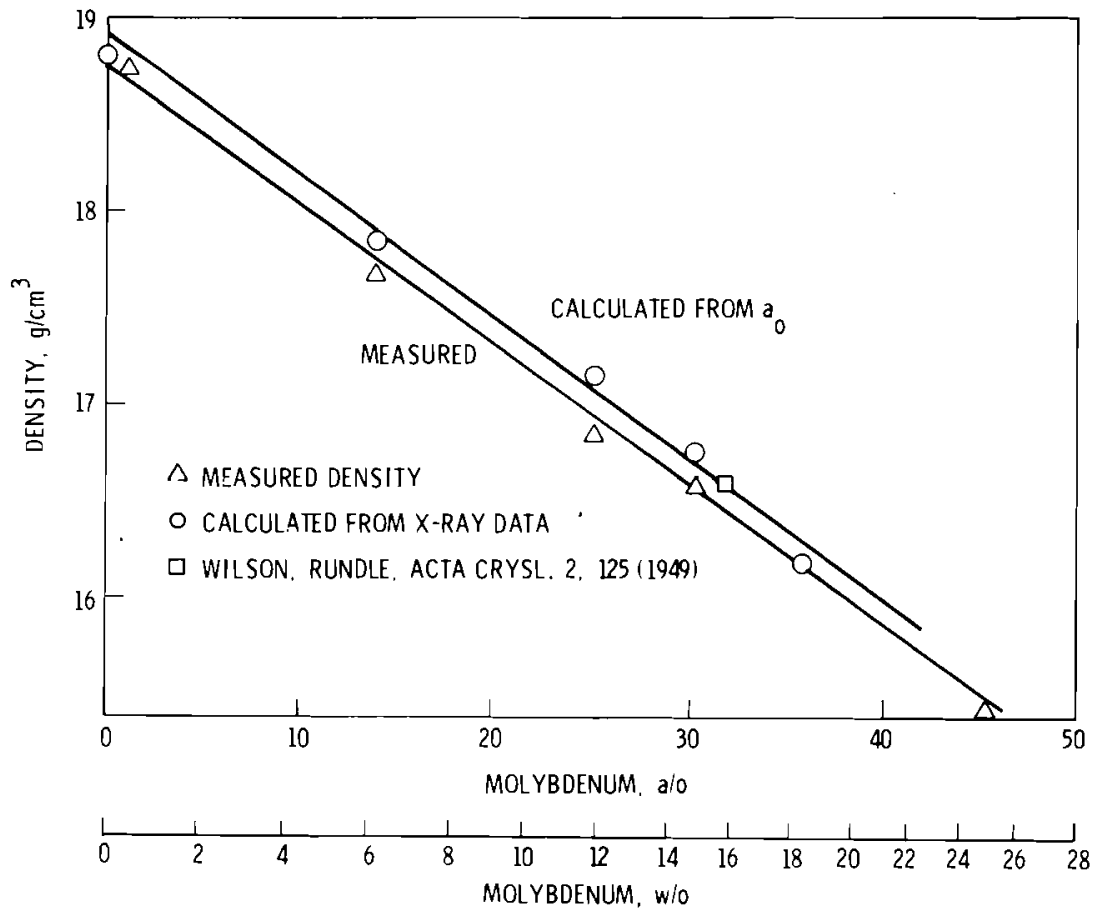

FIGURE 44. (cont.) Density of Uranium-Molybdenum Alloys Quenched from $900^{\circ} \mathrm{C}$

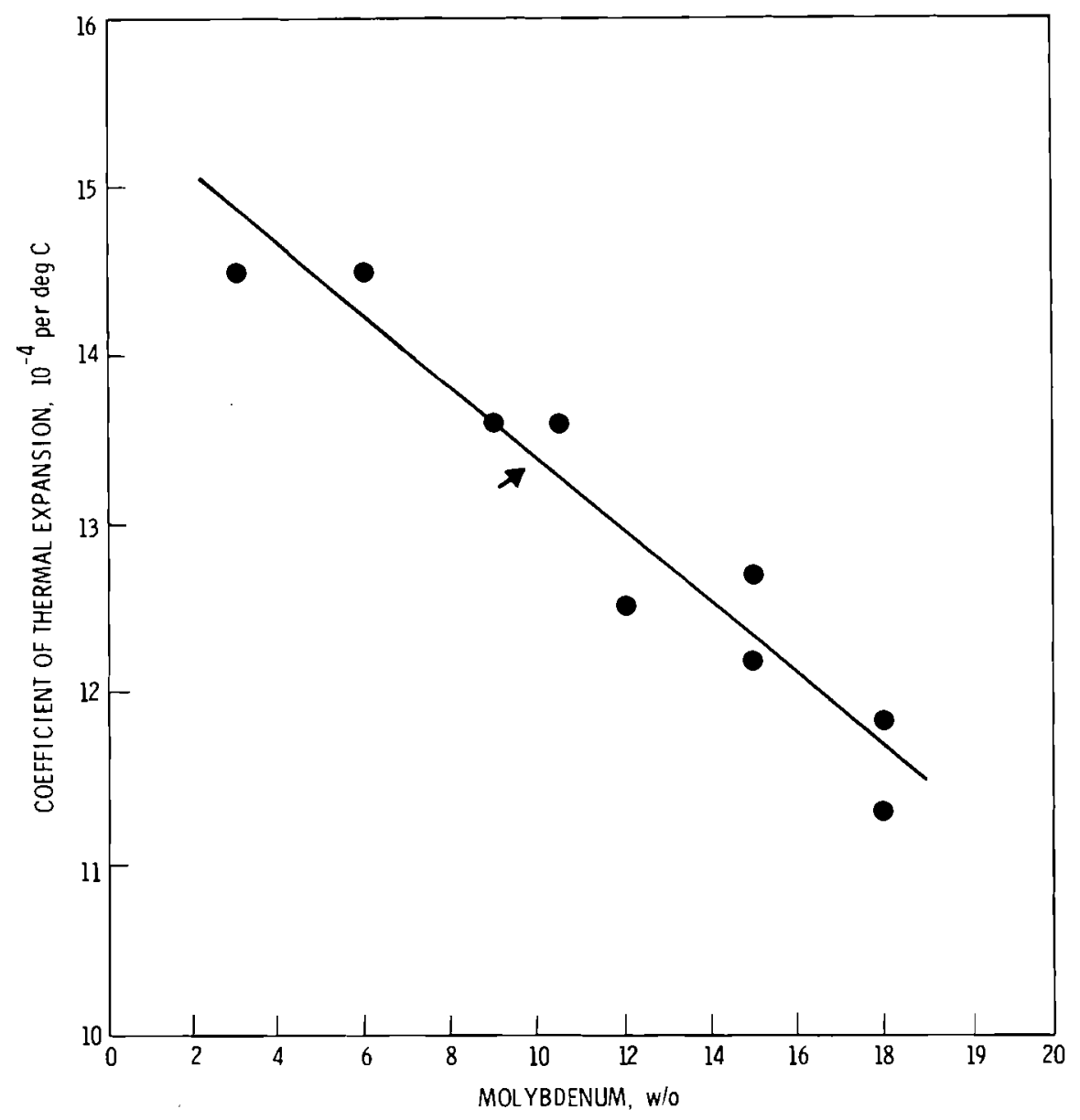

FIGURE 44. (cont.) Linear Thermal Expansion for UraniumMolvbdenum A1 loys 


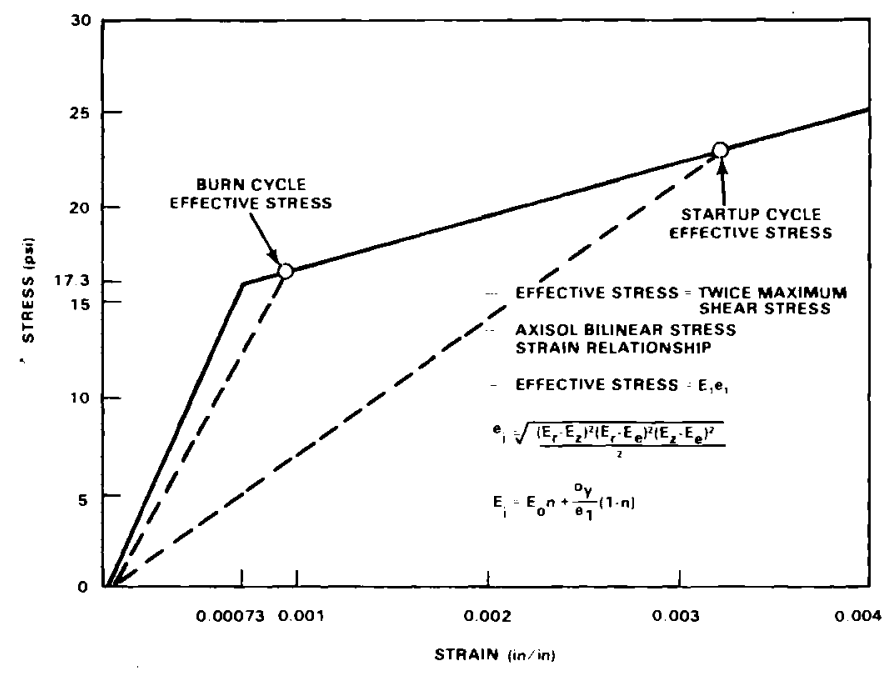

FIGURE 45. Approximate Bilinear Stress Strain Relationship for AXISOL Analysis 316 SST

The stainless cladding, with its higher coefficient of expansion, was generally compressed by the fuel with bulk temperature change. The gradient through the thickness resulted in a slight stress decrease along the inside cladding and an increase in clad compressive stresses at operating temperature on the outer surface. Fully converged solutions were obtained for both load cases. Stress results are summarized below.

\section{Load Case 1 - Startup Cycle}

Major components of a maximum fuel stress intensity of 6060 psi were hoop and longitudinal tensile stresses near the inner cladding. The gradients through thickness which caused the outer, hotter fuel to pull the cooler, inner fuel outward and longitudinally, was the major source of stress. This stress is approximately one-third of the yield stress of the fuel at temperature. 
Major components of maximum clad stress intensity of 22,290 psi were plastic compressive strains in the cladding due to the bulk temperature rise and the difference in clad and fuel coefficients at thermal expansion. Maximum effective strain is approximately 0.00323 , which is nearly $41 / 2$ times the yield strain at temperature. This value is well within the elongation bounds of the material at temperature, but a detailed cyclic strain history analysis would have to be done to determine if the cladding would ultimately shake down to elastic action for this loading cycle.

A simplified strain history tracing from the single cycle analysis performed indicates significant plastic action into the second cycle due to the gradient through the thickness. The bulk temperature rise from room temperature to around $1100^{\circ} \mathrm{F}$ can be shown to cycle elastically, resulting in cladding tensile stresses of approximately $27 \mathrm{ksi}$ (RT yield $=30 \mathrm{ksi}$ ) on c00l-down.

The cladding's cyclic life can be roughly approximated by using the ASME BPVC fatigue curve and a stress based on the effective strain and the modulus at temperature. This "elastic" stress level indicates a fatigue life of around 1000 cycles, adequate for the short life of a fuel slug. Incremental plastic deformation, or ratcheting, has not been examined at this analysis level, as a rigorous cyclic strain history analysis was not considered appropriate at this level of conceptual design.

\section{Load Case 2 - Operating Cycle}

A maximum fuel stress intensity of 4062 psi, completely elastic, primarily results from the gradient through the thickness and is in the same location as the startup cycle peak fuel stress.

A maximum cladding stress intensity of 18,940 psi indicates slight inelasticity, but effective strain is much less than twice yield strain at temperature, indicating elastic cycling immediately for the operating cycle. Effective strain is 0.00094 , which, in conjunction with the modulus at temperature, can be used to approximate fatigue life for the operating cycle strain traverse. This elastic stress indicates a fatigue life of $10^{6}$ cycles, adequate for a short-term pellet cladding. 


\section{Discussion}

The key problem identified by this simplified stress analysis is the need for more careful strain history analysis of the slugs for the startup cycle. Feasibility for the thermal loading, precluding this problem has been adequately demonstrated, as regards fatigue life. Sizeable margins exist to cover possible detrimental effects not examined in this analysis. Such problems can be separated into three categories, briefly outlined below:

A. Radiation effects

1. embrittlement

2. neutron swelling (U-Mo and SST)

3. sputtering and blistering

B. Cladding problems

1. debonding

2. thermal ratcheting

3. fracture

C. Faulted conditions

1. loss of coolant flow

2. local hot spots

Category $A$ items might be best addressed by the use of a less radiationsensitive material (e.g., nimonic PE-16).

Category $B$ items might be easily handled by thorough use of the existing cladding technology developed for fission systems to find an optimum cladding material for these specific conditions. For these studies, 316 is a convenient starting point.

Category $C$ items define an area presently in its infancy for hybrid systems; this area will present its own special problems.

\section{BURNER AND MODERATOR REGION}

The blanket burner and moderator were analyzed as a single unit. (Figure 11) The burner consisted of 5 vol\% $316 \mathrm{SS}, 15 \mathrm{vol} \% \mathrm{He}$, and 80 vol\% 
salt. The moderator consisted of 5 vol\% salt and 95 vol\% graphite. The composition of the salt is $52 \mathrm{~mole}_{\mathrm{B}} \mathrm{BeF}_{2}, 47.5 \mathrm{~mole} \% \mathrm{LiF}\left(0.83 \mathrm{a} / \mathrm{O} \mathrm{Li}{ }^{6}\right), 0.5$ mole\% $\mathrm{PuF}_{3}$. This composition resembles the molten salt, flibe. The power generated in the salt in the burner region is $7.4 \mathrm{MW} / \mathrm{m}^{3}$ and $52 \mathrm{MW} / \mathrm{m}^{3}$ in the salt in the moderator region (negligible power is generated in the graphite).

In designing the heat removal system for the burner-moderator region, transfer of the heat to the helium system in the blanket appeared desirable as this has two beneficial effects. First, if the salt remains in the blanket during the power-off portion of the cycle, it acts as a thermal storage medium. This minimizes the thermal shock to the structural materials, piping, etc. Secondly, not removing energy with the salt would eliminate the necessity of large molten salt pumps. Only a processing stream flow to remove the tritium would be required, which can be accomplished with current MSRE pumps.

The question then becomes whether the heat can be removed from the moderator region and still maintain acceptably $10 \mathrm{w}\left(600^{\circ} \mathrm{C}\right)$ graphite-salt interface temperatures. The concept shown in Figure 11 would be the most acceptable from the neutronics standpoint and perhaps from a fabrication standpoint also.

A two-dimensional code was used which included the appropriate power generation in each region, conduction in the moderator, conduction and natural convection in the burner, and heat transfer to the bank of helium coolant tubes. The code was also equipped to handle phase changes in the salt since the heat of fusion is substantial and a region of permanently solid salt is undesirable. Thermophysical properties were permitted to be temperature dependent. Average thermophysical properties and power generation rate were applied in the moderator region based on volume percents and structure; however, a lack of complete agreement seems to exist in the iterature on the thermophysical properties of this particular salt (notably liquidus temperature and viscosity).

Figure 12(a) shows thermal profiles in the helium coolant, SS tube wa11, burner and moderator. These profiles represent conditions at the reactor midplane (Section A-A in Figure 11) at the end of a power-on period $(1500 \mathrm{sec})$ and at the end of a power-off period $100 \mathrm{sec}$ ). The helium coolant 
inlet temperature is $350^{\circ} \mathrm{C}$ and outlet temperature is $490^{\circ} \mathrm{C}$ with a nominal pressure of $50 \mathrm{~atm}, 1 \mathrm{~atm}$ pressure drop, and velocity of $100 \mathrm{~m} / \mathrm{sec}$.

The salt and graphite will be in contact in the moderator at temperatures near $1800^{\circ} \mathrm{C}$. Compatibility problems begin to appear above a temperature of approximately $600^{\circ} \mathrm{C}$. This temperature difference cannot be reduced significantly by any reasonable changes in helium velocity or inlet temperature. Note: natural convection in the salt effectively promotes a nearly isothermal profile except at the SS interface. At this interface, the relatively low thermal conductivity of the salt leads to a very steep thermal gradient.

In view of the excessively high temperatures, another situation was examined where one bank of helium coolant tubes was placed at the burnermoderator interface and an additional bank was placed in the center of the moderator. The thermal profile for this case satisfied compatibility requirements for both graphite and SS as shown in Figure 12(b). Unfortunately, introducing additional SS results in excessive neutron absorption, thus yielding inadequate tritium and plutonium production. Using this configuration would require using a tubing material with much lower absorption cross section than SS or higher fissile plutonium enrichment in the burner salt.

Neither case considers circulation of the burner salt in the graphite moderator. With the large temperature gradients calculated in Case 1 , significant natural circulation would probably occur. To make any meaningful calculations, however, would require spending some time designing discrete channels in the graphite moderator. The channels would have to vary, depending on the orientation of the blanket as it wraps around the plasma chamber. (This effort was beyond the scope of this study.)

It may also be possible to induce forced circulation of the burner salt in the graphite moderator. The process stream for extracting tritium could be brought back into the blanket so that it caused some circulation in that region. More work must be done on laying out the blanket tanks before any meaningful analysis of this concept can be made. 
A final situation was briefly examined. The original helium coolant configuration (two rows, one each at the outer face of each burner) was maintained but the molten salt was pumped through the burner and moderator regions. An average velocity of approximately $10 \mathrm{~cm} / \mathrm{sec}$ is estimated to be sufficient to keep temperatures within bounds. A heat exchange along with the tritium recovery cycle loop would then be used external to the blanket and shield. This situation could be considered as a last resort since it grossly changes the dynamic characteristics of the blanket heat removal and requires the development of large molten salt pumps.

The analysis did not consider magnetohydrodynamic (MHD) effects that are expected to be especially noticeable on natural convection currents in the molten salt and hence the temperature profile. Transient natural convection velocities of the order of $1 \mathrm{~m} / \mathrm{sec}$ were noted in the absence of MHD forces. Other MHD effects of potential concern are increased pumping losses and corrosion. It is recommended that MHD effects be included in future detailed thermal hydraulic studies. 


\section{NEUTRONICS}

Concurrent with the early effort in the project to establish a minimum" shield thickness, neutronic survey calculations were made. These initial calculations were to guide the more detailed calculations when design details, such as the shield thickness and plasma radius were firmed up.

As noted, one of the intitial ground rules of the TCT Hybrid design study was to maximize the production of fissile material in the hybrid blanket region. Should the survey calculations show this to be undesirable, an alternative such as electric power production could be evaluated.

To determine the neutronic performance expected from various blankets, a literature survey of all previous blanket calculations was made. The various designs were then ranked according to their neutronic performance, that is, on each blanket's ability to breed tritium, fissile fuel and power. The results generally showed that blankets utilizing metal fuels were best, followed by carbides, then oxides and salts. Uranium systems out-performed thorium systems and performance increased with enrichment.

To obtain adequate fissile material production rates, considerable neutron multiplication will be required in the TCT Hybrid blanket. This will occur primarily by fissioning of fissile or fertile $U$ isotopes in the converter region. Fission results in a considerable energy multiplication (200 MeV/fission). Approximately $80 \%$ of the fission energy is contained in the kinetic energy fission products, which is turned to sensible heat within a few microns of where the fission occurred. This can lead to very high power densities in the converter region if high neutron multiplication and high wall loadings are combined. As a guide to the blanket survey calculations, Figure 46 was developed from a simple slab geometry. It relates allowed wall loading to allowed converter region power density for various neutron multiplication factors. The neutron yields per fission were assumed to be three. The average power density for various fission reactor lattices are also indicated in Figure 46. 


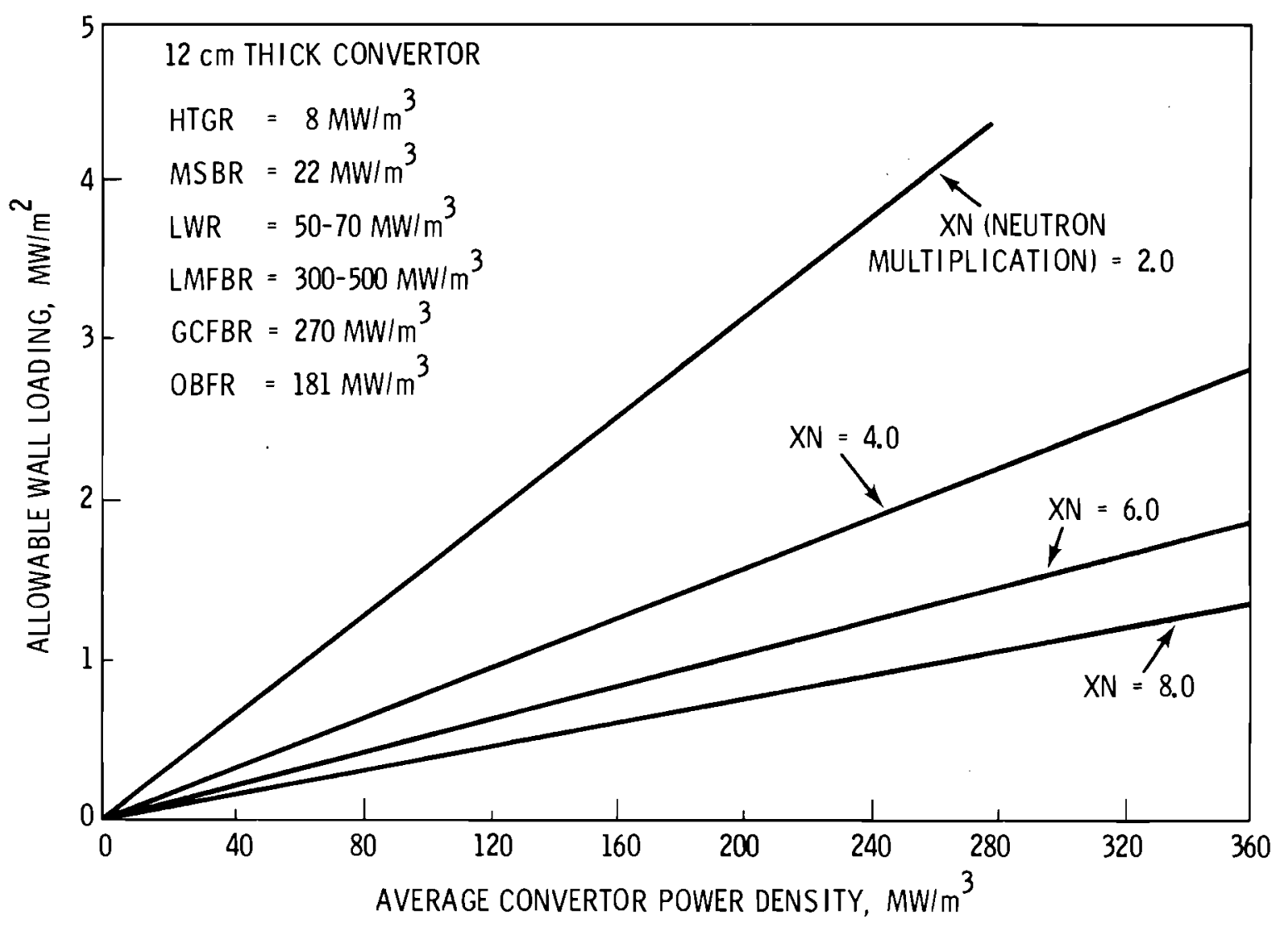

FIGURE 46. Wal1 Loading Versus Al Towable Converter Power Density

The ANISN ${ }^{(44)}$ code which solves the one-dimensional Boltzman equation, was used to perform the neutronic analys is of the blanket. All calculations were made in cylindrical geometry; that is, the torus was approximated as an infinite cylinder. The $\mathrm{P}_{3}-\mathrm{S}_{8}$ approximation was used in all analyses. The transport equation solution gives space-dependent scalar neutron fluxes, which are used to calculate reaction rates. The reaction rates reported are expressed as reactions per source neutron, i.e., per fusion, and may therefore by scaled to any desired fusion power level.

Two different sets of cross sections were used. The first survey calcuTations were made with a 30-energy group obtained from ENDF/B-IV ${ }^{(45)}$ Tibrary and were processed into 30 groups using ETOG. ${ }^{(46)}$ The capture and fission cross sections for ${ }^{235} U$ and ${ }^{238} U$ were self-shielded and developed from EGGNIT $^{(47)}$ and GRANIT ${ }^{(48)}$ calculations. (These cross sections existed prior 
to this study.) As the survey calculations expanded, this set was inadequate because it did not contain all elements of interest.

The second set of cross sections was derived by collapsing a 100 energy group set ${ }^{(49)}$ over a typical hybrid blanket spectrum. These cross sections were derived from the ENDF/B library and were infinitely dilute. They were also collapsed into 30-energy groups; however, they were not compatible with the previous 30-group set because the energy group boundaries could not be made the same. The maximum energy of the 100-group set was $14.92 \mathrm{MeV}$, whereas the upper boundary on the previous 30 -group was $18.22 \mathrm{MeV}$.

At this point, the collapsed 100-energy group infinite dilute cross sections were felt to be adequate for the survey calculations, since it was anticipated that as the design was finalized, a cross section set would be developed using ETOG, EGGNIT and GRANIT. This set would correspond to the temperatures and cell characteristics of the blanket being investigated. This procedure would be too time-consuming and expensive to develop an individual set for each blanket.

However, upon completing the second set of survey calculations, it was felt that the calculated energy multiplications were too low. This resulted from the high rate of neutron absorption in the resonance regions due to having used the infinite dilute cross sections. Few neutrons were reaching thermal energy and producing fission in ${ }^{235} U$. This was confirmed by a comparison with a previous calculation. ${ }^{(50)}$ In this previous calculation for a blanket with an enrichment of $1.35 \%{ }^{235} U$, using shielded cross sections resulted in an energy multiplication of 40 . When this blanket was calculated using infinite dilute cross sections, however, the energy multiplication was 5.2. However, during this period of time, it was decided that the blanket would contain molten salt and survey calculations on solid blankets were stopped. (Some of the more interesting survey calculations are reported in the next section.)

\section{RESULTS PART I}

Hybrid blankets are usually divided into three main zones: a converter, a tritium breeding zone, and a fertile and/or fissile lattice. The converter 
region is designed to take advantage of energetic $14 \mathrm{MeV}$ neutrons from the plasma to produce neutron multiplication from fast fissions, $(n, 2 n)$ and $(n, 3 n)$ reactions in ${ }^{238} U$. Thus, it is advantageous to have the highest possible optical thickness of ${ }^{238} U$ facing the plasma, which would be accomplished using uranium metal. However, in the first survey calculations, the fuel was depleted $\mathrm{UO}_{2}$ for both the converter and fertile lattices. Depleted $\mathrm{UO}_{2}$ was chosen for the first calculations since it would require the least extension of current technology and least expense.

The tritium breeding zones produce tritium from $L i^{6}(n, \alpha) T$ and $L i^{7}(n, n \alpha) T$ reactions. In theory, a viable reactor must have a tritium breeding ratio in excess of one; in practice, it will probably have to be on the order of 1.4 or greater to take into account neutron losses in the diverter and beam ports.

Note that since plutonium and tritium are produced from neutron absorption, the breeding rates of tritium and plutonium may be changed by varying the atom ratios of ${ }^{238} U$ and ${ }^{6} L i$ in the breeding blanket. Thus, in the survey calculations, no attempt at optimization was made when it was felt that the tritium breeding ratio could be made greater than one at the expense of plutonium production.

The lattice, depending upon the design, would produce power and/or fuel. The power would be produced from the fission of ${ }^{235} \mathrm{U}$ and produced ${ }^{239} \mathrm{Pu}$. A small percent of the power in the lattice would be produced from the fast fission of ${ }^{238} \mathrm{U}$; however, most of the $14 \mathrm{MeV}$ neutrons will be degraded in energy traveling through the converter. In the case of the lattice containing $\mathrm{UO}_{2},{ }^{239} \mathrm{Pu}$ would be produced from neutron capture in ${ }^{238} \mathrm{U}$.

The initial survey calculations were made with the shielded, 30-energy group set previously discussed. The transport calculation was made using ANISN with the $\mathrm{S}_{8}-\mathrm{P}_{3}$ approximation. The physical size of the reactor chosen was: plasma radius - $150 \mathrm{~cm}$; vaccum wall - $200 \mathrm{~cm}$; blanket thickness $72 \mathrm{~cm}$; and shield thickness $-28 \mathrm{~cm}$. The blanket was divided into three zones: a converter, lattice and tritium breeding zone. The thickess and composition of these zones were varied in a parameter study. 
Three cases are presented using the shielded cross sections. In Case 1 an eleven-inch converter is followed by a thermal lattice. The volume fractions in the converter correspond to those that would be obtained if the converter were composed of SS clad $\mathrm{UO}_{2}$ plates. This is followed by a tritium breeding zone. Last is a reflector and shield of SS. The rationale for this blanket is that the neutrons from fast fissions in the converter would be thermalized by the carbon, which would produce fissions in ${ }^{235} \mathrm{U}$. The neutrons leaking from the rear of the lattice into the tritium zone would produce tritium from $L i^{6}(n, \alpha) T$ reactions. The schematic for this blanket is shown in Figure 47 and the results are given in Table 3.

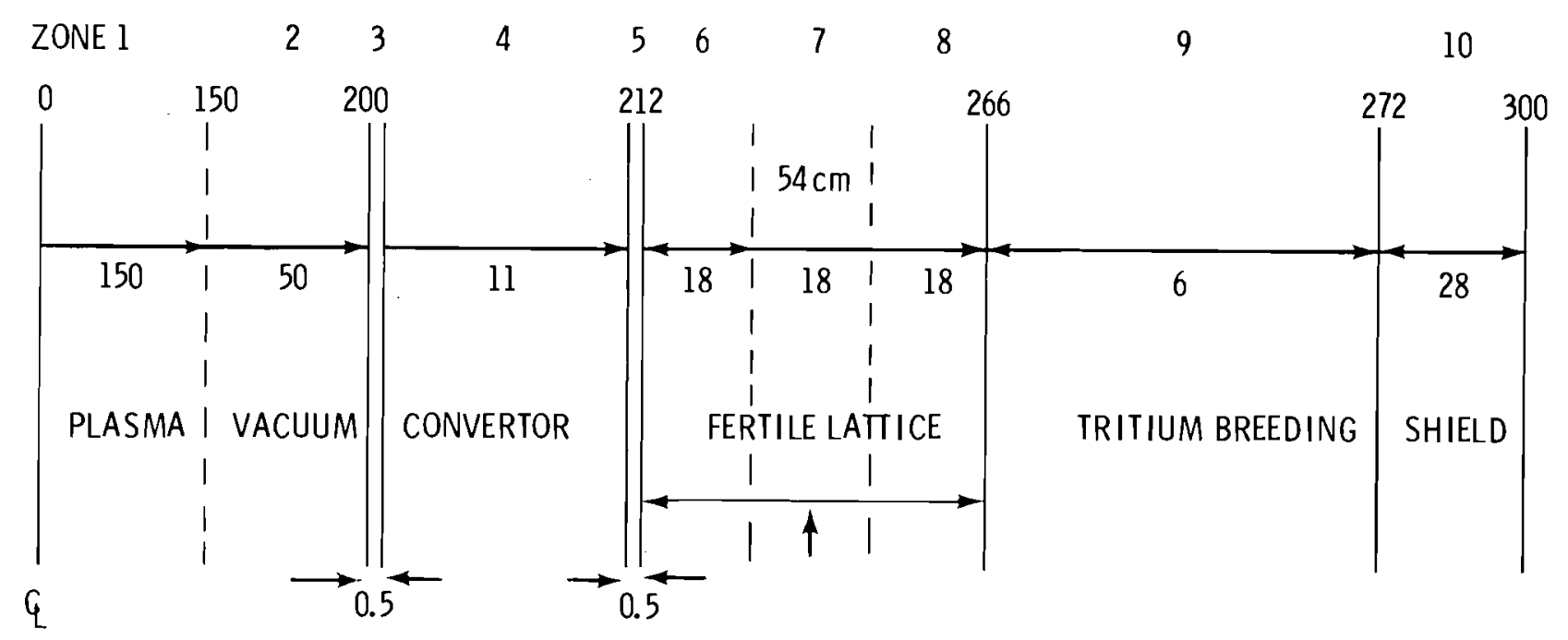

\begin{tabular}{|c|c|c|c|c|c|}
\hline CONVERTOR VOL \% & LATICE VOL \% & SHIELD & DEPLETED U & NATURAL Li & BREEDING ZONE \\
\hline $47 \% \mathrm{UO}_{2}$ & $59.7 \% \mathrm{C}$ & $100 \%$ SS & $0.3 \% 235 \mathrm{U}$ & $7.5 \% 6 \mathrm{Li}$ & $95 \% \mathrm{Li}$ \\
\hline $21 \%$ SS & $16.0 \% \mathrm{He}$ & & & $92.5 \% 7_{\mathrm{Li}}$ & $5 \%$ SS \\
\hline $32 \%$ COOLANT He & $14.4 \% \cup 0_{2}$ & & & & \\
\hline
\end{tabular}

\section{$9.9 \%$ SS}

FIGURE 47. Case 1 of TCT Hybrid Blanket Survey Calculations

Case 2, which contained only a converter and tritium breeding zone, was an attempt to improve the tritium breeding ratio. In this case, the 
neutrons produced in thick converters leaked into the tritium breeding zone. The results from this blanket are given in Table 4 and the schematic is shown in Figure 48.

TABLE 3. Neutron Production Rates Per Source for Case 1 Blanket Configuration

\begin{tabular}{|c|c|c|c|c|c|c|}
\hline & & one & & & & \\
\hline${ }^{6} \operatorname{Li}(n, a)$ & 0.0415 & 9 & & & & \\
\hline${ }^{7} L_{i}(n, a)$ & 0.00028 & 9 & & & & \\
\hline Total & 0.04178 & & & & & \\
\hline${ }^{235} U(n, f)$ & 0.02989 & 4 & ${ }^{238} U(n, f)$ & 0.2178 & $\frac{\text { Zone }}{4}$ & \\
\hline & 0.02785 & 6 & & 0.0305 & 6 & \\
\hline & 0.01470 & 7 & & 0.0066 & 7 & \\
\hline & 0.00395 & $\mathcal{E}$ & & 0.0014 & 3 & \\
\hline Total & 0.07639 & & + Total & 0.2563 & & $=0.326 \sim 66 \mathrm{Mev}$ \\
\hline${ }^{238} U(n, Y)$ & 0.7148 & 4 & & & & \\
\hline & 0.458 & 6 & & & & \\
\hline & 0.1958 & 7 & & & & \\
\hline & $\underline{0.0048}$ & 8 & & & & \\
\hline Total & 1.3734 & & & & & \\
\hline
\end{tabular}

TABLE 4. Neutron Production Rates Per Source for Case 2 Blanket Configuration

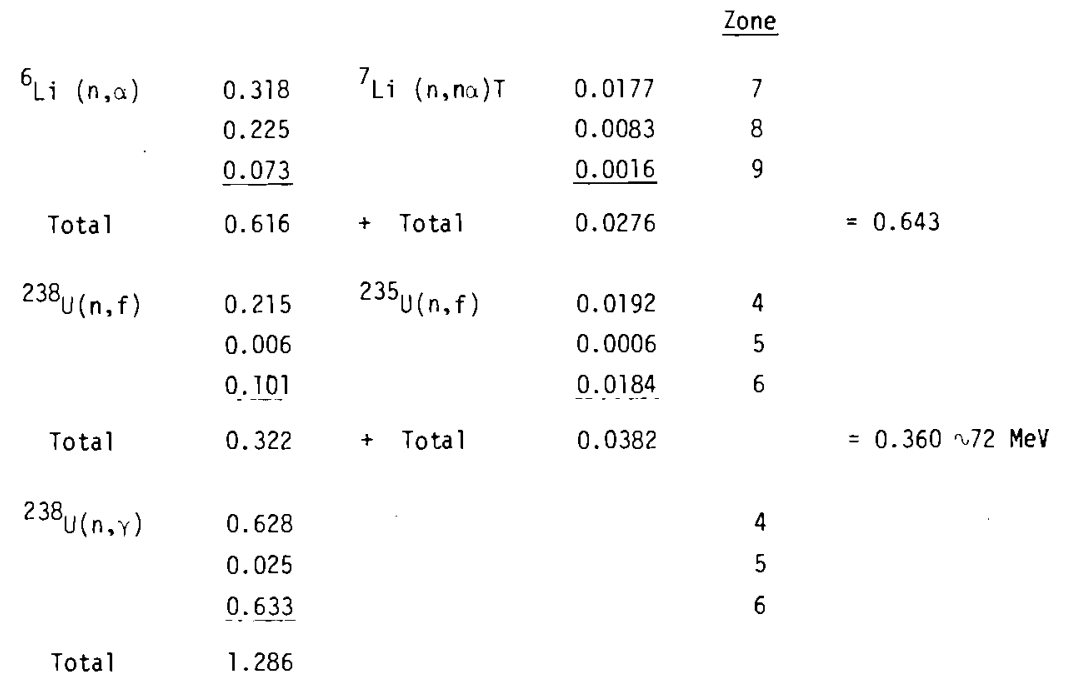




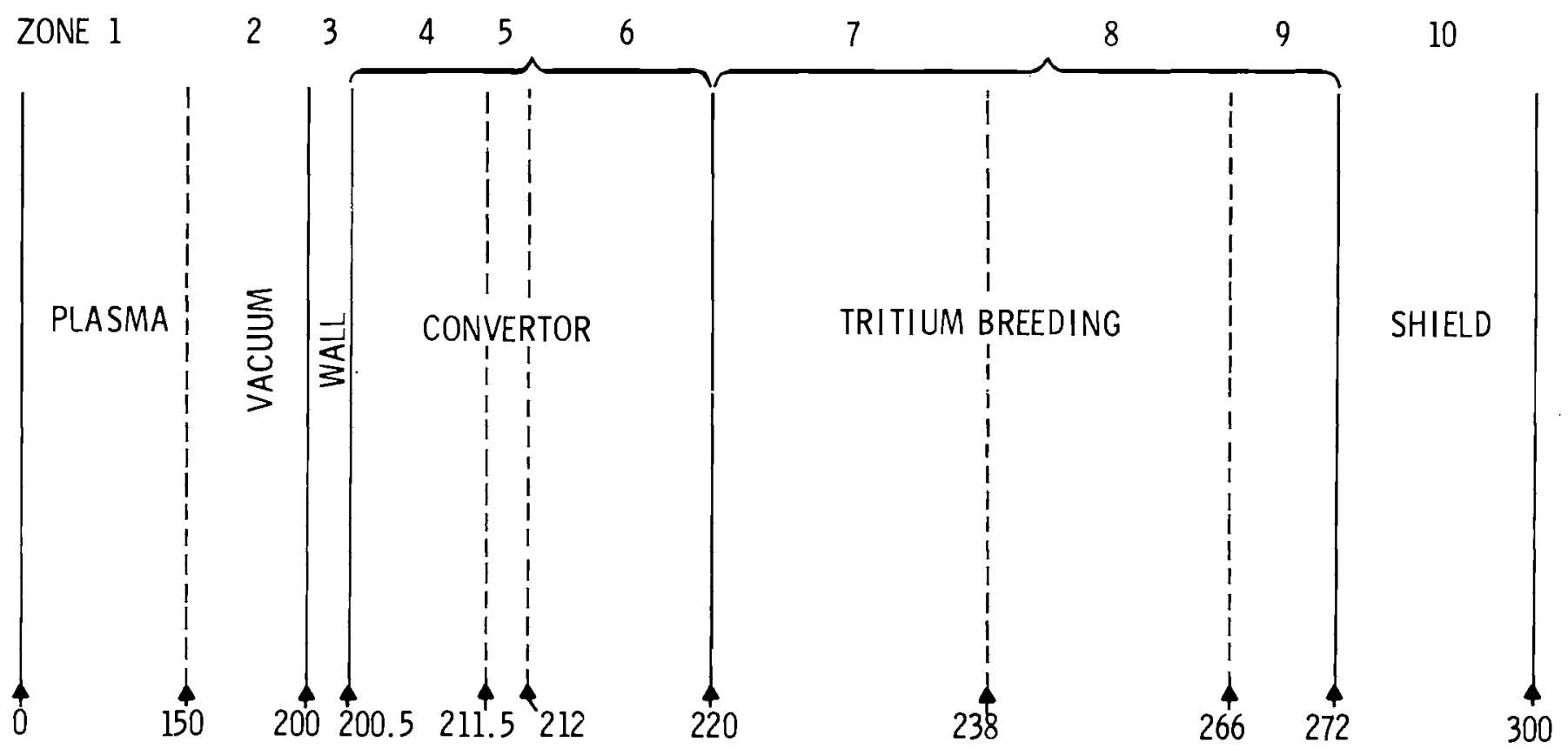

\begin{tabular}{|c|c|c|c|c|}
\hline CONVERTOR & TRITIUM BREEDING & SHIELD AND WALL & DEPLETED U & NATURAL Li \\
\hline Z 4-5-6 & Z 7-8-9 & Z 3-10 & $0.3 \% 235 U$ & $7.5 \% 6 \mathrm{Li}$ \\
\hline VOL \% & VOL \% & $100 \%$ SS & & $92.5 \% 7 \mathrm{Li}$ \\
\hline $47 \% \cup \mathrm{O}_{2}$ & $95 \% \mathrm{Li}$ & & & \\
\hline $\begin{array}{l}21 \% \mathrm{SS}^{2} \\
32 \% \mathrm{He}\end{array}$ & $5 \%$ SS & & & \\
\hline
\end{tabular}

FIGURE 48. Case 2 of TCT Hybrid Blanket Survey Conditions

In Case 3 the lattice was composed of the same material as the converter, thus representing a fast lattice. The rationale was to produce as many fast fissions as possible. Since few thermal neutrons were expected, the tritium breeding zone was placed between the converter and lattice to produce tritium from both $L i^{7}(n, n \alpha) T$ and $L i^{6}(n, \alpha) T$ reactions. A schematic of this blanket is shown in Figure 49 and the results are given in Table 5. 


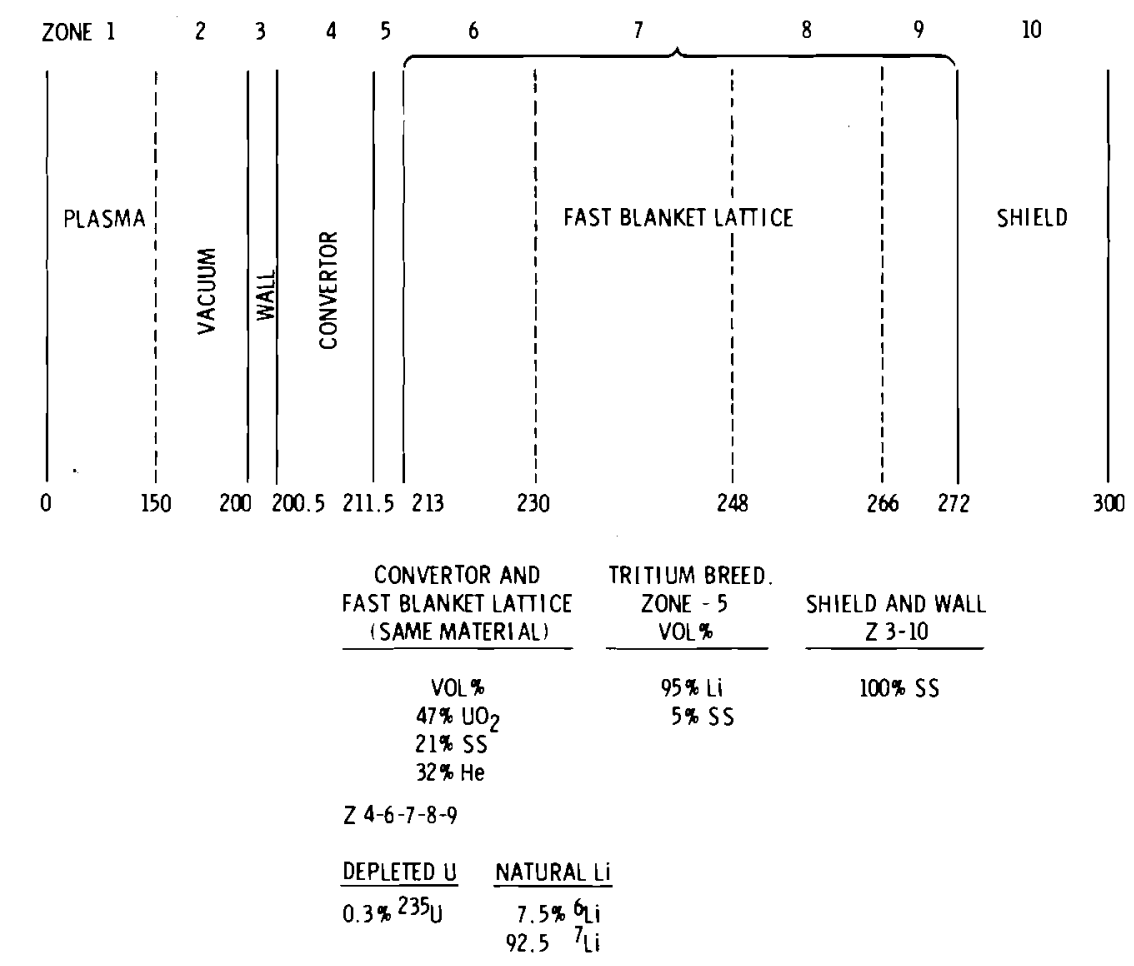

FIGURE 49. Case 3 of TCT Hybrid Blanket Survey Calculations

TABLE 5. Neutron Production Rates per Source for Case 3 Blanket Configuration

\begin{tabular}{|c|c|c|c|c|c|}
\hline \multirow{3}{*}{$\begin{array}{c}{ }_{\text {Li }(n, \alpha) T} \\
\text { Total }\end{array}$} & \multirow[b]{2}{*}{0.107} & & \multicolumn{3}{|c|}{ Zone } \\
\hline & & ${ }^{7} \mathrm{Li} \quad(n, n \alpha) T$ & 0.011 & 5 & \\
\hline & 0.108 & & & & \\
\hline \multirow[t]{5}{*}{${ }^{235} U(n, f)$} & 0.0191 & ${ }^{238} \cup(n, f)$ & 0.215 & 4 & \\
\hline & 0.0205 & & 0.0970 & 6 & \\
\hline & 0.0112 & & 0.025 & 7 & \\
\hline & 0.0047 & & 0.0057 & 8 & \\
\hline & 0.0009 & & $\underline{0.0006}$ & 9 & \\
\hline Total & 0.0564 & + Total & 0.3423 & & $=0.39 \sim 80 \mathrm{MeV}$ \\
\hline \multirow[t]{5}{*}{${ }^{238} U(n, \gamma$} & 0.631 & & & 4 & \\
\hline & 0.697 & & & 6 & \\
\hline & 0.374 & & & 7 & \\
\hline & 0.150 & & & 8 & \\
\hline & $\underline{0.028}$ & & & 9 & \\
\hline Total & 1.880 & & & & \\
\hline
\end{tabular}


These results indicate that performance increases with increased fast fission rates. In Case 1 (with its high carbon percentage in the lattice) any fast neutrons that pass through the converter or that are born of fission in the lattice are rapidly thermalized, thus reducing the number of fast fissions in the ${ }^{238} \mathrm{U}$. The fast lattice in case 3 has produced more neutrons per fusion that in Case 1, giving improved performance in terms of power and plutonium production.

\section{RESULTS PART II}

Using ANISN in a $\mathrm{S}_{8}-\mathrm{P}_{3}$ transport approximation, a new series of survey calculations using the set of infinite dilute cross sections was made. In these calculations the plasma radius was reduced to $100 \mathrm{~cm}$ and the first wall was placed at $150 \mathrm{~cm}$, which is smaller than in the previous cases. The converter blanket and shield thickness were extended to $150 \mathrm{~cm}$. The results for a fast and thermal blanket are given heré. In another concurrent study, blankets containing molten salts were investigated using the same cross section set. ${ }^{(51)}$

Figure 50 shows a schematic of the thermal blanket. The volume fractions shown are representative and do not apply to all cases.

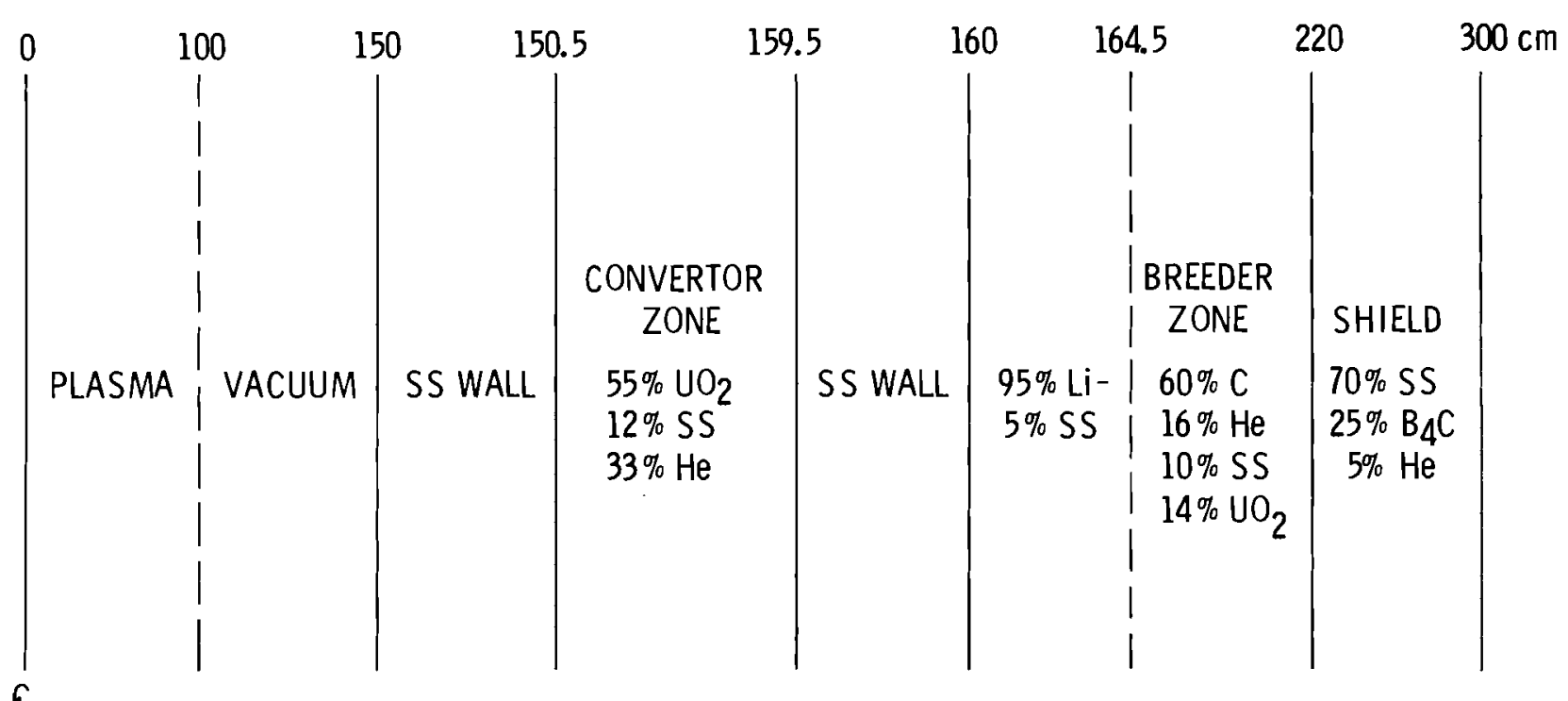

FIGURE 50. Hybrid Blanket Model 
The converter region consists of helium-cooled SS clad uranium oxide plates. When noted, some plutonium oxide is added. The breeder zone is varied from case to case in a parameter study.

In the first three cases, a $4.5 \mathrm{~cm}$ zone containing liquid natural lithium was placed between the converter and thermal lattice. In Figure 50, this is shown as a zone from 160 to $164.5 \mathrm{~cm}$. A zone of $\mathrm{SS} \mathrm{clad} \mathrm{UO}_{2}$ pins in a helium cooled carbon lattice was placed from 164.5 to $220 \mathrm{~cm}$. The $\mathrm{UO}_{2}$ was depleted to $.3 \%{ }^{235} \mathrm{U}$ in both converter and lattice. $\mathrm{PuO}_{2}$ was added to the lattice and converter in Cases 2 and 3. The results are given in Table 6 .

TABLE 6. Production Rates for Blanket with Helium-Cooled Carbon and Pin Lattice

Per Source Neutron Production Rates

\begin{tabular}{|c|c|c|c|c|c|}
\hline Case & Convert & attice & Energy & Tritium & Net \\
\hline & $\% 235 \mathrm{U}$ & $\% \mathrm{Pu}$ & Multiplication & Production & Fissile \\
\hline 1 & .3 & 0. & 4.45 & .248 & 1.45 \\
\hline 2 & .3 & .42 & 4.8 & .253 & 1.44 \\
\hline 3 & .3 & 1. & 5.4 & .261 & 1.44 \\
\hline
\end{tabular}

By increasing the size of the lithium zone, the tritium production could be made greater than one; however, this would be at the expense of fissile fuel production. The energy multiplication even with enrichment remains quite low.

In the next case considered, the converter was enriched with $1 \%$ in ${ }^{239} \mathrm{Pu}$ and the entire breeder zone $(160-220 \mathrm{~cm})$ was filled with natural liquid lithium. The results are shown in Table 7 .

TABLE 7. Production Rates for Blanket with Converter and Large Lithium Zone

Per Source Neutron Production Rates

\begin{tabular}{|c|c|c|c|c|c|}
\hline \multirow{2}{*}{$\begin{array}{l}\text { Case } \\
\text { No. }\end{array}$} & \multicolumn{2}{|c|}{ Converter } & \multirow{2}{*}{$\begin{array}{c}\text { Energy } \\
\text { Multiplication }\end{array}$} & \multirow{2}{*}{$\begin{array}{l}\text { Tritium } \\
\text { Production }\end{array}$} & \multirow{2}{*}{$\begin{array}{c}\text { Net } \\
\text { Fissile }\end{array}$} \\
\hline & $\% 235 \mathrm{U}$ & $\% \overline{\mathrm{Pu}}$ & & & \\
\hline 4 & .3 & 1. & 4.24 & 1.28 & .38 \\
\hline
\end{tabular}


In Case 4, a tritium breeding ratio greater than one was achieved, at the expense of fissile fuel production. Comparison with Case 3 shows that most of the fission occurred in the converter since the energy multiplication dropped only to 4.24 from 5.4 .

In the next two cases an attempt was made to increase the power production in the lattice. The converter was left depleted and the lattice was helium-cooled and consisted of SS clad fuel rods in a carbon matrix as in Cases 1, 2, and 3 . These results are shown in Table 8.

\section{TABLE 8. Production Rates for Enriched Lattice and Depleted Converter}

Per Source Neutron Production Rates

\begin{tabular}{|c|c|c|c|c|c|}
\hline Case & \multicolumn{2}{|c|}{ Lattice } & Energy & Tritium & Net \\
\hline No. & $\% 235$ & $\% \mathrm{Pu}$ & Multiplication & Production & Fissile \\
\hline 5 & .3 & 1. & 4.28 & .337 & 1.1 \\
\hline 6 & .3 & 2.92 & 6.14 & .353 & .977 \\
\hline
\end{tabular}

Case 5 should be compared with Case 3 . With the depleted converter, a loss in net fissile and power production occurs. The tritium breeding increases since fewer neutrons are absorbed in the depleted converter and leak into the lithium zone. In Case 6 the power production increases slowly; however, if the lithium zone were made larger to increase tritium production, it would decrease power production.

In the next two cases the breeding zone in Figure 50 was filled with SS clad fuel rods in a carbon matrix and was cooled with lithium rather than helium. Both converter and lattice had the same enrichment of fissile fuel. The results are given in Table 9.

Case 9 attempted to increase the fission rate by reducing the competition between ${ }^{239} \mathrm{Pu}$ and ${ }^{6} \mathrm{Li}$. There was a slight increase in power as compared to Case 8 , al though most of the extra neutrons were absorbed in ${ }^{239} \mathrm{U}$, increasing 
the fissile production. Comparing Case 2 to Case 7, almost identical results were obtained when placing the lithium with the fuel rather than in a separate zone (1.74 absorptions as compared to 1.69 absorptions).

A fast blanket was next considered. Figure 51 shows the blanket schematic.

TABLE 9. Production Rates for a Lithium-Cooled Lattice

Per Source Neutron Production Rates

\begin{tabular}{|c|c|c|c|c|c|c|}
\hline \multirow[b]{2}{*}{$\begin{array}{l}\text { Case } \\
\text { No. }\end{array}$} & \multicolumn{2}{|c|}{ Converter \& } & \multirow[b]{2}{*}{$\begin{array}{l}\text { Lattice } \\
\text { Coolant } \\
\end{array}$} & \multirow[b]{2}{*}{$\begin{array}{c}\text { Energy } \\
\text { Multiplication }\end{array}$} & \multirow[b]{2}{*}{$\begin{array}{l}\text { Tritium } \\
\text { Production }\end{array}$} & \multirow[b]{2}{*}{$\begin{array}{r}\text { Net } \\
\text { Fissile }\end{array}$} \\
\hline & $\frac{\mathrm{La}}{\% 235 \mathrm{U}}$ & $\frac{\mathrm{ce}}{\% \mathrm{Pu}}$ & & & & \\
\hline 7 & .3 & .42 & $\begin{array}{l}\text { Natural } \\
\text { Lithium }\end{array}$ & 4.74 & . 397 & 1.34 \\
\hline 8 & .3 & 2.92 & $\begin{array}{l}\text { Natural } \\
\text { Lithium }\end{array}$ & 7.47 & . 459 & 1.32 \\
\hline 9 & .3 & 2.92 & $\begin{array}{l}\text { Lithium } \\
\text { Depleted to } \\
1 \% \text { Li6 }\end{array}$ & 7.97 & .127 & 1.62 \\
\hline
\end{tabular}

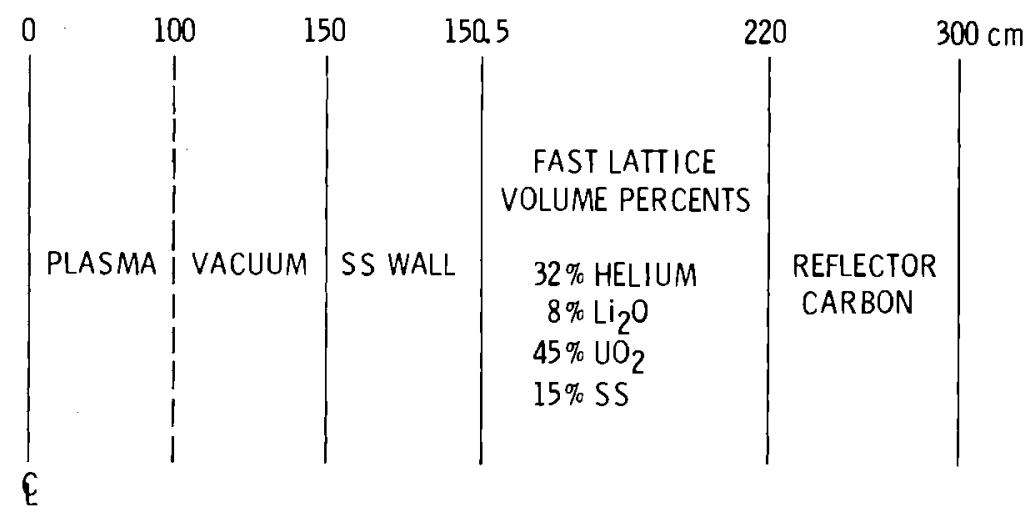

FIGURE 51. Fast Blanket Schematic

The entire blanket from 150.5 to $220 \mathrm{~cm}$ was composed of SS clad $\mathrm{UO}_{2}$ fuel rods. Eight vol\% of the blanket was composed of $\mathrm{Li}_{2} \mathrm{O}$, SS clad rods. The 
blanket was helium-cooled. Five separate cases were considered. In the first four cases the $\mathrm{UO}_{2}$ was enriched in ${ }^{235} U$. In Case $5,{ }^{235} U$ was replaced with ${ }^{239} \mathrm{Pu}$. The results are shown in Table 10.

TABLE 10. Production Rates for a Fast Blanket

\begin{tabular}{|c|c|c|c|c|c|}
\hline $\begin{array}{l}\text { Case } \\
\text { No. }\end{array}$ & $\%^{235} \mathrm{U}$ & $\mathrm{Pu}$ & $\begin{array}{c}\text { Energy } \\
\text { Multiplication } \\
\end{array}$ & $\begin{array}{c}\text { Tritium } \\
\text { Production }\end{array}$ & $\begin{array}{c}\text { Net } \\
\text { Fissile }\end{array}$ \\
\hline 10 & 3. & & 10.3 & .33 & 1.54 \\
\hline 11 & 6. & & 12.3 & .784 & .857 \\
\hline 12 & 10.6 & & 18.7 & 1.46 & .260 \\
\hline 13 & 13.92 & & Critical & & \\
\hline 14 & 0 & 10.6 & 21.0 & 1.77 & .45 \\
\hline
\end{tabular}

Energy multiplication and production rates are somewhat better in the fast lattice than the thermal lattice. For example, compare Case 10 in Table 10 with Case 8 in Table 9. The fast lattice has the higher energy multiplication - 10.3 as compared to 7.47.

In these two cases the percent of fissile fuel in the $\mathrm{UO}_{2}$ is about the same $(3.22 \%$ as compared to $3 \%)$. However, the fast lattice contains about 3 times as much $\mathrm{UO}_{2}$ as the thermal lattice. This increased volume of $\mathrm{UO}_{2}$ could be enough of an economic disadvantage to offset the increased power production when compared to the thermal lattice.

Note that substantial energy multiplication rates are found with increased enrichment. However, since there is a net plutonium production, high enrichments may not be practical since the reactor might become critical.

\section{CONCLUSION}

None of the solid blankets studied appeared to have the necessary energy multiplication and plutonium production rates, when coupled to a TCT, to produce an economically competitive reactor in the near future. These studies were instrumental in the decision to use a molten salt blanket with a uranium metal converter, which had larger production rates, and energy multiplication. 


$$
\text { - }
$$

- 


\section{BIBLIOGRAPHY}

1. ASME Boiler and Pressure Vessel Code, Section VIII, Division 2, 1974 Edition.

2. Bloom, E. E. et al., "Temperature and Fluence Limits for a Type 376 Stainless Steel Controlled Thermonuclear Reactor First Wa11." Nuclear Technology, 31, October 1976.

3. Bonanos, P. and Perkins, H. K., "The Vacuum Wa11, Radiation Damage, Structural Problems," Ch. 12 of A Fusion Power Plant. R. G. Mills, ed., Princeton PPL Report MATT-1050, 1974.

4. Brager, H. R. and Straalsund, J. L., "Defect Development in Neutron Irradiated Type 316 Stainless Steel." Journal of Nuclear Materials, 46(134-158), 1973.

5. Bushne11, D., Stress, Stability and Vibration of Complex Branched She11s of Revolution: Analysis and User's Manual for BOSOR4. Lockheed Missile and Space Company No. D243605, March 1972.

6. Cramer, B. et a1., "An Approach for Determining the Lifetime of a First Wall Strucuture in a Tokamak Reactor." Second Topical Meeting on the Technology of Controlled Nuclear Fission, Richland, WA, September 1976.

7. Hsu, T. R. et al., Theoretical Basis for a Transient Thermal ElasticPlastic Stress Analysis of Nuclear Reactor Fuel Elements. Atomic Energy of Canada, Limited, Report AECL-5233, JuTy 1976.

8. Ianniel10, L. C. (ed.), "Fusion Reactor First Wall Materials." AEC Meeting Summary, Germantown, January 1972.

9. James, L. A. and R. L. Knecht, "Fatigue-Crack Propagation in Fast Neutron Irradiated Types -304 and -376 Stainless Steels." Nuclear Technology, $\underline{19}$, September 1973.

10. James, L. A., The Effect of Elevated Temperature Upon the Fatigue Crack Propagation Behavior of Two Austenitic Stainless Steels. HEDL Report WHAN-SA-105A, 1971.

11. Kohter, W. H., Perry, R. T., Voss, J., "On the Heat Transport and Radiation Damage of a Linas CTR Blanket." Fifth Symposium on Engineering Problems of Fusion Research, Princeton, NJ, 1973.

12. Kulcinski, G. L. et al., "Wisconsin Tokamak Reactor Design," Vol. I, Chapter on Radiation Damage VI-A-I. University of Wisconsin Report, Nuclear Eng. Dept., UWFDM-68, 1974. 
13. Love11, A. J., "Effect of Fast Reactor Fluence on Postirradiation Rupture of Type 316 Stainless Steel." Nuclear Technology, 26, July 1975.

14. Nuclear Systems Materials Handbook. TID-26666, Vol. I, Design Data, Hanford Engineering Development Laboratory, 1976.

15. Roark, R. J. and W. C. Young, Formulas for Stress and Strain. Fifth edition, McGraw-Hi11, 1975.

16. Shahinian, P., Fatigue Crack Propagation in Fast Neutron Irradiated Stainless Steels and Welds. ASTM STP-570, 1974.

17. Sobel, L. H. and W. Flugge, "Stability of Toroidal Shells Under Uniform External Pressure." AIAA Journal, March 1967.

18. Soo, P. et a1., Type 304 and Type 316 Stainless Steel Data for High Temperature Design. Westinghouse Electric Company Report, WARD-3045-T-C-3, November 1972.

19. Swanson, J. A., and DeSalvo, G. J., ANSYS Engineering Analys is System User's Manual. Elizabeth, PA, 1975.

20. Tada, H., The Stress Analysis of Cracks Handbook. Del Research Corporation, Pennsylvania, 1973.

21. Tenney, F. H., A Tokamak Hybrid Study. Princeton Plasma Physics Laboratory, Princeton, NJ, 1977.

22. Wiffen, F. W. and J. O. Stiegler, "Recent Progress in CTR Bulk Radiation Effects Studies." Proceedings of the Second ANS Topical Meeting on the Technology of Controlled Nuclear Fusion, Richland, Wa, 1976, September 21-23.

23. Wiffen, F. W., "The Effects of CTR Irradiation on the Mechanical Properties of Structural Materials." Presented at ANL-AUA Faculty Institute "Cirriculum Development in Fusion," August 9-13, 1976, Argonne National Laboratory, Report No. ORNL-TM-5624, November 1976.

24. Wilson, E. L. and R. M. Jones, Finite Element Stress Analysis of Axisymmetric Solids with Orthotropic, Temperature-Dependent Material Properties. Aerospace Corporation No. TR-0158 (S3816-22)-1, Air Force Report No. BSD-TR-67-228, September 1967.

25. Wire, G. L. and Straalsund, J. L., "A Simple Method for Calculations of Steady-State Creep Rates in Nonconservative Plastic Deformation." Nuclear Technology, 30, July 1976. 


\section{REFERENCES}

1. B. R. Leonard, Jr., "A Review of Fusion-Fission Hybrid Concepts." Nucl. Tech., 20, 161 (1973).

2. B. R. Leonard, Jr., and W. C. Wolkenhauer, "Fusion-Fission Hybrids: A Subcritical Thermal Fission Lattice for a D-T Fusion Reactor, Technology of Controlled Thermonuclear Fusion Experiments and the Engineering Aspects of Fusion Reactors." CONF-721111, pp. 918-930, Apri1 1974, Proceedings of a symposium held at Austin, TX, November 20-22, 1972.

3. Pacific Northwest Laboratory Annual Reports on Controlled Thermonuclear Reactor Technology. 1971 Annual Report, BNWL-1604; 1972 Annual Report, BNWL-1685; 1973 Annual Report, BNWL-1823.

4. W. C. Wolkenhauer, PNL; B. R. Leonard, Jr., PNL; A. M. Sutey, PNL; R. W. Moir, LLL; "Conceptual Design of a Fusion-Fission Hybrid Reactor Based on a Mirror Fusion Reactor with a Subcritical Gas Cooled Fission Blanket." BNWL-SA-4865, First Topical Meeting on the Technology of Controlled Nuclear Fusion, Vo1. 1, pp. 238-255, CONF-740402-p1, San Diego, CA, Apri1 16-18, 1974.

5. W. C. Wolkenhaur, PNL; C. W. Stewart, PNL; R. W. Werner, LLL; J. D. Lee, LLL; "Some Safety Considerations of Hybrid Reactors in Comparison with Fission and Fusion Reactors." BNWL-SA-4988, First Topical Meeting on the Technology of Controlled Nuclear Fusion, Vol. 1, pp. 588-598, CONF-74042-pl, San Diego, CA, Apri1 16-18, 1974.

6. W. C. Wolkenhauer, B. R. Leonard, Jr., U. P. Jenquin, "Advances in the Development of the Mirror Hybrid (Fusion-Fission) Reactor." BNWL-SA-4961, 8 th Symposium on Fusion Technology, Noordwigkerhaut, the Netherlands, June 17-21, 1974.

7. R. W. Werner; J. D. Lee; R. W. Moir; G. A. Carlson, LLL; W. C. Wolkenhauer; B. R. Leonard, Jr.; PNL; "The Interesting Possibilities of Fusion-Fission." IAEA Fifth Conference on Plasma Physics and Controlled Nuclear Fusion Research, IAEA-CN-33/G6-1, Tokyo, Japan, November 11-15, 1974.

8. B. R. Leonard, Jr., W. C. Wolkenhauer, "Progress Toward the Development of a Mirror Hybrid (Fusion-Fission) Reactor." BNWL-SA-4932, IAEA Fifth Conference on Plasma Physics and Controlled Nuclear Fusion Research, IAEA-CN-33/G6-2, Tokyo, Japan, November 11-15, 1974.

9. High Level Radioactive Waste Management Alternatives. WASH-1297, May 1974. 
10. A. M. Platt and K. J. Schneider, editors, High-Level Radioactive Waste Management Alternatives. BNWL-1900, Battelle Pacific Northwest Laboratories, Richland, WA 99352, Vol. I, II, III, and IV, May 1974.

11. W. C. Wolkenhauer, B. R. Leonard Jr., and B. F. Gore, Transmutation of High-Level Radioactive Waste with a Controlled Thermonuclear Reactor. BNWL-1772, Battelle Pacific Northwest Laboratories, Richland, WA 99352 , September 1974.

12. B. F. Gore and B. R. Leonard, Jr., "Transmutations of Massive Loadings of Cesium-137 in the Blanket of a Controlled Thermonuclear Reactor." Nucl. Sci. and Eng., 53, (319) 1974.

13. W.C. Wolkenhauer, et a1., "Status Report: Mirror Hybrid Reactor Studies." BNWL-1835, Battelle, Pacific Northwest Laboratories, Richland, WA 99352, November 1974.

14. D. E. Deonigi, "Economic Regimes for Fission-Fusion Energy Systems." pp 93-115, DCTR Fusion-Fission Energy Systems Review Meeting, ERDA-4.

15. R. C. Liikala, et al., "Review of Batelle-Northwest Technical Studies on Fusion-Fission (Hybrid) Energy Systems." pp 117-171, DCTR Fusion-Fission Energy Systems Review Meeting, ERDA-4.

16. U. P. Jenquin and B. R. Leonard, Jr., "Actinide Transmutation in Fusion Reactor Blankets." Trans. Am. Nucl. Soc., 23(549), 1976.

17. R. C. Liikala, et al., Evaluations of Fusion-Fission (Hybrid) Concepts. Electiric Power Research Institute Report ER-479-SY, EPRI, Palo Alto, CA, February 1976.

18. U. P. Jenquin and B. R. Leonard, Jr., Transmutation of High-Level Actinide Waste in Hybrids. Electric Power Research Institute Report, ER-469, EPRI, Palo Alto, CA, February 1976.

19. D. E. Deonigi and R. L. Engle, Market Penetration Analys is for FusionFission Hybrids. Electric Power Research Institute Report, ER-469, EPRI, Palo Alto, CA, February 1976.

20. D. E. Deonigi and R. L. Engel, Performance Targets for Fusion-Fission Hybrid Reactors. BNWL-2139, Battelle, Pacific iNorthwest Laboratories, Richland, WA 99352, January 1977.

21. J. M. Dawson, H. P. Furth, and F. H. Tenney, Phys. Rev. Let. 26, 1156, 1971 .

22. TCT Two Component Torus Joint Conceptual Design Study, Vol. I-III. Plasma Physics Laboratory, Princeton, NJ and Nuclear Energy Systems Division, Westinghouse Corporation, Pittsburgh, PA, 1974. 
23. D. Bushne11, Stress, Stability and Vibration of Complex Branched Shells of Revolution: Analys is and Users Manual for BOSOR4. Lockheed Missile and Space Company No. D243605, March 1972.

24. A. J. Love11, "Effect of Fast Reactor Fluence on Post-Irradiation Rupture of Type 316 Stainless Stee1." Nuclear Technology, 26, July 1975.

25. F. H. Tenney, A Tokamak Hybrid Study. Plasma Physics Laboratory, Princeton, NJ, 1976.

26. P. Bonanos and H. K. Perkins, "The Vacuum Wa11, Radiation Damage, Structural Problems," Ch. 12 of A Fusion Power Plant. G. Mills, ed., Princeton PPL Report MATT-1050, 1974.

27. H. R. Brager and J. L. Straalsund, "Defect Development in Neutron Irradiated Type 316 Stainless Steel." Journal of Nuclear Materials, 46, 134-158, 1973.

28. W. H. Kohler, R. T. Perry, J. Voss, "On the Heat Transport and Radiation Damage of a Linas CTR Blanket." Fifth Symposium on Engineering Problems of Fusion Research, Princeton, NJ, 1973.

29. Nuclear Systems Materials Handbook. TID-26666, Vo1. I, Design Data, Hanford Engineering Development Laboratory, 1976.

30. G. L. Kulcinski, et a1., "Wisconsin Tokamak Reactor Design," Vo1. 1, Chapter on Radiation Damage VI-A-I. University of Wisconsin Report, Nuclear Engineering Department, UWFDM-68, 1974.

31. E. E. Bloom, et a1., "Temperature and Fluence Limits for a Type 316 Stainless Steel Controlled Thermonuclear Reactor First Wa11." Nuclear Technology, Vo1. 31, October 1976.

32. L. A. James, "Fatigue-Crack Propagation in Fast Neutron Austenitic Types - 304 and -316 Stainless Steels." Atomic Energy Review, 14, 1976.

33. L. A. James, and R. L. Knecht, "Fatigue-Crack Propagation in Fast Neutron Irradiated Types - 304 and -316 Stainless Steels." Nuclear Technology, 19, September 1973.

34. P. Shahinian, Fatigue Crack Propagation in Fast Neutron Irradiated Stainless Steels and Welds. ASTM, STP-570, American Society of Testing Materials, 1974.

35. P. Soo et a 1., Type 304 and Type 316 Stainless Steel Data for High Temperature Design. WARD-3045-T-2c-3, Westinghouse Electric Company Report, Richland, WA 99352, November 1972. 
36. L. H. Soble and W. Flugge, "Stability of Toroidal Shells Under Uniform External Pressure." AIAA Journal, March 1967.

37. E. L. Wilson and R. M. Jones, Finite Element Stress Analyses of Axisymmetric Solids with Orthotropic, Temperature-Dependent Material Properties. Aerospace Corporation No. TR-0158 (S3816-22)-1, Air Force Report No. BSD-TR-67-228, September 1967.

38. R. J. Roark and W. C. Young, Formulas for Stress and Strain. McGrawHill, 1975.

39. G. L. Wire and J. L. Straaslund, "A Simple Method for Calculations of Steady-State Creep Rates in Nonconservative Plastic Deformation." Nuclear Technology, 30, July 1976.

40. C. L. Wheeler et al., COBRA-IV-I: An Interim Version of COBRA for Thermal Hydraulic Analys is of Rod Bundle Nuclear Fuel Elements and Cores. BNWL-1962, Battelle, Pacific Northwest Laboratories, RichTand, WA 99352, March 1976.

41. Fort St. Vrain FSAR, Public Service Company of Colorado.

42. R. G. Adams et al., HTGR Gas Turbine Power Plant Configuration Studies. ASME Transactions, paper 73-WA/Pwr-7, American Society of Mechanical Engineers, 1973.

43. A. Tiberni, Operational Limits for Gas Turbine Compressors during Transient Conditions in a Helium Cooled Reactor. American Society of Mechanical Engineers, ASME Transactions, paper 74-GT-61, 1974.

44. W. W. Engle, Jr., A Users Manual for ANISN, A One-Dimensional Discrete Ordinates Transport Code with Anisotropic Scattering. K-1693, Oak Ridge Nationa1 Laboratory, 1967.

45. H. C. Honeck, ENDF/B, Specifications for an Evaluated Nuclear Data File for Reactor Applications. BNL-50066, USAEC, 1966.

46. D. E. Kusner, R. A. Dannels, and J. Kellman, ETOG-I, A Fortran IV Program to Process Data from the ENDF/B File to the MUFT, GAM, and ANISN Formats. WCAP-3845-1, ENDF-114, December 1969.

47. C. R. Richey, EGGNIT: A Multigroup Cross Section Code. BNWL-1203, Pacific Northwest Laboratories, Richland, WA 99352, November 1967.

48. C. L. Bennett, GRANIT: A Code for Calculating Position Dependent Thermal Neutron Spectra in Doubly Heterogenous Systems by the Integral Transport Method. BNWL-1634, Pacific Northwest Laboratories, Richland, WA 99352, November 1971.

49. 100 Group Neutron Cross-Section Data Based on ENDF/B. DLC-2F, RSIC Data Library Collection, Oak Ridge, TN. 
50. B. R. Leonard, et a1., Status Report Mirror Hybrid Reactor Studies. BNWL-1835, Pacific Northwest Laboratories, Richland, WA 99352, November 1974.

51. D. L. Chapin, Molten Salt Blanket Calculations for a Tokamak FusionFission Hybrid Reactor. MATT 1236, Princeton Plasma Physics Laboratory, Princeton, NJ, Apri 1976. 
APPENDIX A 


\section{THEORY/EXPERIMENT CORRELATION IN URANIUM}

METAL USING A $14 \mathrm{MeV}$ NEUTRON SOURCE

The initial ground rules for the conceptual design of the TCT Hybrid were: 1) optimize production of fissile material, 2) constrain the technology for constructing a machine to that available in the early 1990's, and 3) minimize the capital costs.

Thus, one of the early critical items was an establishment of a minimum shield thickness to protect the inner core of the toroidal field coils. This was necessary because it would be a prime factor in establishing the size of the fusion device, which affects the available blanket volume and capital cost. These parameters are directly related to the initial ground rules.

of particular concern to establishment of a minimum thickness shield was the finding that the present preparation of neutron cross-section "data sets" used in ANISN are inadequate for $14 \mathrm{MeV}$ neutrons. (A-1) The most important deficiency is that the forward peaking of the elastic scattering data is not properly handled, causing underestimation of the penetration of high energy neutrons in the blanket and the shield. The discrepancy between calculated and measured results is probably caused by the substantial negative components of the differential scattering cross section in the forward direction. This can be seen from the data given in Figure $A-1$, which shows the angular dependence of the $14 \mathrm{MeV}$ cross section for ${ }^{238} \mathrm{U}$ modeled with different numbers of terms in the Legendre expansion. The existence of negative values for the differential cross section is nonphysical. The values given on ENDF/B-IV are a $P_{20}$ representation. A low order angular model is desirable in design calculations to keep the cost of the computer runs within reason.

As shown in Figure $A-1$, the $P_{9}$ representation, for example, does improve modeling of the forward-directed peak relative to $P_{3}$, but the $P_{9}$ representation also has substantial negative values at a more forward directed angle 
than the lower order Legendre representations. This could explain why the higher order Legendre model actually resulted in slightly less high energy flux ralculated at several mean free paths from the source. We believe that the Legendre order in the calculations will have to be increased to near $P_{19}$ before the cross section is everywhere positive.

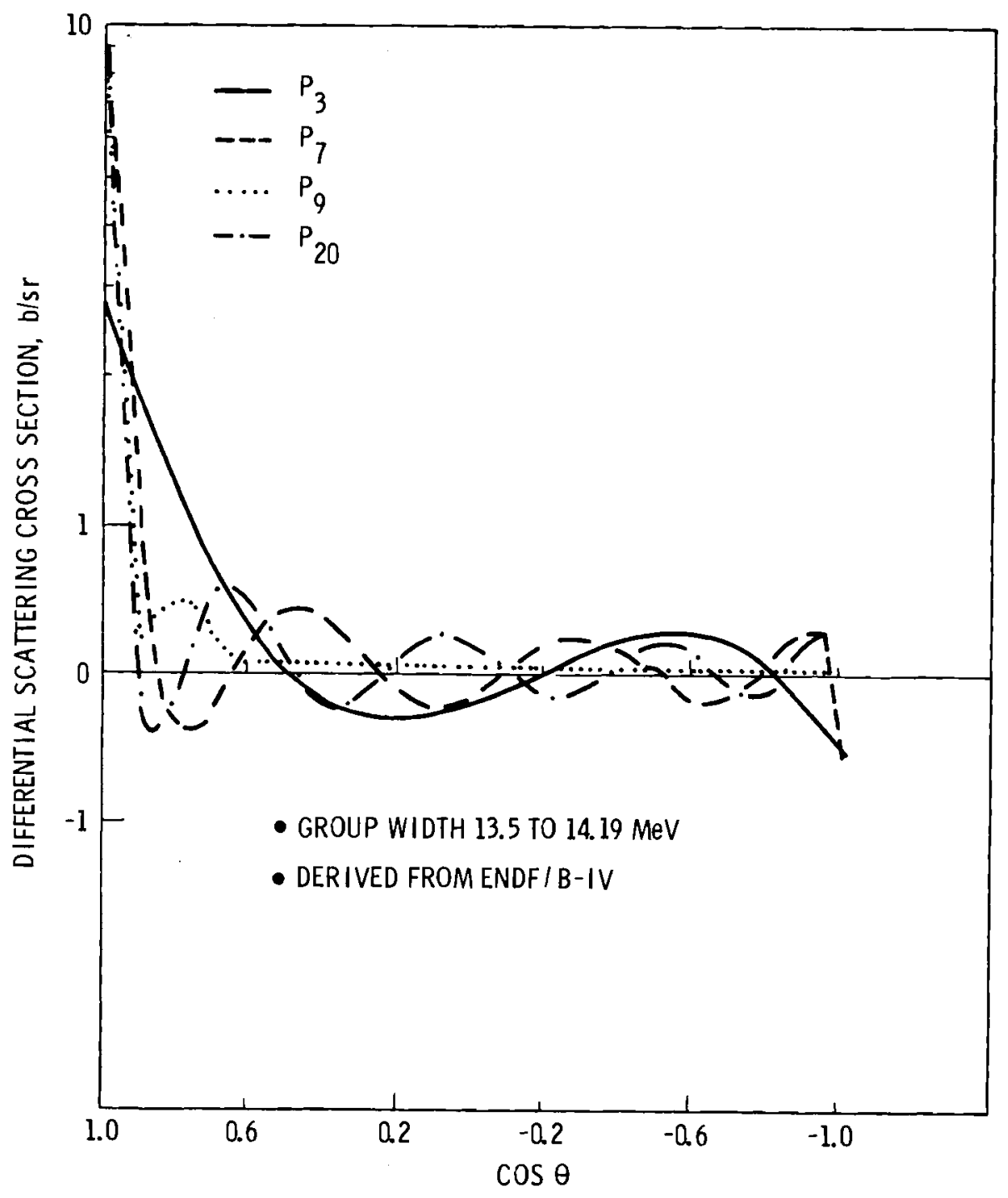

FIGURE A-1. Angular Dependence of the $14 \mathrm{MeV}$ Cross Section for $238 \mathrm{U}$ 
Thus, at the beginning of the TCT Hybrid study, PNL focused on early resolution of this problem. The first step was to determine what bias existed in our current data sets. Comparisons of calculated and measured values were necessary for making this determination.

Experimental measurements of the spatial distribution of several nuclear reactions in a natural uranium assembly driven by a central D,T $14 \mathrm{MeV}$ neutron source were reported by Weale, et al. ${ }^{(A-2)}$ The results of these measurements have been used as a calculational benchmark of methods and nuclear data by investigators $(A-3)$ of concepts of fusion-fission hybrid devices. $(A-4)$ In our own studies of a mirror hybrid device we also reported $(A-1)$ the results of this benchmark calculation using nuclear data from ENDF/B-III.

For the TCT Hybrid, new benchmark caiculations, using a different set of nuclear data, $(A-5)$ were made using the Weale experiment as a basis. This resulted in a modification of the previous interpretation of the comparison given in the mirror hybrid study.

These calculations were performed using a 30-energy group structure in a $\mathrm{P}_{3} \mathrm{~S}_{8} \mathrm{ANISN}(\mathrm{A}-6)$ calculation. In the experiment of Weale, et al., the central $14 \mathrm{MeV}$ neutron source was introduced through a rectangularshaped reentrant hole as shown in Figure A-2. The ANISN calculation did not reproduce this geometry but used a central spherical void. Weale, et al., presented their results graphically as the reaction rate multiplied by the square of the distance from the source. We made our original comparison in the same manner. The calculated rates were compared as a function of the distance from the central void surface of uranium to the experimental rates as a function of the distance from the interior surface of uranium in the direction of the measurements. The comparison in this manner is illustrated on Figure $A-3$ with the ${ }^{63} \mathrm{Cu}(n, 2 n)$ results. The experimental results taken in different directions became more consistent. 


\section{EXPERIMENT CONFIGURATIONS}

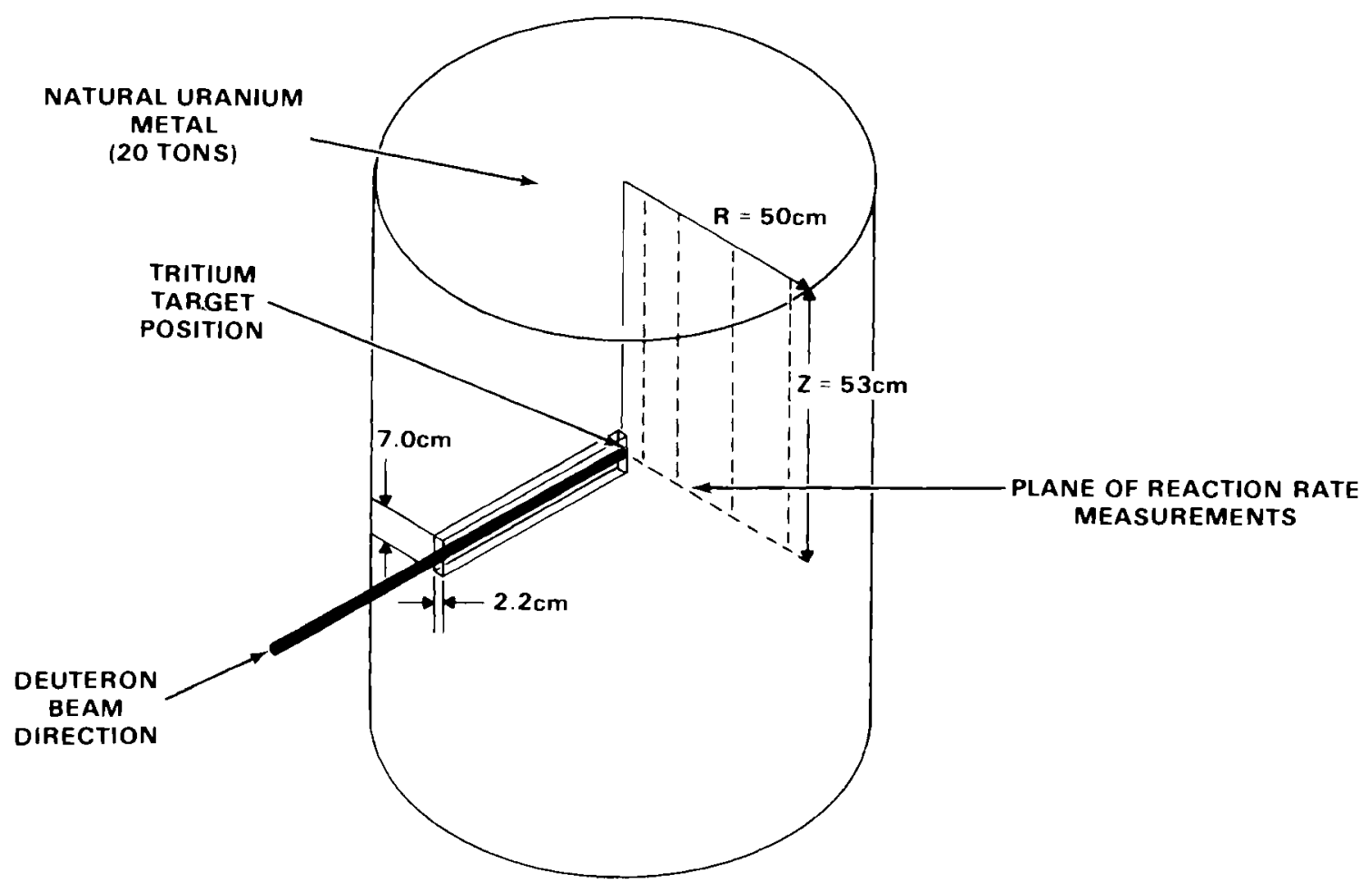

FIGURE A-2. Experiment Configuration

The ${ }^{63} \mathrm{Cu}(n, 2 n)$ reaction has a threshold of $11 \mathrm{MeV}$. Thus, the secondary neutrons resulting from nonelastic events are essentially all born below the threshold for this reaction in either the ENDF/B-III or the ENDF/B-IV descriptions of ${ }^{238} U$ data. For both data we observed, as shown in Figure A-3, a systematic underprediction of this reaction rate which corresponds to an underprediction in the penetration of near $14 \mathrm{MeV}$ neutrons in uranium. The effect is about 15\% in the exponential attenuation factor, which is much larger than the uncertainty in the total nonelastic or elastic cross sections. We interpreted this to mean that the $\mathrm{P}_{3} \mathrm{~S}_{8}$ approximation is not adequate to give an accurate prediction of this benchmark experiment. Further calculations were performed in an attempt to define adequate calculational methods and the extent of deficiencies in ${ }^{238} U$ data descriptions. 


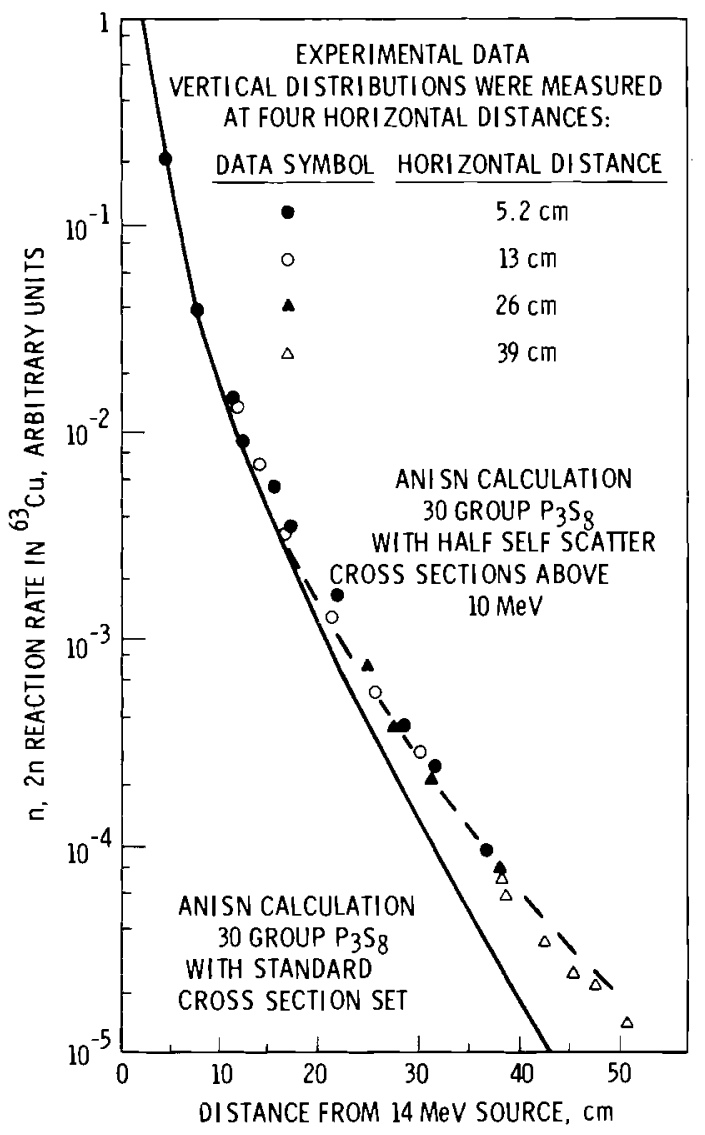

FIGURE A-3. Distribution of $n, 2 n$ Reaction Rate in ${ }^{63} \mathrm{Cu}$

An explanation for the underprediction in the penetration of near $14 \mathrm{MeV}$ neutrons in uranium is illustrated in Figure A-4 by the comparison of the ${ }^{238} \mathrm{U}$ differential scattering cross-section description of ENDF/B-IV given by the $P_{20}$ Legendre expansion to the description truncated at $P_{3}$. The differential scattering cross section is highly forward-peaked and is near zero (but always positive) for values of $\cos \theta$ less than about 0.9. The $P_{3}$ description is less forward-peaked, takes on negative values in the forward direction, and takes on positive values an order of magnitude too large in the backward direction. Since elastic scattering in uranium involves very little energy loss, a reduction of the self-scattering (in-group) cross section of uranium provides a simple way to correct the principal deficiency of the $P_{3}$ description, by increasing the forward peaking of the angular neutron flux. 


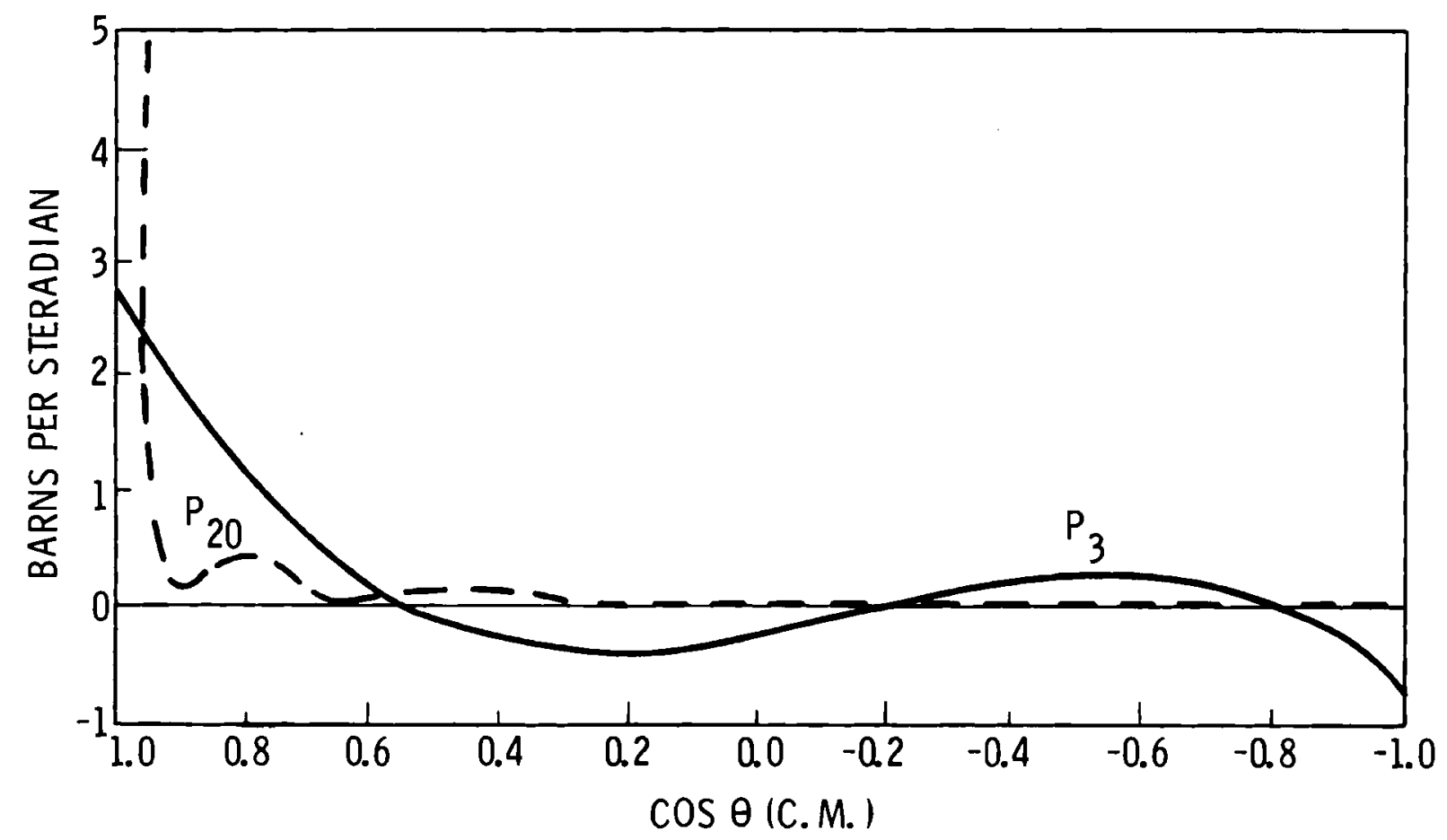

FIGURE A-4. Uranium-238 Differential Scattering Cross Section at $14 \mathrm{MeV}$

Reducing the self-scatter cross sections above $10 \mathrm{MeV}$ to half their values in $P_{3} S_{8}$ ANISN calculations correlates well with the measured ${ }^{63} \mathrm{Cu}$ $(n, 2 n)$ reaction rate distribution, as shown in Figure A-3. Similar improvement in the theory/experiment correlation is illustrated in Figure A-5 with the ${ }^{238} U$ fission results, when the half self-scatter values were used above $10 \mathrm{MeV}$ in the calculations. Extending the half self-scatter values down to $0.8 \mathrm{MeV}$ shows a poorer agreement between calculations and measurements. 


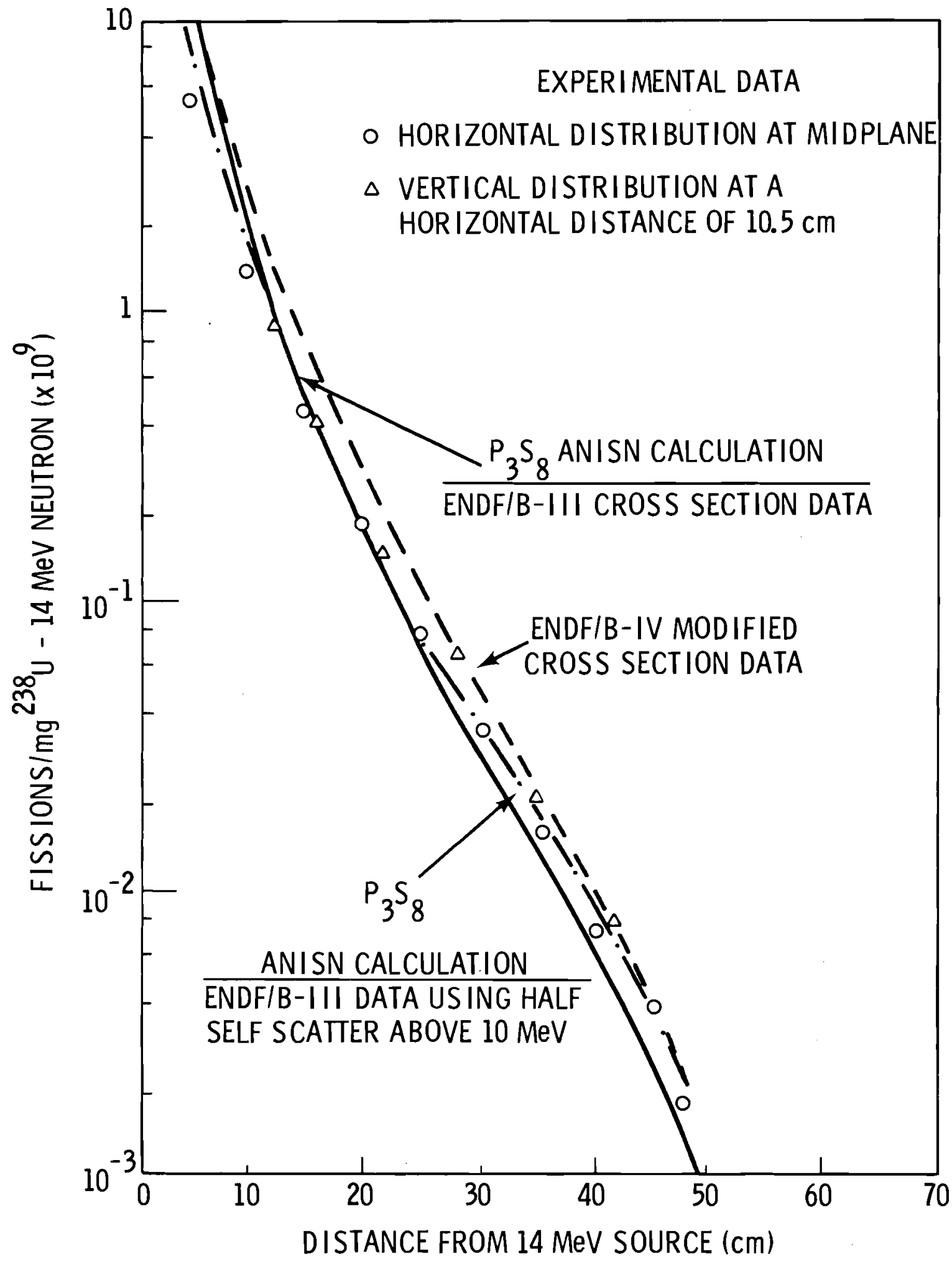

FIGURE A-5. Distribution of ${ }^{238} U$ Fission Rate 


\section{REFERENCES}

A-1. W. C. Wolkenhauer, B. R. Leonard, Jr., U. P. Jenquin, D. F. Newman, A. M. Sutey, C. W. Stewart, D. L. Prezbindowski, R. W. Moir, J. D. Lee and R. W. Werner, Status Report: Mirror Hybrid Reactor Studies. BNWL-1835, Appendi $\mathrm{x}$ B, Batte17e, Pacific Northwest Laboratories, Richland, WA, June 1974.

A-2. J. W. Weale, H. Goodfellow, M. H. McTaggart and M. L. Mullender, "Measurements of the Reaction Rate Distribution Produced by a Source of $14 \mathrm{MeV}$ Neutrons at the Centre of a Uranium Metal Pile." Reactor Science and Technology (Journal of Nuclear Energy, Parts A and B), Vol. 14, pp. 91-99, Pergamon Press Ltd., Northern Ireland.

A-3. J. D. Lee, "Neutronics of Sub-Critical Fast Fission Blankets for D-T Fusion Reactors." Proc. 7th Conf. Intersociety Energy Conversion Engineering, p. 294, American Chemical Society, 1972.

A-4. B. R. Leonard, Jr., "A Review of Fusion-Fission (Hybrid) Concepts." Nuclear Technology, 20, pp. 161-178, 1973.

A-5. D. F. Newman and B. R. Leonard, Jr., "Correlation of Reaction Rates in Uranium Metal Using a $14 \mathrm{MeV}$ Neutron Source." Trans. Am. Nucl. Soc., 21:69, 1975.

A-6. W. W. Engle, Jr., A User's Manual for ANISN, A One Dimensional Discrete Ordinates Transport Code with Anisotropic Scattering. K-1696, 0ak Ridge National Laboratory, March 1967.

A-7. R. J. Howerton and M. H. MacGregor, Evaluated Neutron Reaction Data for Uranium-238. UCRL-51427, Lawrence Livermore Laboratory, July 1973.

A-8. B. R. Leonard, J. K. Thompson, Nuclear Data, Report on Controlled Thermonuclear Reactor Technology, January 1975 - September 1975. BNWL-1939-1, Battelle, Pacific Northwest Laboratories, Richland, WA 99352 , October 1975. 
APPENDIX B 


\section{APPLICATION OF THE COBRA-IV THERMAL-HYDRAULIC CODE TO THE ANALYSIS OF TCT HYBRID CONVERTER TUBES}

The COBRA-IV computer program $(B-1)$ being developed at the Pacific Northwest Laboratory by Battelle-Northwest is an extended subchannel analysis code that computes the flow and enthalpy distributions in nuclear fuel rod bundles and cores for both steady-state and transient conditions. It is a very powerful tool because it can be applied to the most complicated fuel configuration with relative ease.

The basic concept of subchannel analysis considers a nuclear fuel rod bundle to be divided into subchannels whose boundaries are defined by the adjacent fuel rod surfaces. The subchannels are divided axially into discrete control volumes for which the equations for continuity, energy, and momentum are written. Volume or surface averages were used to define dependent variables of mass flow rate, pressure, enthalpy and density. The transient thermal response of the fuel or solids is included and is interfaced with the hydraulics through heat transfer coefficients.

The COBRA-IV code contains two numerical solution methods. One is an implicit technique similar to that used in COBRA-IIIC; ${ }^{(B-2)}$ the other, an explicit method, is new.

In general, the implicit scheme is used for steady-state and long term transient simulation. The explicit method is used for transients where flows are expected to reverse flows or circulate. Both solution methods made use of the same models to simulate the fuel rods and conducting walls. The fuel conduction model uses the method of weighted residuals by the orthogonal collocation technique. ${ }^{(B-3)}$

The basic equations of the mathematical fluid low model are derived by applying the general equations of continuity, energy, and momentum to a subchannel control volume. The equations are: 
Continuity

$$
A \frac{\partial \rho}{\partial t}+\frac{\partial m}{\partial x}+[D C]^{\top} w=0
$$

Energy

$$
A \frac{\partial \rho h}{\partial t}+\frac{\partial m h}{\partial x}+[D C]^{\top} h * w=q^{\prime}
$$

Axial Momentum

$$
\frac{\partial m}{\partial t}-\frac{\partial m u}{\partial x}+[D C]^{\top} u^{\star} w+A \frac{\partial P}{\partial x}=F
$$

Transverse Momentum

$$
\frac{\partial w}{\partial t}-\frac{\partial u^{\star} w}{\partial x}=\frac{\partial v_{y} w}{\partial y}-[D C] P=c
$$

In the above equations, $[D C]$ is a matrix operator which performs the lateral finite difference operation between subchannels, [DC $]^{\top}$ is the transpose of $[D C]$ and performs a summing operation instead of differencing, $F$ is the axial friction and gravity force, $c$ is the lateral friction force, and $q^{\prime}$ is the heat transfer to the coolant from all sources.

In addition to the conservation equations, it is necessary to specify fluid properties and constitutive equations to form a closed set of equations for solution. In COBRA, specifications are required for axial and lateral friction or form losses, heat transfer coefficients, coefficients for turbulent exchange, slip ratio, and an equation of state for an incompressible but thermally expanding fluid. This is written as:

$$
\rho=\rho\left(h, p^{*}\right)
$$

where $P^{\star}=$ reference pressure.

The fuel conduction model in COBRA-IV is derived from the two-dimensional heat conduction equation. This equation is written below for both planar and cylindrical geometry with the radial coordinate nondimensionalized, using the relationship $r=r^{\prime} R\left(r^{\prime}\right.$ - radial coordinate and $R=$ fuel radius): 


$$
\begin{aligned}
& \rho c \frac{\partial T}{\partial t}=\frac{1}{R^{2}} \frac{1}{r^{a-1}} \frac{\partial}{\partial r} r^{a-1} K(T) \frac{\partial T}{\partial r}+\frac{\partial}{\partial x} K(T) \frac{\partial T}{\partial x}+q \\
& a=1 \text { Planar } \\
& a=2 \text { Cylindrical }
\end{aligned}
$$

Equation 1 is reduced to a linear partial differential equation by introducing Kerchoff's transformation for temperature dependent thermal conductivity. The fuel is assumed to be surrounded by a cladding modeled by a lumped parameter version of equation 6 :

$$
\rho c \frac{\partial T_{c}}{\partial t}+K_{c} \frac{\partial^{2} T_{c}}{\partial x^{2}}+H_{g} \frac{R}{t_{c} R_{c}}-\left(T_{f}-T_{c}\right)-\frac{H_{s}}{t_{c}}\left(T_{c}-T_{s}\right)=0
$$

where $\mathrm{H}_{\mathrm{g}}$ represents the combined conductance of the clad and the fuel-clad gap, $H_{S}$ is the outer surface coefficient and $t_{c}$ is the clad thickness. Equations 6 and 7 are solved by a combination of the method of weighted residuals and finite difference techniques. A lumped parameter model similar to Equation 7 is also provided for modeling heat conducting walls.

For a complete explanation of the code construction and solution methods, refer to the COBRA-IV Users Manual. (B-1) Two major changes to COBRA modeling were required to study the TCT converter. A convenient means to input ideal gas properties was developed and the fuel model was converted to cylindrical she11 geometry.

When the fluid is below saturation temperature, the properties are found as a function of enthalpy by a direct table lookup ignoring pressure dependence. To incorporate ideal gas properties, this table is calculated from an input gas constant, prandt 1 number, specific heat and viscosity temperature function. The density is found with the ideal gas equation of state at the reference pressure and the temperature is related to enthalpy directly by the specific heat which is assumed constant. The thermal conductivity is computed from the input prandtl number, specific heat, and viscosity function. Thus only the viscosity, conductivity, density, and of course, enthalpy, vary with temperature. 
The saturation properties are set arbitrarily to very high values so the code will always think the fluid is subcooled. This limits velocities to under about 0.2 mach so the incompressible assumption will hold.

The original COBRA fuel model is built around a symmetric material configuration. That is, one of the boundary conditions is a plane or line of symmetry where $\partial T / \partial r=0$. For the TCT hollow U-Mo slug, this is not applicable. The modification involved considering an inner clad, gap conductance and surface coefficient as well as the original outside clad.

Aside from rather complex changes in the computation logic, no difficulties were encountered. The capability to consider temperature dependent thermal conductivity was a casualty, however, since time did not permit application of the Kerchoff transformation to the new nonsymmetric MWR system.

TABLE B-1. COBRA-IV Input Data for TCT Hybrid Converter

1. Hel ium Properties

Temperature range - $500^{\circ} \mathrm{F}-2000^{\circ} \mathrm{F}$

Pressure - 750 psia

Inlet temperature - $579^{\circ} \mathrm{F}$

Gas constant - $386 \mathrm{ft}-1 \mathrm{~b}_{\mathrm{f}} / \mathrm{LB} \mathrm{B}_{\mathrm{ri}}=\mathrm{R}$

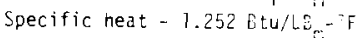

Prandt number - 0.7

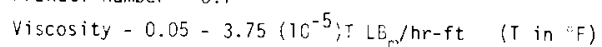

2. Correlations

Friction factor $-0.316 \mathrm{e}^{-0.25}$

Heat transfer coefficient ${ }^{2}=0.023 \frac{K}{O_{h}} R^{0.8} \mathrm{Pr}^{0.4}$

3. Geometry

a. Channel Data

$$
\begin{array}{lccc}
\text { Area } & \begin{array}{c}
\text { Wetted } \\
\text { No. }
\end{array} & \begin{array}{c}
\text { Heated } \\
\text { (in.2) }
\end{array} & \begin{array}{c}
\text { Perim.(in.) } \\
\text { Perim.(in.) }
\end{array} \\
1 & 0.686 & 2.936 & 2.936 \\
2 & 1.935 & 16.38 & 7.455 \\
\text { Length - } 384 & \text { in. (16 axial divisions) }
\end{array}
$$

b. Fuel Data

Inner dia. 0.945 in.

\begin{tabular}{|c|c|c|}
\hline Properties & Fuel $\left(U-M_{0}\right)$ & Clad (55) \\
\hline $\begin{array}{l}\text { density }\left(1 \mathrm{~b} / \mathrm{ft}^{3}\right) \\
\text { heat capacity }\left(\mathrm{Btu} / \mathrm{Ib}^{\mathrm{O}} \mathrm{F}\right) \\
\text { conductivity }\left(\mathrm{Btu} / \mathrm{hr}-\mathrm{ft}-{ }^{\circ} \mathrm{F}\right)\end{array}$ & $\begin{array}{c}1050 \\
0.04 \\
16.0\end{array}$ & $\begin{array}{c}497 \\
0.14 \\
12.0\end{array}$ \\
\hline
\end{tabular}

Outer dia. $2.331 \mathrm{in}$.

Clad thickness -0.02 in.

Gap conductance - infinite 
With the above modification completed, the TCT converter tubes were quite easy to model with COBRA as two flow channels with one on either side of the hollow fuel slug. No hydraulic connection was made because of the lack of design information, but the isolation of the channels is conservative in this case. The COBRA input parameteras are listed in Table B-1 for a typical case run.

Once the model changes were stabilized, a full operational cycle of 1100 seconds required on $1 y$ about 3 seconds execution time on a CDC 7600 machine. In this case, COBRA-IV proved an effective analysis tool. 


\section{REFERENCES}

B-1. C. L. Wheeler et a 1., COBRA-IV-1: An Interim Version of COBRA for Therma 1-Hydraulic Analysis of Rod Bundle Nuclear Fuel Elements and Cores. BNWL-1962, Battelle, Pacific Northwest Laboratories, Richland, WA 99352 , March 1976.

B-2. D. S. Rowe, COBRA-IIIC: A Digital Computer Program for Steady-State and Transient Thermal-Hydraulic Analys is of Rod Bundle Nuclear Fuel Elements. BNWL-1695, Battelle-Northwest, Richland, WA, March 1973.

B-3. R. J. Cena, N. F. Sather, and D. S. Rowe, "Predicting Fuel-Rod Temperature Response by Orthogonal Collocation." ANS Transactions, Vol. 21 , pp. 205-206, June 1975. 


\section{APPENDIX C}




\section{THE BOSOR 4 SHELL OF REVOLUTION PROGRAM}

The BOSOR4 code performs stress, stability and vibration analyses of segmented, branched, ring-stiffened, elastic shells of revolution with various wall constructions. BOSOR4 can represent branched shel1 structures and shells of revolution, with very large mean circumferential radii of curvature.

The program is very general with respect to geometry of meridion, she11-wal1 design, edge conditions, and loading. It has been thoroughly checked out by comparisons with other known solutions and tests. The BOSOR4 capability is summarized in Table $\mathrm{C}-1$. The code represents three distinct analyses:

(1) a nonlinear stress analysis for axisymmetric behavior of axisymmetric shel1 systems (large deflections, elastic);

(2) a iinear stress analysis for axisymmetric and nonsymmetric behavior of axisymmetric shell systems submitted to axisymmetric and nonaxisymmetric loads;

(3) an eigenvalue analysis in which the eigenvalues represent buckling loads or vibration frequencies of axisymmetric shell systems submitted to axisymmetric loads. (Eigenvectors may correspond to axisymmetric or nonsymmetric modes.)

TABLE C-1. BOSOR4 Capabi1 ity Summary

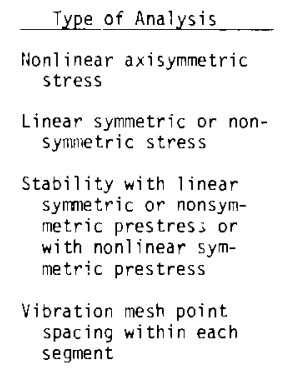
segment

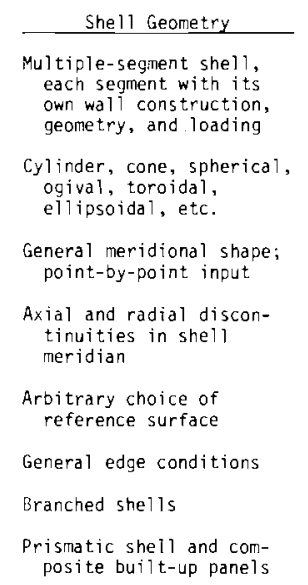
Wall Construction
Monocoque, variable or constant thickness
Skew-stiffened shells
Fiber-wound shells
Layered orthotropic shells
Corrugated, with or without. skin
Layered orthotropic with temperature dependent material properties

Any of the above wall types reinforced by stringers and/or rings treated as "smeared out"

Any of the above wall types further reinforced by
rings treated as discrete Wall properties variable along meridian

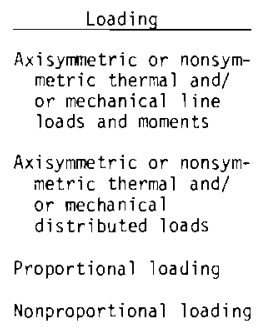

Nomproportional loading 
BOSOR4 has an additional branch corresponding to buckling of nonsymmetrically loaded shells of revolution. However, this branch is really a combination of the second and third analyses just listed.

The BOSOR4 is based on the following assumptions:

(1) The wall material is elastic.

(2) Thin-shell theory holds; i.e., normals to the undeformed surface remain normal undeformed.

(3) The structure is axisymmetric and, in vibration analysis and nonlinear stress analysis, the loads and prebuckling or prestress deformations are axisymmetric.

(4) The axisymmetric prebuckling deflections in the nonlinear theory, while considered finite, are moderate; i.e., the square of the meridional rotation can be neglected compared with unity.

(5) In calculating displacement and stresses in nonsymmetrically loaded shells, linear theory is used. This branch of the program is based on standard small-deflection analysis.

(6) A typical cross-section dimension of a discrete ring stiffener is small compared with the radius of the ring.

(7) The cross sections of the discrete rings remain undeformed as the structure deforms, and the rotation about the ring centroid is equal to the rotation of the shell meridian at the attachment point of the ring (except, of course, if the ring is treated as a flexible shell branch).

(8) The discrete ring centroids coincide with their shear centers.

(9) If the meridional stiffeners are present, they are sufficiently numerous to be included in the analysis by an averaging or 'smearing' of their properties over any parallel circle of the shell structure; circumferential stiffeners can be treated as discrete.

The analysis is based on energy minimization with constraint conditions. The total energy of the system includes strain energy of the shell segments 
and discrete rings, potential energy of the applied line loads and pressures, and kinetic energy of the shell segments and discrete rings. The constraint conditions arise from displacement conditions at the boundaries of the structure, displacement conditions that may be prescribed anywhere within the structure, and at junctures between segments. The constraint conditions are introduced into the energy functional by means of Lagrange multipliers.

These components of energy and constraint conditions are initially integrodifferential forms. The circumferential dependence is eliminated by separation of variables. Displacements and meridional derivatives of displacements are then written in terms of the shell reference surface displacement components, $u_{i}, v_{j}$, and $w_{j}$ at the finite-difference mesh points and Lagrange multipliers $\lambda_{j}$. Integration is done simply by multiplying the energy per unit length of meridian by the length of the 'finite difference element' (described below).

In the nonlinear axisymmetric stress analysis, the energy expression has terms linear, quadratic, cubic and quartic in the dependent variables $u_{i}$ and $w_{j}$. The cubic and quartic energy terms arise from the 'rotation-squared' terms that appear in the expression for reference surface meridional strain and in the constraint conditions. Energy minimization leads to a set of nonlinear algebraic equations that are solved by the Newton-Raphson method. Stress and moment resultants are calucalted in a straightforward manner from the mesh-point displacement components through the constitutive equations and the kinematic relations.

The results from the nonlinear axisymmetric or linear nonsymmetric stress analysis are used in the eigenvalue analyses for buckling and vibration. The 'prebuckling' or 'perotation' $x_{0}$ appear as known variable coefficients in the energy expressions governing buckling and vibration. These expressions are homegenous quadratic forms. The values of a parameter (load or frequency) which render the quadratic forms stationary with respect to infinitesimal variations of the dependent variables, represent buckling loads or natural frequencies. These eigenvalues are calculated from a set of linear homogenous equations.

Details of the BOSOR4 program are given in Reference (C-1). 
ANSYS

ANSYS (Engineering ANalysis SYStem) is a large-scale general purpose computer program for the solution of several classes of engineering analysis problems. Analysis capabilities include:

- static and dynamic

- plastic, creep and swelling

- small and large deflections

- steady state and transient heat transfer

- steady state fluid flow.

The matrix displacement method of analysis based upon finite element idealization is used throughout the program. In this method the total structure to be analyzed is modeled mathematically as an assembly of discrete structural members, known as finite elements. Consequently, the geometry and material properties of each finite element are established. Many categories of finite elements have been developed; each possesses an intrinsic set of assumed distortion functions related to its degrees of freedom. In the displacement method the complete array of finite elements is mathematically assembled such that the degrees of freedom of each element automatically satisfy compatibility and equilibrium at their mutual boundaries.

The library of available finite elements numbers are more than thirty for static and dynamic analyses, and more than ten for heat transfer and fluid flow analyses. This variety of elements gives the ANSYS program the capability of analyzing frame structures (two-dimensional plane and axisymmetric), solids, flat plates, three-dimensional solids, axisymmetric and three-dimensional shells, and nonlinear problems including interfaces and cables.

Loading on the structure may include forces, displacements, pressures, temperatures or response spectrums. Loadings may be arbitrary time functions for 1 inear and nonlinear dynamic analyses. Loadings for heat transfer analyses include internal heat generation, convection and radiation boundaries, and specified temperatures or heat flows. 
The ANSYS program uses the wave front, or "frontal," direct solution method for the system of simultaneous linear equations developed by the matrix displacement method. It gives highly accurate results in minimum computer time and can solve large structures. Any number of elements can be used in a problem. The number of nodes may exceed 2500 for threedimensional problems and 5000 for two-dimensional problems. This solution method places a wave front restriction on the problem definition. The wave front restriction depends on the amount of core storage available for a given problem. Up to 500 degress of freedom on the wave front can be handled in a large core. The wave front limitation tends to be restrictive only for analysis of arbitrary three-dimensional solids or when ANSYS is used on a smal1 computer.

Geometry plotting is available for all elements in the ANSYS library, including isometric and perspective views of three-dimensional structures. Subroutines are also available for plotting stress and displacements from two- and three-dimensional solid or shell analyses, mode shapes from dynamic analyses, and stress-strain plots from plastic and creep analyses. Velocities and accelerations may also be plotted from dynamic analyses.

The input data for the ANSYS program were designed to facilitate defining the problem to the computer. Options for multiple coordinate systems in cartesian, cylindrical, or spherical coordinates are available, as well as multiple region generation capabilities to minimize the input data for repeating regions. Sophisticated geometry generation capabililites are included for two-dimensional plane and axisymmetric structures and for intersecting three-dimensional shel1 structures.

The ANSYS program capabilities are continually being enhanced by the addition of new or improved elements, new analysis capabilities, and new input, output and graphic techniques. The ANSYS User's Manual is modified periodically to reflect the latest additions. 


\section{AXISOL PROGRAM}

The AXISOL program uses the finite element method to determine displacements and stresses within complex two-dimensional structures subjected to arbitrary loading. Elastic, nonlinear material properties are considered by a successive approximation technique. Based on this approach, Wilson developed a digital computer program, which has subsequently been modified by BattelleNorthwest and additional capabilities added. This program may be used to analyze plane stress (or plane strain) structures or axisymmetric structures subjected to axisymmetric loads.

In the finite element approximation of solids, the continuous structure is replaced by a system of elements interconnected at joints or nodal points. Figure C-la illustrates a finite element idealization of a typical axisymmetric solid. This cross section then is approximated by an assemblage of triangles and quadrilaterals, as shown in Figure C-1b. Each triangular or quadrilateral element is a ring, which is itself axisymmetric about the axis of symmetry of the complete solid.

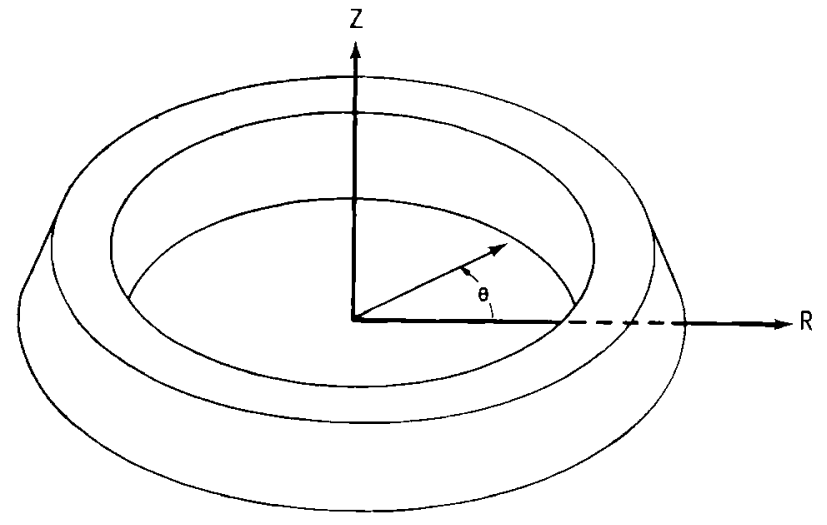

A. ACTUAL SOLID

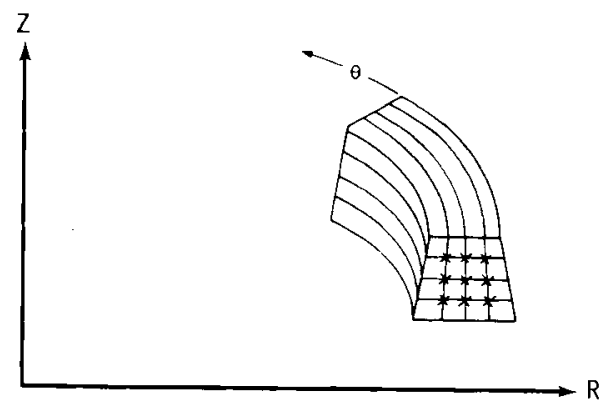

B. FINITE ELEMENT APPROXIMATION

FIGURE C-1. The Finite Element Idealization 
Since complete axisymmetry is assumed, then the displacement, stresses, temperatures, and similar parameters show no variation in the $\theta$ direction. In the $\mathrm{R}$ and $\mathrm{Z}$ directions shown in Figure $\mathrm{C}-1$, however, the displacement or temperature field is free to vary linearly within each element. For the elasticity problem this produces a state of constant strain within each element, except for $\varepsilon_{\theta}$ which can vary as $1 / r$ with comparable stresses within each element. Equilibrium equations, in terms of unknown nodal point displacements, are developed at each nodal point. A solution of this set of equations constitutes a solution to the system.

Compared to other numerical approaches, the advantages of the finite element method are numerous. The method is completely general with respect to geometry and material properties. Complex bodies composed of many different materials are easily represented. Since anisotropic materials are automatically included in the formulation, filament structures are readily handled. Displacement or stress boundary conditions may be specified at any nodal point within the finite element system. Arbitrary thermal, mechanical and acceleration loads are possible. Mathematically, it can be shown that the method converges to the exact solution as the number of elements is increased; therefore, any desired degree of accuracy may be obtained. Also, the finite element approach generates equilibrium equations which produce a symmetric, positive-definite matrix which may be placed in a band form and solved with a minimum of computer storage and time.

In theory, the error associated with a given problem may be reduced as much as desired by reducing the element size appropriately. Actually, practical limits are imposed both by the computer code and the time available for data preparation. In general, refined element networks may be used so that stresses within $10 \%$ of the correct value can be obtained. 


\section{REFERENCES}

C-1. D. Bushne11, Stress, Stability and Vibration of Complex Branched Shells of Revolution: Analysis and Users Manual for BOSOR4. Lockheed Missile and Space Company No. D243065, March 1972. 


\section{DISTRIBUTION}

No. of

Copies

\section{OFFSITE}

A. A. Churm

DOE Chicago Patent Group 9800 S. Cass Ave.

Argonne, IL 60439

J. M. Williams

DOE Division of Magnetic

Fusion Energy

Washington, DC 20545

3 F. E. Coffman

DOE Division of Magnetic Fusion Energy

Washington, DC 20545

K. M. Zwilsky

DOE Division of Magnetic

Fusion Energy

Washington, DC 20545

J. Baublitz

DOE Division of Magnetic

Fusion Energy

Washington, DC 20545

J. W. Beal

DOE Division of Magnetic

Fusion Energy

Washington, DC 20545

L. Bogart

DOE Division of Magnetic

Fusion Energy

Washington, DC 20545

M. M. Cohen

DOE Division of Magnetic

Fusion Energy

Washington, DC 20545

H. S. Culling ford

DOE Division of Magnetic

Fusion Energy

Washington, DC 20545
No. of

Copies

E. N. C. Dalder

DOE Division of Magnetic

Fusion Energy

Washington, DC 20545

J. F. Decker

DOE Division of Magnetic

Fusion Energy

Washington, DC 20545

C. R. Finfgeld

DOE Division of Magnetic

Fusion Energy

Washington, DC 20545

J. N. Grace

DOE Division of Magnetic

Fusion Energy

Washington, DC 20545

E. E. Kintner

DOE Division of Magnetic

Fusion Energy

Washington, DC 20545

R. N. Kostoff

DOE Division of Magnetic

Fusion Energy

Washington, DC 20545

J. V. Martinez

DOE Division of Magnetic

Fusion Energy

Washington, DC 20545

J. 0. Neff

DOE Division of Magnetic

Fusion Energy

Washington, DC 20545

T. C. Reuther

DOE Division of Magnetic

Fusion Energy

Washington, DC 20545 
No. of

Copies

C. R. Head

DOE Division of Magnetic

Fusion Energy

Washington, DC 20545

P. M. Stone

DOE Applied Plasma

Physics Program

Washington, DC 20545

Assistant Director for

Technology

DOE Division of Reactor

Research and Development

Washington, DC 20545

Chief, Fuel Systems Branch DOE Division of Reactor

Research and Development Washington, DC 20545

\section{DOE Technical Information} Center

2 Director, ANL Fusion Power

Program, Building 208

Argonne National Laboratory 9700 S. Cass Ave.

Argonne, IL 60439

M. S. Kaminsky

Argonne National Laboratory

9700 S. Cass Ave.

Argonne, IL 60439

V. H. Maroni

Argonne National Laboratory

9700 S. Cass Ave.

Argonne, IL 60439

P. M. Persiani

Argonne National Laboratory

9700 S. Cass Ave.

Argonne, IL 60439
No. of

Copies

M. Petrick

Engineering and Technology Division

Argonne National Laboratory

9700 S. Cass Ave.

Argonne, IL 60439

W. E. Parkins, Manager

Atomics International

Component Engineering and Technology Division

North American Rockwell

P.0. Box 309

Canoga Park, CA 91304

2 Chairman, Department of Applied Sciences

Brookhaven National Laboratory

Associated Universities

Upton, NY 11973

Associate Chairman for

Chemistry and Materials

Programs, Department of

Applied Sciences

Brookhaven National Laboratory Associated Universities

Upton, NY 11973

A. N. Goland

Brookhaven National Laboratory Associated Universities

Upton, NY 11973

D. Gurinsky

Brookhaven National Laboratory DOE Brookhaven Area Office

Upton, NY 11973

S. Pearlstein

Brookhaven National Laboratory DOE Brookhaven Area Office

Upton, NY 11973

J. R. Powell

Brookhaven National Laboratory

DOE Brookhaven Area Office

Upton, NY 11973 
No. of

Copies

A. J. Impink, Jr.

Carnegie Mellon University

Pittsburgh, PA 15213

R. A. Gross

Columbia University

Plasma Physics Laboratory

236 SW Mudd B1dg.

New York, NY 10027

Program Manager for Fusion Power

Electric Power Research

Institute

3412 Hillview Ave.

Palo Alto, CA 94304

W. C. Gough

Electric Power Research Institute

3412 Hillview Ave.

Palo Alto, CA 94303

2 Manager, Fusion Engineering Department

Gulf General Atomic Co.

P.0. Box 81608

San Diego, CA 92138

G. R. Hopkins

Gulf General Atomic Co.

P.0. Box 81608

San Diego, CA 92138

Z. Sabri

Nuclear Engineering Department

261 Sweeney Hall

Iowa State University

Ames, IA 50010

H. K. Forsen

Jersey Nuclear Company

777 106th Ave., NE

Bellevue, WA 98004
No. of

Copies

R. Borg

Lawrence Livermore Laboratory

P.0. Box 808

Livermore, CA 94550

T. K. Fowler

Lawrence Livermore Laboratory

P.0. Box 808

Livermore, CA 94550

A. C. Haussmann

Lawrence Livermore Laboratory

P.0. Box 808

Livermore, CA 94550

A. L. Hunt

Lawrence Livermore Laboratory

P.0. Box 808

Livermore, CA 94550

R. Moir

Lawrence Livermore Laboratory

P.0. Box 808

Livermore, CA 94550

C. J. Taylor

Lawrence Livermore Laboratory

P.0. Box 808

Livermore, CA 94550

L. L. Wood

Lawrence Livermore Laboratory

P.0. Box 808

Livermore, CA 94550

Division Leader, CTR Division Los Alamos Scientific

Laboratory

P.0. Box 1663

Los Alamos, NM 87544

D. J. Dudziak

Los Alamos Scientific

Laboratory

P.0. Box 1663

Los Alamos, NM 87544 
No. of

Copies

D. B. Henderson

Los Alamos Scientific

Laboratory

CTR Division

P.0. Box 1663

Los Alamos, NM 87544

L. Stewart

Los Alamos Scientific

Laboratory

CTR Division

P.0. Box 1663

Los Alamos, NM 87544

B. Coppi

Department of Physics

Massachusetts Institute of Technology

Cambridge, MA 02139

0. K. Harling

Massachusetts Institute of Technology

Cambridge, MA 02139

L. Lidsky

Department of Nuclear Engineering

Massachusetts Institute of Technology

Cambridge, MA 02139

D. Rose

Massachusetts Institute of Technology

Cambridge, MA 02139

R. E. Stickney

Mechanical Engineering

Massachusetts Institute of Technology

Cambridge, MA 02139

Manager, Technology

Applications and Development

Mound Laboratory

P.0. Box 32

Miamisburg, OH 45342
No. of

Copies

J. J. Reinmann

NASA--Lewis Research Center

2100 Brookpark Rd.

Cleveland, $\mathrm{OH} 44135$

V. Arp

National Bureau of Standards

Cryogenics Division

Boulder, CO 80302

Director, Metals and Ceramics Division

Oak Ridge National Laboratory P.0. Box $Y$

Oak Ridge, TN 37830

Program Manager, Fusion Reactor Technology Program

B1dg. 9204-1

Oak Ridge National Laboratory P.0. Box Y

Oak Ridge, TN 37830

J. L. Scott, Manager

Magnetic Fusion Energy Materials

Metals and Ceramics Division

Bldg. 4500 SM, S-178

P.0. Box $X$

Oak Ridge, TN 37830

A. P. Fraas

Oak Ridge National Laboratory P.0. Box $Y$

Oak Ridge, TN 37830

J. Rand McNally, Jr.

Oak Ridge National Laboratory

P.0. Box $Y$

Oak Ridge, TN 37830

D. Steiner

Oak Ridge National Laboratory

P.0. Box $Y$

Oak Ridge, TN 37830 
No. of

Copies

R. Werner

Oak Ridge National Laboratory

P.0. Box X

Oak Ridge, TN 37830

R. Cooper

Physics International

2700 Merced St.

San Leandro, CA 94577

R. A. Huse

Public Service Electric and Gas Co.

80 Park Place

Newark, NJ 07101

H. Perkins

Department of Chemistry

Princeton University

Princeton, NJ 06540

Director, Plasma Physics Laboratory

Princeton University

Box 451

Princeton, NJ 08540

Project Manager, TFTR

Plasma Physics Laboratory

Princeton University

Box 451

Princeton, NJ 08540

R. G. Mills

Plasma Physics Laboratory

Princeton University

Box 451

Princeton, NJ 08540

E. C. Tanner

Plasma Physics Laboratory

Princeton University

Box 451

Princeton, NJ 08540
No. of

Copies

F. H. Tenney

Plasma Physics Laboratory

Princeton University

Box 451

Princeton, NJ 08540

2 W. Bauer

Division Supervisor of Physical Research

Sandia Laboratories

Livermore, CA 94550

M. Kristiansen

Texas Tech. University

Lubbock, TX 79409

A. F. Haught

United Aircraft Research Laboratory

United Aircraft Corp.

East Hartford, CT 06108

Head, Thermo Structural

Materials Branch

U.S. Naval Research Laboratory

Metallurgy Division

Code 6390

Washington, DC 20390

L. Levine

U.S. Naval Research Laboratory

Washington, DC 20390

C. Z. Serpan, Jr.

U.S. Naval Research Laboratory

Washington, DC 20390

F. Chen

UCLA School of Engineering and Applied Science

Boelter 7731

Los Angeles, CA 90024

A. J. Lichtenberg University of California

Electronics Research Laboratory

College of Engineering

Berkeley, CA 94720 
No. of

Copies

C. D. Hendricks

University of Illinois

Nuclear Engineering Laboratory

Urbana, IL 61801

T. Kamash

University of Michigan

Nuclear Engineering Department

Ann Arbor, MI 48105

Dean Abrahamson

University of Minnesota

School of Public Affairs

Social Science Building/308

Minneapolis, MN 55455

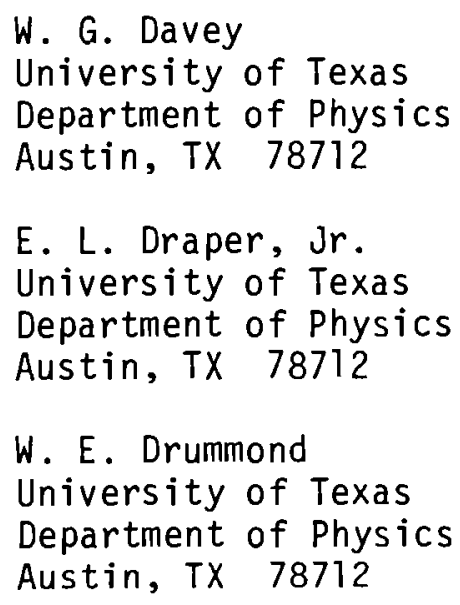

A. Hertzberg University of Washington

Aerospace Research Laboratory 316 Guggenheim

Seattle, WA 98105
A. L. Babb
University of Washington
Nuclear Engineering Department
Seattle, WA 92105

R. Conn

University of Wisconsin

Nuclear Engineering Department

Madison, WI 53706
No. of

Copies

G. L. Kulcinski

University of Wisconsin

Nuclear Engineering Department

Madison, WI 53706

C. W. Maynard

University of Wisconsin

Nuclear Engineering Department

Madison, WI 53706

D. Lichtman

Department of Physics

University of Wisconsin

Milwaukee, WI 53201

E. E. Donaldson

Washington State University

Department of Physics

Pullman, WA 99163

Manager, Fusion Power Systems

Department

Westinghouse Electric Corp.

P.0. Box 355

Pittsburgh, PA 15230

\section{ONSITE}

3 DOE Richland Operations office

W. A. Burns

P. G. Holsted

H. E. Ransom

Rockwel 1 Hanford Operations

J. D. Kaser

3 Hanford Engineering Development Laboratory

Manager, Materials Engineering

D. G. Doran

H. H. Yoshikawa 
No. of

Copies

82 Battelle-Northwest

D. T. Aase (10)

L. Ault

D. R. Baer

M. C. C. Bampton

W. E. Bickford

S. H. Bush

R. A. Busch

N. E. Carter

D. B. Cearlock

T. D. Chikalla

W. J. Coleman

S. D. Dahlgren

D. E. Deonigi

D. A. Dingee

T. J. Doherty

C. E. Elderkin

R. M. Fleischman

J. C. Fox

R. F. Foster

J. J. Fuquay

H. R. Gardner

W. J. Gray

A. J. Haverfield

J. S. Hartman

J. A. Hebert

F. P. Hungate

A. B. Johnson, Jr.

R. H. Jones

T. J. Kabele

N. Laegreid

B. R. Leonard

R. C. Liikala

D. Mahlum

R. P. Marshall

R. A. McCann

E. D. McClanahan

J. L. McElroy

D. F. Newman

J. M. Nielsen

R. E. Nightingale

D. E. 01 esen

N. J. 01 son

J. F. Park

R. W. Perkins
R. T. Perry

L. T. Pedersen

J. Rasberry

L. C. Schmid

D. B. Shipler

E. P. Simonen

C. L. Simpson

C. W. Stewart

R. W. Stewart

D. L. Styris

A. M. Sutey (3)

W. L. Templeton

V. L. Teofilo

J. K. Thompson

M. T. Thomas

G. L. Tingey

M. Vagins

B. E. Vaughan

W. R. Wiley

H. J. Willenberg

T. L. Willke

Technical Information (5)

Technical Pulications 
. 